\title{
ESTIMATIVA DA EROSÃO EM SULCOS E ENTRE SULCOS NA MICROBACIA HIDROGRÁFICA DO CÓRREGO DO CEVEIRO- PIRACICABA (SP)
}

ROBERTA BOTTINO MONTOLAR SPAROVEK

Engenheiro Agrônomo

Orientador: Prof. Dr. Pablo Vidal-Torrado

Dissertação apresentada à Escola Superior de Agricultura "Luiz de Queiroz", Universidade de São Paulo, para obtenção do título de Mestre em Agronomia, Área de Concentração: Solos e Nutrição de Plantas.

PIRACICABA

Estado de São Paulo - Brasil

Maio - 1998 


\section{ERRATA}

p. linha

6 terceira

9 nona

9 vigésima quinta

10 décima quinta

10 décima nona

11 sexta

11 vigésima quinta

12 sétima

13 sexta e décima sexta

13 vigésima segunda

14 quinta

14 vigésima nona

15 décima terceira

16 vigésima primeira

17 décima quarta

18 oitava

20 terceira

20 décima quarta

31 primeira

32 terceira

36 décima primeira

37 quarta

37 quarta

42 décima

42 décima primeira

53 vigésima

57 quarta

57 quinta

58 décima oitava

62 nona

71 décima quinta

74 terceira
Onde se lê

Marques et al., 1995

Beasley, 1972

Wischhmeier \& Smith

Brooks, 1991

WEEP

Hamletet et al. (1992)

Bertoni \& Lombardi Neto, 1990

Wischemeier \& Smith, 1978

Wischemeier \& Mannering, 1969

Wischemeier et al., 1971

Wischemeier et al., 1971

Wischemeier \& Smith, 1965

Wischemeier et al., 1971

Wischemeier et al, 1971

Wischemeier \& Smith, 1978

Wischemeier \& Smith, 1978

Wischemeier \& Smith, 1978

Schhertz, 1983

Sparovek et al., 1991

RAIJ et al. (1987)

Instituto Brasileiro de Geografia

Estatística (IBGE)

Denardim, 1990

Wischemeier et al., 1971

Denardim, 1990

Marques et al., 1996

Sparovek et al., 1995

Wischemeier \& Smith, 1978

Mellerowicz, 1994

SAMPRA (Köffler, 1992)

Tabela 11

KÖFFLER, N.F.

PROCHONOW, M.C.R.
Leia-se

Marques, 1995

Beasly, 1972

Wischmeier \& Smith

Brooks et al., 1991

WEPP

Hamlett et al. (1992)

Bertoni \& Lombardi Neto, 1993

Wischmeier \& Smith, 1978

Wischmeier \& Mannering, 1969

Wischmeier et al., 1971

Wischmeier et al., 1971

Wischemeier \& Smith, 1965

Wischmeier et al., 1971

Wischmeier et al., 1971

Wischmeier \& Smith, 1978

Wischmeier \& Smith, 1978

Wischmeier \& Smith, 1978

Schertz, 1983

Sparovek, 1991

Raij et al. (1987)

e Instituto Geográfico e

Cartográfico (IGC)

Denardin, 1990

Wischmeier et al., 1971

Denardin, 1990

Marques et al, 1997

Sparovek \& Lepsch, 1998

Wischmeier \& Smith, 1978

Mellerowicz et al, 1994

SAMPA (Koffler, 1992)

Tabela 14

KOFFLER, N.F.

PROCHNOW, M.C.R.

\section{REFERÊNCIAS BIBLIOGRÁFICAS}

BERTONI, J.; LOMBARDI NETO, F. Conservação do Solo. 3.ed. São Paulo: Ícone Editora Ltda, 1993. 355p.

SAVIGEAR, R.A.G. A Technique of Morphological Mapping. Association of American Geographers, v. 53, n.3, p 514-588. 1965. 


\title{
Dados Internacionais de Catalogaçāo na Publicaçāo (CIP) DIVISĀo DE BIBLIOTECA E DOCUMENTAÇĀO - Campus "Luiz de Queiroz"/USP
}

\author{
Sparovek, Roberta Bottino Montolar \\ Estimativa da erosão em sulcos e entre sulcos na Microbacia Hidrográfica do \\ Córrego do Ceveiro-Piracicaba (SP) / Roberta Bottino Montolar Sparovek, - . \\ Piracicaba, 1998. \\ 95 p. : il.
}

Dissertação (mestrado) - Escola Superior de Agricultura Luiz de Queiroz, 1998. Bibliografia.

1. Degradação do solo 2. Erosão em sulco 3. Erosão entre sulco 4. Microbacia do Córrego do Ceveiro I. Título 


\section{S u m ár i o}

RESUMO

Página

SUMMARY

iii

\section{INTRODI}

INTRODUÇÃO

v

REVISÃO DE LITERATURA

2.1 A Bacia hidrográfica como unidade integradora de processos ..............................................

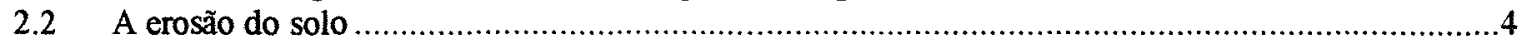

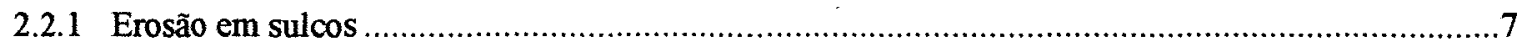

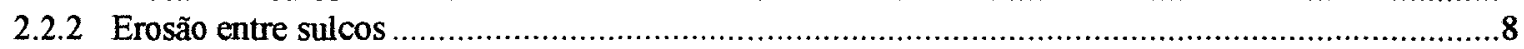

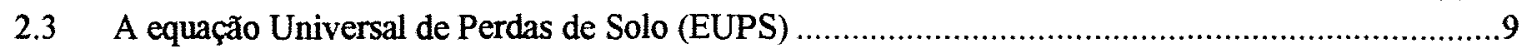

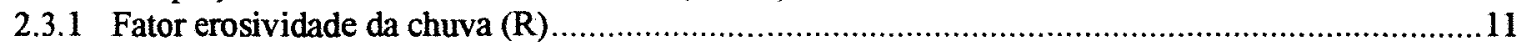

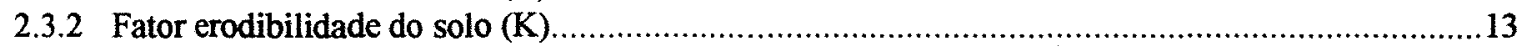

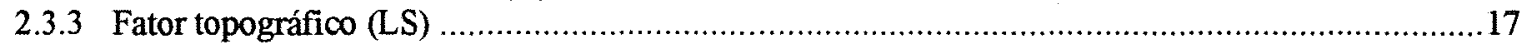

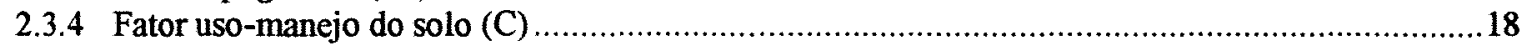

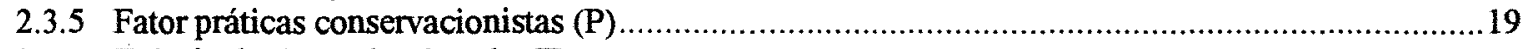

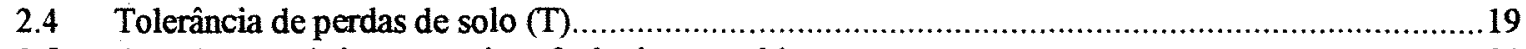

2.5 As ações antrópicas e sua interferência no ambiente ...............................................................21

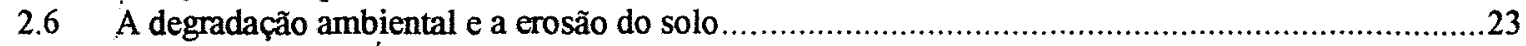

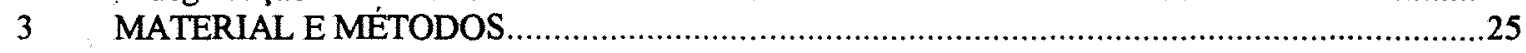

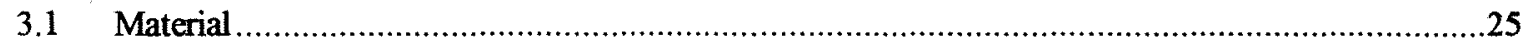

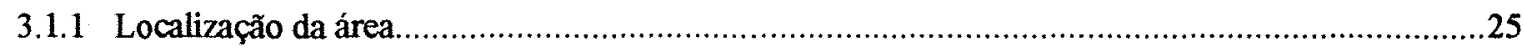

3.1.2 Clima 25

3.1 .4 Relevo 28

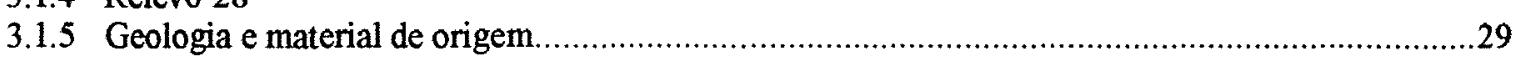

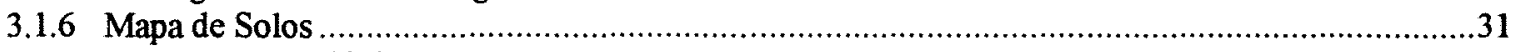

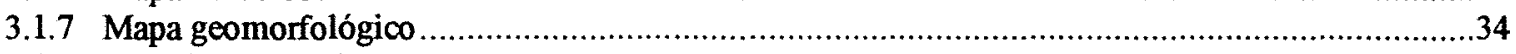

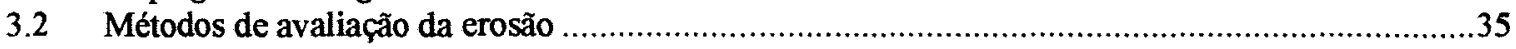

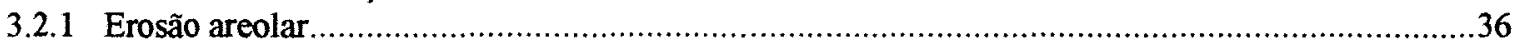

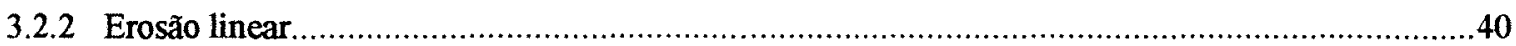

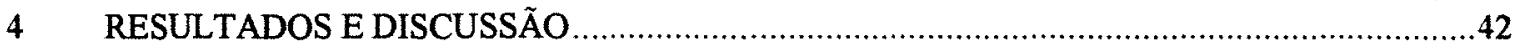

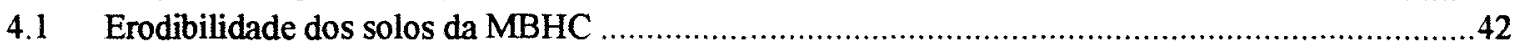

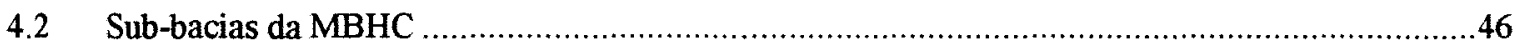

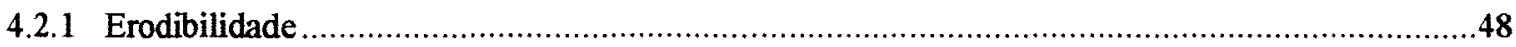

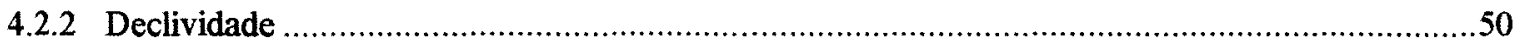

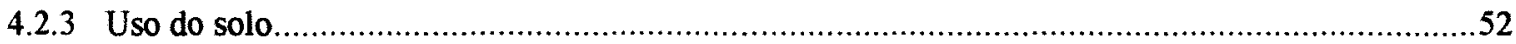

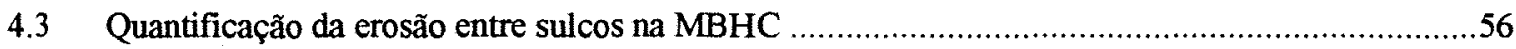

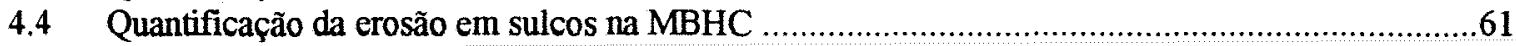

4.5 Quantificação da erosão nas sub-bacias da MBHC ………...........................................................62

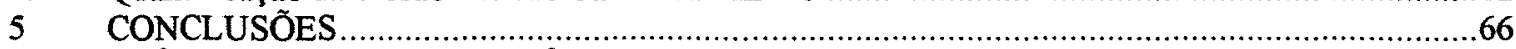

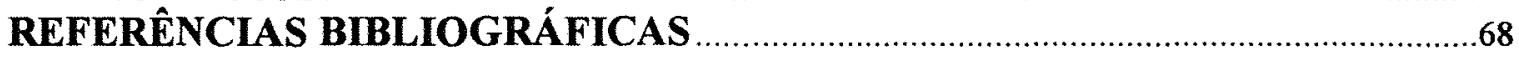

Anexo A

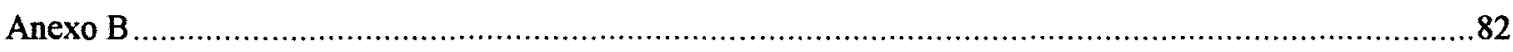

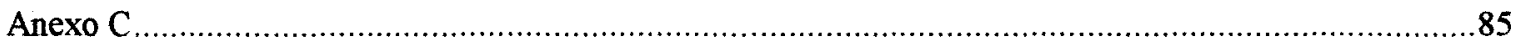




\section{ESTIMATIVA DA EROSÃO EM SULCOS E ENTRE SULCOS NA MICROBACIA HIDROGRÁFICA DO CÓRREGO DO CEVEIRO-PIRACICABA (SP)}

Autor: Roberta Bottino Montolar Sparovek Orientador: Prof. Dr. Pablo Vidal-Torrado

\section{RESUMO}

A erosão do solo é responsável pelos maiores impactos ambientais łecorrentes da agricultura convencional. Os sedimentos produzidos pela erosão muitas vezes contendo nutrientes e produtos tóxicos aplicados no solo são transportados, em grande parte, para os leito dos rios e outros corpos d'água, poluindo e assoreando os rios e reservatórios. As consequeencias deste processo são enchentes, empobrecendo os solos e diminuindo a vida útil de reservatórios e usinas hidroelétricas. Os estudos envolvendo os recursos naturais, principalmente aqueles relacionados com a erosão do solo, vêm sendo executados na escala de microbacia hidrográfica $(\mathrm{MBH})$ por esta ser considerada ideal do ponto de vista hidrológico e ambiental.. A Microbacia Hidrográfica do Córrego do Ceveiro (MBHC), localizada no Município de Piracicaba (SP) possui uma área de 1.990 ha. A microbacia há muitas décadas vem sendo explorada economicamente pela agricultura, e atualmente a cultura canavieira ocupa $66 \%$ de sua área total. 0 objetivo deste trabalho foi determinar e comparar os processos de erosão entre sulcos e em sulcos na MBHC. Através da utilização da Equação Universal de Perdas de Solo ( EUPS), estimou-se a taxa de erosão entre sulcos na MBHC e para as sub-bacias que a compõem, para os anos de 1962, 1978 e 1995. A erosão entre sulcos foi estimada através de observações de campo. As taxas de erosão entre sulcos sofreram um decréscimo ao longo dos anos estudados, tendo sido da ordem de $126 \mathrm{Mg} \mathrm{ha}^{-1}$. ano ${ }^{-1}$ para o ano de 1962 , $59 \mathrm{Mg} \mathrm{ha}^{-1}$ ano $^{-1}$ para o ano de 1978 e $26 \mathrm{Mg} \mathrm{ha}^{-1}$. ano ${ }^{-1}$ para 1995. A perda de solo via 
erosão em sulcos avaliada em 1996, foi da ordem de $58,7 \mathrm{Mg} \mathrm{ha}^{-1} \mathrm{ano}^{-1}$. Estes dois processo de erosão (entre sulcos e em sulcos) são responsáveis pela intensa degradação dos solos e dos recursos hídricos da área de estudo. Esta degradação está fortemente relacionada com o uso do solo, agravado pelas características do meio físico, com solos altamente suscetíveis à erosão, declividades limitantes para o uso agrícola intensivos em grande parte da área. 


\section{RILL AND INTERRILL EROSION ESTIMATION IN THE CEVEIRO WATERSHED- PIRACICABA (SP), BRAZIL}

Author: Roberta Bottino Montolar Sparovek Adviser: Prof. Dr. Pablo Vidal-Torrado

\section{SUMMARY}

Soil erosion is responsible for great environmental impacts related to conventional agriculture. The sediments produced by this process usually contain nutrients and pollutants are transported and deposited in to rivers, lakes and other water bodies, silting and polluting them. The consequences are floods, soil degradation and lifetime reduction of reservoirs and hydroelectric plants. Research in natural resources, specifically those related to soil erosion, consider the watershed scale (W) as ideal for hydrologic studies. The Ceveiro watershed $(\mathrm{CW})$ is located in Piracicaba (Brazil) and has an are of 1,990 ha. This watershed is been cultivated with sugarcane for several years and presently $66 \%$ is occupied with this crop. The objective of this study was estimate rill and interrill erosion processes in the CW. Using the Universal Soil Loss Equation (USLE) interrill erosion was estimated for the entire area and for subwatersheds for the years of 1962, 1978 and 1995. Rill erosion was determined on field in 1996. Soil erosion rates decreased with time $\left(126 \mathrm{Mg} \mathrm{ha}^{-1} \mathrm{yr}^{-1}\right.$ for $1962,59 \mathrm{Mg} \mathrm{ha}^{-1} \mathrm{yr}^{-1}$ for 1978 and $26 \mathrm{Mg} \mathrm{ha}^{-1} \mathrm{yr}^{-1}$ for 1995). Rill erosion was estimated in $58,7 \mathrm{Mg} \mathrm{ha}^{-1} \mathrm{yr}^{-1}$. These two processes (rill and interrill soil erosion) were responsible for intense land and water resources degradation. This degradation is most related to land use, but soil erodibility, steep slope and intensive land use are contributing factors. 


\section{INTRODUÇÃO}

Por um longo periodo o Homem vem utilizando os recursos naturais sem a preocupação de tornar as suas intervenções o menos impactantes possíveis para o ambiente. Nas últimas décadas, têm sido crescentes as preocupações relacionadas à qualidade de vida e aos problemas ambientais, como a poluição, a erosão do solo, o super aquecimento global, o desmatamento e a manutenção da biodiversidade. Neste contexto, surge um novo desafio, o de produzir alimentos para uma população crescente com a menor degradação possível dos recursos naturais.

Alguns dos maiores impactos ambientais decorrentes da agricultura convencional estão relacionados com a erosão do solo e a degradação dos recursos hídricos. Os sedimentos produzidos pela erosão, muitas vezes contendo nutrientes e produtos tóxicos aplicados no solo, são transportados, em grande parte, para o leito dos rios e outros corpos d'água. As conseqüências deste processo são a poluição das águas, o assoreando os rios e reservatórios, causando enchentes, empobrecendo os solos e diminuindo a vida útil de reservatórios e usinas hidroelétricas. Os estudos envolvendo os recursos naturais, principalmente aqueles relacionados com a erosão do solo, vêm sendo executados na escala de microbacia hidrográfica $(\mathrm{MBH})$, por ser esta considerada ideal do ponto de vista hidrológico e ambiental. Considerando esta abordagem torna-se necessário a quantificação dos sedimentos produzidos pela erosão do solo e também o conhecimento da movimentação destes sedimentos na $\mathrm{MBH}$, a identificação de sua origem e dos seus pontos de acumulação, possibilitando deste modo a compreensão dos aspectos da erosão associados à degradação dos recursos naturais.

A Bacia Hidrográfica do Rio Piracicaba (BHP), localiza-se no entorno metropolitano de São Paulo em uma das áreas de maior crescimento econômico do Brasil, e vem sofrendo intensas transformações ambientais como consequiência do seu crescimento não planejamento e do uso inadequado de suas terras. Problemas, como 
baixa qualidade e disponibilidade de água, falta de saneamento e elevada demanda por recursos hídricos são comuns nesta região. Este quadro é agravado pelo fato da BHP contribuir, com aproximadamente $30 \mathrm{~m}^{3} \mathrm{~s}^{-1}$ de água, no abastecimento da região metropolitana da cidade de São Paulo. Os danos ambientais causados na BHP estão diretamente associados à erosão do solo, que é um processo que pode levar a degradação das terras para a produção agrícola.

Localizada no município de Piracicaba (SP), a Microbacia Hidrográfica do Córrego do Ceveiro (MBHC) é uma sub-bacia da BRP, com uma área de 1.990 ha, e que há décadas vem sendo explorada economicamente pela agricultura, atualmente a cultura canavieira ocupa $66 \%$ de sua área total. As ações do Homem na ocupação agrícola da MBHC influenciaram significativamente as deposições decorrentes da erosão do solo. Considerando que a qualidade e disponibilidade de água superficial é influenciada pela erosão do solo e pelos depósitos dela decorrentes, a ocupação agrícola exerceu e continua exercendo influência sobre a qualidade e disponibilidade de água na MBHC. $\mathrm{O}$ elevado grau de degradação em que encontra-se a MBHC, pode ser observado pelo assoreamento de um reservatório de água construído em 1978, com a finalidade de abastecer o distrito de Ártemis com água potável, e hoje encontra-se desativada para tal fim.

O presente trabalho pretende quantificar a erosão antrópica que vem ocorrendo na MBHC, estimando as taxas de erosão em sulcos e entre sulcos e identificando a provável origem e áreas fonte, desta forma fornecendo subsídios para a compreensão dos aspectos da erosão do solo ligados à degradação do meio físico da MBHC. 


\section{REVISÃO DE LITERATURA}

\subsection{A Bacia hidrográfica como unidade integradora de processos}

Segundo Prochonow (1995) é aceito como conceito global que a Microbacia Hidrográfica $(\mathrm{MBH})$ é a unidade funcional que mais favorece o desenvolvimento de conceitos hidrológicos. Estudos envolvendo os recursos naturais, especialmente aqueles com interesse em aspectos ligado a qualidade e a disponibilidade de água, vêm sendo executados na escala de MBH. A MBH pode ser definida como a menor unidade de área suficiente para comportar um rio. Assim do ponto de vista hidrológico, pode ser considerada a menor unidade da paisagem capaz de integrar todos os componentes da atmosfera, biomassa, solos, rochas subjacentes, água e paisagem circundante (Moldan \& Cenry, 1994). Do ponto de vista geomorfológico a MBH é um sistema aberto, que continuamente está recebendo energia através do clima e que, sistematicamente, perde energia, através da água e dos sedimentos que a deixam (Christofoletti, 1974). Uma das principais características do sistema aberto é a sua estabilidade, onde o acréscimo ou a liberação contínua de energia encontram-se em perfeito equilibrio. Qualquer alteração, seja pela entrada ou saída de energia do sistema, imediatamente inicia-se uma mudança compensatória que tende a restaurar um novo equilibrio do ecossistema da bacia (Guerra \& Cunha, 1996).

Pela própria escala, a MBH pode ser considerada um ecossistema que compreende outros sub-sistemas: florestas, rios, pastagens, áreas agrícolas e urbanizadas; na qual coexistem componentes abióticos e bióticos em constante interrelacionamento. Constituindo-se num complexo integrado e intrincado, com um grande número de processos que condicionam as interações entre os seus componentes, interações estas que podem ser definidas pelos fluxos ou ciclos de matéria e energia (Clark II et al. 1985). O clima e a tectônia local atuam como fornecedores de energia para a bacia hidrográfica, e os fluxos energéticos são eliminados através da saída de 
água, sedimentos e solúveis do sistema (Guerra \& Cunha, 1996). Constantes ajustes nos elementos das formas e nos processos associados ocorrem na bacia de drenagem em função da dinâmica de entrada e saída de energia. A MBH tem um papel fundamental na evolução do relevo, uma vez que os cursos de água constituem importantes modeladores da paisagem.

$\mathrm{Na} \mathrm{MBH}$ os componentes do relevo cabeçeira, encosta, baixadas e rios estão interligados e interagindo. $\mathrm{O}$ uso do solo na cabeceira da $\mathrm{MBH}$, influência diretamente as áreas de baixadas, os componentes da $\mathrm{MBH}$ estão ligadas ao comportamento do rio. Deste modo, a microbacia é a unidade ecossistêmica e morfológica que melhor reflete os impactos ambientais causados pelas interferências antrópicas, pois a água captada na sua área de contribuição é um excelente indicativo dos problemas causados na degradação dos recursos naturais pelos diferentes eventos de sua ocupação. Os processos, como o ciclo bioquímico de nutrientes, acúmulo e liberação de substâncias tóxicas, intemperismo das rochas, erosão e transporte de materiais intemperizados podem ser abordados de forma sistêmica, quando estudados em escala de MBH (Clark II et al., $1985)$.

\subsection{A erosão do solo}

A erosão do solo é fenômeno natural que compreende os processos de desprendimento, transporte e deposição das partículas constituintes da massa de solo, sendo a água, o vento e as ondas os agentes causadores (César, 1952). Este fenômeno ocorre entre as fases sólidas e líquidas que constituem a maior parte do globo terrestre, com fundamentos nos princípios do equilíbrio e impulsionado pela gravidade possuindo uma tendência niveladora que se processa ininterruptamente.

A erosão geológica, ou natural, se processa lenta e indefinidamente, sua origem data dos primórdios da formação da terra, e vem através dos séculos contribuindo para a formação e transformação do solo e modelagem da paisagem (forma do relevo), sendo a responsável pela transformação das montanhas em colinas e formação dos terras baixas e vales férteis. A erosão antrópica ou acelerada reflete as interferências das atividades humana no ambiente. Estas atividades estão relacionadas com o desmatamento, plantio, 
construções e outras práticas que levam a intensificação do processo erosivo, tornando estes mais violentos.

Neste estudo somente será abordada a erosão hídrica, onde a precipitação e a enxurrada são os agentes erosivos. $\mathrm{Na}$ erosão hídrica o desprendimento das partículas do solo se dá através do impacto das gotas de chuva na superfície do solo e pela ação do escoamento superficial ou enxurrada. Após o desprendimento das partículas, estas são transportadas pela enxurrada. O transporte dos sedimentos ocorre segundo as características do relevo e material de origem dos solos, características climáticas do local e características da cobertura e do manejo (César, 1952). Os sedimentos, produzidos no processo de erosão do solo, só são transportados quando as enxurradas possuem energia suficiente para movimentar as partículas do solo que foram desagregadas. Quando a água da chuva não consegue infiltrar no solo, corre na sua superficie no sentido do declive do terreno e atinge grandes proporções, formando as enxurradas com capacidade de transportar os sedimentos erodidos. A capacidade de transporte é a capacidade dos agentes erosivos de transportar sedimentos, a carga de sedimentos que é transportada corresponde a taxa atual de sedimentos que estão sendo carregados pela enxurrada, podendo ser maior ou menor que a capacidade de transporte. Quando a carga de sedimentos é menor que a capacidade de transporte ocorre o desprendimento das partículas do solo por fluxo superficial. Quando a taxa de sedimentos contida na enxurrada for maior que a capacidade de transporte estes tendem a depositar a uma taxa proporcional à diferença entre capacidade de transporte e carga de sedimentos (Foster et al. , 1985).

$O$ processo de deposição reduz a carga de sedimentos, ocorrendo acúmulo destes na superficie do solo. A distribuição do tamanho dos sedimentos erodidos em um dado solo, depende da distribuição do tamanho das partículas primárias do solo, do grau de agregação, do potencial do impacto da gota de chuva para desagregar as partículas do solo e da porção de material desprendido, que podem ser transportados por salpicamento (força do impacto da gota de chuva na superfície do solo) e pela enxurrada (Meyer et al., 1983). A topografia é um fator que determina a velocidade do processo erosivo das encostas através da rugosidade topográfica e da presença de declives acentuados e 
instáveis, a erosão será mais intensa em solos com declividade maior. A influência da topografia na erosão é analisada pela ponderação de dois fatores: declividade e comprimento de rampa (Marques et al., 1995).

As chuvas representam o principal elemento climático altamente relacionados com os desequilibrios que se registram na paisagem das encostas. Guerra \& Cunha (1996), citam como fatores primordiais a serem analisados para o entendimento do processo erosivo a variação espacial da intensidade das precipitações associada à sua freqüência (volume e concentração das chuvas em alguns meses do ano). O processo de erosão das encostas pode ser acelerado pelas condições naturais, ou seja, pelas chuvas concentradas, encostas desprovidas de vegetação, contato solo-rocha abrupto, encostas íngremes e descontinuidades litológicas, pedológicas e ações antrópicas (Guerra \& Cunha, 1996).

Em estudos realizados na escala de $\mathrm{MBH}$ o balanço de sedimentos é uma importante ferramenta para a compreensão do processo erosivo, pois ele quantifica as taxas de produção, transporte e liberação de sedimentos. A identificação das fontes de sedimentos, ou seja o local onde estes sedimentos são gerados, é o primeiro passo na construção do balanço de sedimentos, permitindo isolar os diferentes processos erosivos e sua contribuição na sedimentação dos canais.

Os outros passos na definição do balanço de sedimentos são: a) a identificação dos fatores envolvidos no processo de transporte; b) a determinação dos intervalos de recorrência de cada processo de transporte e c) a quantificação e tempo de permanência dos sedimentos nas áreas onde estes tendem a se armazenar tais como leques aluviais e planicies de inundações (Dune \& Dietrich ,1982).

Para Oliveira (1994) os pesquisadores da área agronômica consideram a erosão em dois grandes universos: a erosão laminar (areolar ou entre sulcos) e a em sulcos, não fazendo distinção entre as notáveis diferenças de comportamento existente entre sulcos e boçorocas, senão por suas relações com o manejo agrícola do solo. Já os pesquisadores da área da geomorfologia estabelecem suas classificações de acordo com o objetivo de seus mapeamentos, o que envolve fundamentalmente, considerações a respeito das feições erosivas da região objeto e das escalas de abordagens, não considerando o porte 
como o único critério adotado para a classificação das feições erosivas, mas também o comportamento diferenciado das classes de erosão que geram tais feições.

Foster et al. (1985) propõem uma classificação da erosão fundamentada nos padrões ou modelos de escoamento, dividindo o escoamento superficial em concentrado e difuso, que constituem a base para a caracterização da produção de sedimentos, através das perdas de solo. Os autores descrevem os padrões de escoamento a partir da constatação de que o escoamento superficial ao longo de uma vertente se estabelece em numerosos canais pequenos denominados sulcos (rills) correspondentes à erosão em sulcos (rill erosion), quando os canais evoluem para profundidades que não podem ser cruzadas por máquinas agrícolas estes sulcos são chamados de ravinas e estas em estágio mais desenvolvido são denominadas voçorocas. O escoamento nas áreas entre os sulcos tendem para os sulcos, e definem a erosão correspondente a este processo como erosão entre sulcos (interril erosion).

\subsubsection{Erosão em sulcos}

A erosão em sulcos é um processo hidráulico onde o ponto de cisalhamento na interface solo-água promovem a liberação e transporte das partículas de solo (Foster et al.,1985; Grissinger, 1995), caracteriza-se por uma série de sulcos sinuosos, irregularidades no terreno, que se localizam ao longo do declive, resultante das correntes de água que deslizam sobre os terrenos, durante as chuvas intensas ou constantes (Bertoni \& Lombardi Neto, 1993).

Um dos fatores de sua formação se deve ao fato da erosão areolar não proporcionar um desgaste absolutamente igual em toda a superficie do solo, ocorrendo a concentração das enxurradas onde a erosão areolar mais se manifestou, originando um fluxo de água que irá determinar a formação de um sulco (César, 1952), o que não quer dizer que toda erosão em sulco necessariamente teve sua fase inicial na erosão areolar. Existes outros casos onde a erosão areolar se processa indefinidamente, sem sofrer transformações específicas que façam esta evoluir para erosão em sulcos. Segundo FAO (1967) não existe nenhum ponto definido que assinale o fim da erosão areolar e o começo da erosão em sulcos. 
Existe casos, em que o desgaste da superfície do solo se processa deste a origem em formas de sulcos, isto acontece em resposta ao microtopografia do terreno e às características da vegetação e podem resultar das condições de manejo do solo e das práticas de cultivo (Grissinger, 1995).

$\mathrm{Na}$ sua fase inicial, os sulcos podem ser desfeitos com as operações normais de preparo de solo e muitas vezes nem são percebidos pelos agricultores, porém em estágio mais adiantado, eles atingem tal profundidade que interrompem o trabalho de máquinas agrícolas, causando sérios prejuízos para a produtividade do solo.

A classificação agronômica das feições erosivas lineares elaborada segundo suas relações com o manejo do solo, conforme os manuais da capacidade de uso da terra (Lepsch, 1983), classifica os sulcos como superficiais, quando podem ser cruzados por máquinas agrícolas e se desfazem com o preparo do solo; como rasos quando podem ser cruzados por máquinas agrícolas, mas não se desfazem com o preparo do sol; profundos, quando não podem ser cruzados por máquinas agrícolas mas ainda não atingiram o horizonte $\mathrm{C}$ e, finalmente, muito profundos quando o horizonte $\mathrm{C}$ é atingido. Este último tipo é chamado nos manuais acima citados como voçorocas, para Barros ${ }^{1}$ citado por Oliveira (1994) embora estas feições sejam feias, não são tão danosas como as erosões que carregam as terras em camadas.

\subsubsection{Erosão entre sulcos}

O agente erosivo mais importante nas áreas de ocorrência da erosão entre sulcos é o impacto da gota da chuva na superfície do solo, causando o desprendimento de suas partículas, outro componente da erosão areolar (entre sulcos) é o impacto da gota da chuva na lâmina de água que se forma, quando a água da chuva não consegue mais infiltrar no solo, propiciando o aumento vertical da lâmina de água no sentido da vertente, é interceptada pelas gotas causando turbulência no fluxo da enxurrada, aumentando a sua capacidade erosiva (Foster et al., 1985). Na erosão entre sulcos ocorre a interação dos quatro processos que compõem a erosão hídrica (desagregação e

\footnotetext{
${ }^{1}$ BARROS, W.P. A erosão do solo no Brasil. S. 1, Ministério da Viação e das Obras Públicas. Serviço de Documentação. 350p. (Coleção Mauá). 1956.
} 
transporte pela gota da chuva e desagregação e transporte pelo fluxo superficial), sendo que a desagregação induzida pela gota da chuva e o transporte pelo fluxo superficial são os processos dominantes (Sharma, 1995).

Quando a água se move na superficie do solo, forças horizontais agem nas partículas do solo na direção do fluxo, por rolamento ou arrastamento estas forças desagregam as partículas da massa do solo. O movimento ascendente da água desprende também as partículas, por ação elevatória. Quando as partículas que estão sendo transportadas pela enxurrada golpeiam ou arrastam outras partículas na superfície do solo colocando-as em movimento, aqui ocorre o desprendimento por abrasão (Beasley, 1972).

A erosão entre sulcos deve ser considerada a mais séria, responsável pela remoção das partículas mais leves do solo, matéria orgânica e nutrientes solúveis, e só é notada quando a produtividade dos solos já foi removida. Os efeitos mais pronunciados desta forma de erosão são notados de forma indireta, ou seja, coloração mais clara do solo, aparecimento de raízes queda na produtividade agrícola, coloração das águas superficiais (Bertoni \& Lombardi Neto, 1993).

Segundo Foster et al. (1982), os fatores que afetam a erosão entre sulcos são: erosividade da chuva, erodibilidade do solo, características do relevo (comprimento do declive e declividade) e o manejo da cobertura vegetal, estes fatores serão abordados no próximo item desta revisão.

\subsection{A equação Universal de Perdas de Solo (EUPS)}

A Equação Universal de Perdas de Solo (EUPS) foi desenvolvida em 1954, no "National Runoff and Soil Loss Data Center", da Agricultural Research Service, na Universidade de Purdue, EUA, o modelo inicial apresentava restrições climáticas ou geográficas, foi então revisada em 1978 por Wischhmeier \& Smith, que atualizaram e incorporaram os novos dados disponíveis, superando as restrições encontradas nos primeiros estudos (Bertoni \& Lombardi Neto, 1993).

A EUPS (Equação 1) é representada pela seguinte equação: 
Equação 1 : A = R.K.L.S.C.P.

onde:

$\mathrm{A}=$ perda média anula de solo por unidade de área, $\mathrm{Mg} \mathrm{ha}^{-1}$;

$\mathrm{R}=$ fator erosividade das chuvas, $\mathrm{MJ} \mathrm{ha}^{-1} \mathrm{~mm} \mathrm{ha}^{-1}$;

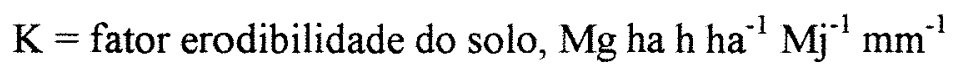

$\mathrm{L}=$ fator comprimento do declive, $\mathrm{m}$;

$\mathrm{S}=$ fator grau do declive, $\%$;

$\mathrm{C}=$ fator uso e manejo;

$\mathrm{P}=$ fator práticas conservacionistas.

A EUPS exprime a ação dos principais fatores que influenciam a erosão do solo pela chuva. Os fatores $\mathrm{R}, \mathrm{K}, \mathrm{L}$ e $\mathrm{S}$ são dependentes das condições naturais e os fatores $\mathrm{C}$ e P são dependentes das ações antrópicas, ou seja, as diferentes formas de ocupação e uso das terras.

Apesar de ser um modelo empírico com algumas limitações, a EUPS tem sido amplamente utilizada (Brooks, 1991; Mellerowicz, et al., 1994; Renard et al, 1994) na previsão de perdas de solo por erosão laminar (entre sulcos), por ser um modelo eficiente e prático (Ranieri, 1996 e Marques et al.,1997) não necessitando de grandes número de informações para o seu bom funcionamento.

Alguns modelos físicos, como é o caso da WEEP, the Water Erosion Predicition Project, tem sido desenvolvido para ocupar o lugar do empirismo da EUPS (Mellerowicz et al., 1994), mas estes modelos necessitam ser alimentados com um número muito grande de informações, tornando-se muitas vezes inviável a sua utilização principalmente nos países em desenvolvimento, como é o caso do Brasil, cuja base cartográfica e de dados em geral é escassa (Ranieri, 1996).

Ranieri (1996) aponta como aplicação da EUPS as seguintes finalidades: a) previsão das perdas anuais médias de terra para áreas com determinadas práticas de utilização; b) orientações para o planejamento de práticas de cultivo, de manejo e conservação; c) previsão de alterações nas perdas de solos ocasionadas por mudanças nas práticas de cultivo e conservação; d) determinação de modos de aplicação ou alteração das práticas agrícolas; estimativa de perdas de solo para uso distintos na 
agricultura e) estimativa de perdas de solos visando a determinação de práticas conservacionistas.

O fato da EUPS ser um modelo empírico e ter sido desenvolvida em parcelas unitárias e uniformes, este modelo apresenta algumas limitações quando aplicada em bacias hidrográficas, como por exemplo, adotar condições uniformes para os aspectos morfológicos da encosta considerando os perfis retilíneos. Halmet et al. (1992), apontam como problemática principal o cálculo do comprimento do declive quando a EUPS é aplicada para a estimativa de perdas de solo em bacias hidrográfica.

Castro ${ }^{2}$, citado por Ranieri (1996), aponta como erro ocorrido na estimativa de perdas de solo para bacias hidrográficas através do uso da EUPS, o fato do processo erosivo ser considerado de caráter contínuo, não contemplando o fenômeno de deposições nas encostas, o mesmo autor ainda levanta a problemática da subjetividade semi quantitativa de algumas variáveis da EUPS.

Para Renard et al. (1994) os principais fatores relacionados com a erosão para a estimativa de perdas de solo aplicando a EUPS são representados de forma empírica, o mesmo autor relata que este empirismo pode super estimar as perdas de solo em mais de 300 vezes quando comparada com os resultados obtidos através da utilização da RUSLE (Revised Universal Soil Loss Equation), este modelo é uma versão melhorada da EUPS, onde os valores das variavéis são determinados a partir de dados obtidos de uma gama maior de informações obtidas nos EUA.

A seguir serão apresentados e discutidos os fatores que compõem a EUPS.

\subsubsection{Fator erosividade da chuva (R)}

O fator erosividade da chuva (R) é um índice numérico que indica a capacidade da chuva, esperada em determinada localidade, de causar erosão em uma área sem proteção (Bertoni \& Lombardi Neto, 1990).

Dados de perdas de solo em terrenos cultivados associados com as características da chuva, quando os outros fatores relacionados são mantidos constantes,

\footnotetext{
${ }^{2}$ CASTRO, A.G. de. Técnicas de sensoriamento remoto e Sistemas Geográficos de Informações no estudo integrado de bacias hidrográficas. S.J. dos Campos. Diss. (Mestrado) - (INPE).
} 
mostram que as perdas de solo são diretamente proporcionais ao valor do produto da energia cinética total da chuva por sua intensidade em trinta minutos (Wischemeier \& Smith, 1978). Esta é considerada a melhor correlação para expressar o potencial erosivo da chuva. O produto da energia cinética pela intensidade da chuva é chamado por Bertoni \& Lombardi Neto (1993) de "índice de erosão" (EI), é a abreviação do termo energy-times-intensity, indica como a desagregação da partícula combina com a capacidade de transporte (Wischemeier \& Smith, 1978).

A relação para a obtenção do índice de erosão, é dada pela Equação 2:

Equação 2: $\mathrm{EI}=67,355\left(\mathrm{r}^{2} / \mathrm{P}\right)^{0,85}$

onde:

$\mathrm{EI}=$ média mensal do índice de erosão, $\mathrm{MJ} \mathrm{ha}^{-1} \mathrm{~mm}^{-1}$;

$\mathrm{r}=$ precipitação média mensal, $\mathrm{mm}$;

$\mathrm{P}=$ precipitação média anual, $\mathrm{mm}$.

O índice de erosão não deve ser considerado simplesmente um parâmetro de energia, visto que as pesquisas mostram que somente os dados de energia da chuva, não são bons indicadores do seu potencial erosivo. Uma chuva longa e lenta pode apresentar a mesma energia que uma chuva rápida com alta intensidade, mas está última apresenta um potencial erosivo muito maior. A avaliação numérica da erosividade da chuva dentro de um período é determinada através da soma dos valores de EI de cada chuva, isoladamente, dentro daquele período. A soma de todos os valores de EI das chuvas caídas em um ano em determinado local, dará o valor anual de EI. O fator $\mathrm{R}$ da equação, para um dado local, é a média dos valores anuais de EI de um período longo de tempo (vinte ou mais anos).

Bertoni \& Lombardi Neto (1993) apresentam o mapa de isoerodentes (linhas que ligam pontos de igual potencial de erosão) para o Estado de São Paulo construído por Lombardi Neto et al. ${ }^{3}$, utilizando a equação de EI, estabeleceram os valores do $\mathrm{EI}_{30}$, para 115 locais escolhidos do estado. As linhas mostram os valores médios anuais de

\footnotetext{
${ }^{3}$ LOMBARDI NETO, F.; SIL VA, I. R.; CASTRO, O. M. Potencial de erosão das chuvas do Estado de São Paulo. In: Encontro Nacional de Pesquisa sobre Conservação do Solo, 3., Recife, 1981.
} 
erosividade e o fator $\mathrm{R}$ da EUPS, os valores intermediários podem ser interpolados linearmente.

\subsubsection{Fator erodibilidade do solo (K)}

Alguns solos são mais facilmente erosivos do que outros, mesmo quando os outros fatores relacionados com a erosão são mantidos constantes (FAO,1967). Segundo Wischemeier \& Mannering (1969), a erodibilidade (fator K) é uma propriedade inerente ao solo, sendo um importante fator na previsão das perdas de terra por erosão, uma vez que a erodibilidade representa o efeito integrado dos processos que regulam o comportamento do solo frente aos agentes erosivos (Lal, 1994).

As propriedades que se relacionam com a erodibilidade dos solos são principalmente de ordem física, podendo variar de acordo com a natureza química das frações mais finas do solo. Estas propriedades são complexas e dependem da combinação de parâmetros individuais de cada solo, especialmente aquelas que determinam a velocidade de infiltração da água no perfil e aquelas que determinam a resistência a dispersão e ao arraste de partículas durante a chuva e o escoamento superficial (Wischemeier \& Mannering, 1969).

As propriedades que afetam o grau de resistência à erosão de um solo são textura, estrutura, porosidade e permeabilidade, capacidade de infiltração, matéria orgânica e composição química do complexo argila (César, 1952).

Os solos com textura argilosa resistem mais à erosão pela coesão das partículas, enquanto os solos arenosos resistem pela permeabilidade e peso dos seus constituintes, para Wischemeier et al. (1971) a erodibilidade tende a aumentar com o aumento do teor de silte. A textura influencia na permeabilidade do solo, e quando maior a permeabilidade menor o risco de erosão, devido a menor formação de deflúvios. Este comportamento está diretamente relacionado com a intensidade da chuva. César (1952), alerta para a importância de se conhecer a textura do solo em superficie e sub-superficie, os solos com textura arenosa no horizonte superficial e argilosa em profundidade (os solos podzólicos), em precipitações relativamente baixas, podem saturar a camada superficial e formar deflúvios com alto poder erosivo. 
O grau de agregação das partículas do solo está relacionado com a sua estrutura, os solos com estrutura granular (maior grau de agregação das partículas), apresentam maior permeabilidade, por sua vez, maior capacidade de retenção de água e menor suscetibilidade à erosão, quando comparadas às estruturas maciças, laminar e em blocos (Wischemeier et al., 1971). Na estrutura granular, as partículas menores que são transportáveis, apresentam-se fortemente ligadas, constituindo os agregados.

Para César (1952) a propriedade física mais importante com relação a resistência a erosão é a capacidade de infiltração, sendo ela a principal causa anuladora dos deflúvios. Em geral, quando maior a capacidade de infiltração, maior é a resistência à erosão do solo, exceto em casos de chuvas prolongadas quando a perda de solo se torna maior em solos com alta capacidade de infiltração, isto se deve ao fato da infiltração da água no perfil do solo não ocorrer de forma uniforme para uma determinada chuva, sendo máxima no início e com o tempo vai diminuindo até ocorrer o escoamento superficial.

A matéria orgânica tem grande influência na erodibilidade do solo, pois possui ação importante na coordenação das estruturas fisicas do solo: coesão, porosidade estrutura, permeabilidade. Quanto não decomposta ou semi decomposta desempenha um papel importante na proteção do solo contra o impacto da gota da chuva. Quando decomposta confere aos solos arenosos maior coesão das partículas e torna os solos argilosos, altamente compactado, mais leves.

A natureza química da argila confere ao solo propriedades físicas que se relacionam com a sua erodibilidade, dentre estas a mais importante é a plasticidade. Quanto mais alta for a relação sílica-sesquióxidos de suas moléculas, mais plástica será a argila, e os solos que dela se compõem serão mais erosívies, devido a menor capacidade de infiltração.

O fator erodibilidade, na equação, é um parâmetro quantitativo, determinado experimentalmente no campo numa parcela-padrão com $22 \mathrm{~m}$ de comprimento, $9 \%$ de declividade e mantida, permanentemente, descoberta e com preparo de solo no sentido do declive (Wischemeier \& Smith, 1965). Sob estas condições, os fatores L,S, C e P 
assumem valores unitários e o fator $\mathrm{K}$ iguala-se a $\mathrm{A} \mathrm{R}^{-1}$, sendo desta maneira, a perda de solo (A) expressa por unidade de índice de erosão da chuva (EI).

$\mathrm{O}$ fator $\mathrm{K}$ pode ser determinado por três métodos. $\mathrm{O}$ primeiro baseia-se na relação entre as perdas de solo e o fator erosividade das chuvas, avaliado sob condições naturais em parcelas-padrões; o segundo método obedece a mesma técnica do primeiro mas sob condições de chuvas artificiais, o que as vezes faz com que as parcelas não possuam as dimensões da parcela-padrão e necessitam de correções para os valores da erodibilidade obtidos. Estes dois métodos exigem muitos anos de determinação e apresentam custos muito elevados (Bertoni \& Lombardi Neto, 1993). O terceiro método, é o indireto, que baseia-se na computação dos valores de erodibilidade através de equações matemáticas, com variáveis independentes que contenham parâmetros de solos altamente correlacionados com a erodibilidade.

Utilizando este método indireto Wischemeier et al. (1971), através da avaliação de parâmetros físicos (porcentagem de silte e areia muito fina, porcentagem de areia entre 2,0 e $0,1 \mathrm{~mm}$, tipo de estrutura e classe de permeabilidade) e a porcentagem de matéria orgânica, apresentaram a combinação desses parâmetros graficamente em um nomograma, que permite a obtenção rápida e mais econômica do fator $\mathrm{K}$, quando comparado com os métodos direto. Porém a utilização do nomograma tem sido amplamente questionada por pesquisadores da área de conservação do solo, principalmente quanto a sua utilização em solos tropicais, quando a apresentam baixa porcentagem de silte e areia muito fina (Denardin, 1990).

Com o objetivo de verificar a aplicabilidade de modelos matemáticos, apresentados em bibliografia, para os solos brasileiros Denardin (1990) estimou a erodibilidade de 31 solos do Brasil. Utilizando parâmetros obtidos por análise laboratoriais (físicas e químicas) de rotina, com exceção do parâmetro " $M$ " que divide a fração areia em cinco classes (areia muito fina, areia fina, areia média, areia grossa e areia muito grossa) e não em duas (areia grossa e areia fina) como vem sendo realizado nas rotinas dos laboratórios. O autor concluiu que as variáveis independentes mais significativas para a estimativa da erodibilidade dos solos brasileiros são: permeabilidade, matéria orgânica, óxido de alumínio e fração areia entre 2,0 e $0,5 \mathrm{~mm}$, 
ajustando modelos aplicáveis para uma gama muito grande de solos, com variações nas características físicas e químicas.

A utilização dos modelos propostos por Denardin (1990) possibilita a determinação da erodibilidade dos solos de maneira rápida, em comparação com os métodos diretos, tornando-se um parâmetro possível de ser calculado no processo de classificação de solos.

Silva et al. (1986) estudaram seis solos do semi-árido brasileiro, mediante simuladores de chuva e concluíram que o solo Podzólicos Vermelho Amarelo, textura média apresentaram maior valor do fator $\mathrm{K}$, quando comparado com os resultados obtidos nos solos litólicos e Bruno não Cálcico Vértico, os autores associaram estes resultados a textura arenosa, estrutura fraca e descontinuidade entre os horizontes do primeiro e à presença de pedregosidade dos outros solos que atenuam a ação desagregadora do impacto das gotas de chuva.

Resultado semelhante foi obtido por Lombardi Neto \& Bertoni (1975), em trabalho onde estudaram 66 perfis de solo que ocorrem no estado de São Paulo, analisando-os segundo método de Middleton, com algumas modificações. Os autores concluíram que os solos com B textural e com B latossólico apresentaram comportamento diferenciado em relação á erosão, os solos com B textural são mais suscetíveis à erosão.

Pundek (1994) estimou os valores de K para alguns solos do estado de Santa Catarina, aplicando sempre que possível os três métodos: nomograma de Wischemeier et al. (1971), método de Middleton modificado por Bertoni \& Lombardi Neto (1993) e a equação de Denardin (1990). Os resultados foram comparados com os dados de pesquisa a campo realizados nos mesmos solos em outros estados do Brasil e o valor final de $\mathrm{K}$ foi estabelecido para aqueles que se apresentavam com maior freqüência nas comparações. Os menores valores de $\mathrm{K}$ foram encontrados para solos com horizonte $\mathrm{B}$ latossólico, para o solo Latossolo Vermelho Amarelo $\mathrm{K}=0,0182 \mathrm{Mg} \mathrm{ha} \mathrm{h} \mathrm{ha}{ }^{-1} \mathrm{MJ}^{-1} \mathrm{~mm}^{-1}$, seguido pelos solos com horizonte com $\mathrm{B}$ textural, Terra Roxa Estruturada $\mathrm{K}=$ $0,0227 \mathrm{Mg} \mathrm{ha} \mathrm{h} \mathrm{ha}^{-1} \mathrm{MJ}^{-1} \mathrm{~mm}^{-1} \mathrm{e}$ solo Podzólico Vermelho Amarelo $\mathrm{K}=$ $0,0375 \mathrm{Mg}$ ha h ha ${ }^{-1} \mathrm{MJ}^{-1} \mathrm{~mm}^{-1}$; os solos com B incipiente, o Cambissolo apresentou 
valores de $\mathrm{K}=0,0356 \mathrm{Mg}^{\mathrm{ha} \mathrm{h} \mathrm{ha}} \mathrm{MJ}^{-1} \mathrm{~mm}^{-1}$ e os menores valores foram encontrados para os solos pouco desenvolvidos, solos Litólicos com contato lítico $\mathrm{K}=$ $0,0458 \mathrm{Mg}_{\text {ha h ha }} \mathrm{MJ}^{-1} \mathrm{~mm}^{-1}$ e com contato litóide $\mathrm{K}=0,0421 \mathrm{Mg}^{\mathrm{g}} \mathrm{h} \mathrm{ha} \mathrm{MJ}^{-1} \mathrm{~mm}^{-1}$.

Por sua vez, Marques et al. (1997) critica os modelos desenvolvidos, ou adaptados, para o clima tropical, como os apresentados por Denardin (1990) e Lima et al. (1990), segundo os autores estes não apresentaram resultados satisfatórios, possivelmente devido a grande heterogeneidade do comportamento destes solos frente aos processos erosivos, propondo deste modo a estimativa do fator $\mathrm{K}$ para cada grupamento específico de solo, e não um único método para todo o universo de solos existente nas regiões tropicais.

\subsubsection{Fator topográfico (LS)}

O comprimento do declive e seu gradiente afetam grandemente a intensidade de erosão do solo, para a aplicação prática da EUPS são considerados conjuntamente como um fator topográfico: LS (Wischemeier \& Smith, 1978).

O fator LS expressa matematicamente a relação esperada de perda de solo por unidade de área em um declive qualquer em relação a perda correspondentes de uma parcela unitária de $25 \mathrm{~m}$ de comprimento e $9 \%$ de declive. Bertoni \& Lombardi Neto (1993), apresentaram a seguinte equação (Equação 3)para a determinação do fator topográfico:

Equação $3: \mathrm{LS}=0,00984 \cdot C^{0,63} \cdot D^{1,18}$

onde:

$\mathrm{LS}=$ fator topográfico;

$\mathrm{C}=$ comprimento de declive em metros;

$\mathrm{D}=$ grau de declividade em porcentagem.

Para as áreas onde é adotada a prática conservacionista de terraceamento, o comprimento do declive a ser usado na determinação do valor do fator LS na equação deve ser o intervalo entre terraços.

Para Bertoni \& Lombardi Neto (1993) um dos maiores erros implícitos no uso desta equação é o fato do comprimento do declive ser considerado uniforme, utilizando 
um gradiente médio de comprimento de rampa, o que pode superestimar as perdas de solo de declives convexos e superestimar aquelas de declive convexo.

\subsubsection{Fator uso-manejo do solo (C)}

Áreas cultivadas reduzem as perdas de solo, devido à proteção que a cultura oferece, esta proteção depende do tipo de cobertura vegetal, seqüência de cultura, práticas de manejo, estágio de crescimento e desenvolvimento da cultura durante o período das chuvas. $O$ efeito uso e manejo não poderia ser avaliado separadamente devido as diversas interações que ocorrem (Wischemeier \& Smith, 1978).

O fator uso-manejo do solo (C) expressa a relação esperada entre as perdas de solo de um terreno cultivado em dadas condições e as perdas correspondentes de um terreno mantido continuamente sem cobertura e cultivado (Bertoni \& Lombardi Neto, 1993), medindo desta forma o efeito combinado de todas as variáveis de cobertura e manejo.

A cultura apresenta comportamento gradual de proteção ao solo, durante o seu ciclo vegetativo, sofrendo ainda a influência das estações do ano e quantidades de eventos erosivos que ocorrem durante o periodo de desenvolvimento. Para fins práticos, o ano agrícola é dividido em períodos ou estágio da cultura, definidos para que os efeitos de cobertura e manejo possam ser considerados uniformes dentro de cada período, a saber:

(a) período $\mathrm{D}$ - preparo do solo: do preparo do solo até o plantio;

(b) período 1 - plantio: do plantio até um mês após plantio;

(c) período 2 - estabelecimento: um mês até dois meses após o plantio;

(d) periodo 3 - estabelecimento e maturação: dois meses após o plantio até a colheita;

(e) período 4 - resíduo; da colheita até o preparo do solo.

$\mathrm{O}$ fator $\mathrm{C}$ é obtido através da combinação das diferentes intensidades de perda de solo em cada período de desenvolvimento da cultura com os dados relativos à chuva, ou seja, em relação a porcentagem de distribuição do índice de erosão (EI) anual para determinado local. 
De Maria et al. (1994) determinaram o fator C da EUPS para a cultura da canade-açúcar, obtidos em parcelas sob chuvas naturais, em dois tipos de solos: um Latossolo Roxo Distrófico (A moderado, textura argilosa) e um podzólico vermelho amarelo (textura arenoso/média) com 13\% e 12\% de declive respectivamente, e encontraram o valor de $C$ para esta cultura igual a 0,11 , que pode ser considerado como único para o Estado de São Paulo uma vez que não houve diferença entre os valores do fator $\mathrm{C}$ para as regiões estudadas.

\subsubsection{Fator práticas conservacionistas $(\mathrm{P})$}

O fator práticas conservacionistas $(\mathrm{P})$ expressa a relação entre a intensidade esperada de perdas de solo com determinada prática conservacionista e aquelas que ocorrem quando a cultura está plantada no sentido do declive.

Bertoni \& Lombardi Neto (1993) citam como práticas conservacionistas mais comuns para as culturas anuais o plantio em contorno, plantio em faixas de contorno, terraceamento e alternância da capinas. Na Tabela 1 estão apresentados os valores do fator P, obtidos pela Seção de Conservação do Solo do Instituto Agronômico de Campinas, para as práticas conservacionistas de proteção do solo contra a erosão.

Tabela 1 : Valor do fator práticas conservacionistas (P) da equação de perda do solo, para algumas práticas conservacionistas.

\begin{tabular}{lc}
\hline \multicolumn{1}{c}{ Práticas conservacionistas } & Valor do fator P \\
\hline Plantio morro abaixo & 1,0 \\
Plantio em contorno & 0,5 \\
Alternância de capina + plantio em contorno & 0,4 \\
Cordões de vegetação permanente & 0,2 \\
\hline
\end{tabular}

Fonte: Bertoni e Lombardi Neto, 1993.

\subsection{Tolerância de perdas de solo (T)}

Para avaliar o impacto da erosão do solo no ambiente é necessário saber o quanto de solo que está sendo perdido em uma determinada área, e o quanto ainda é 
tolerável perder sem que o recurso natural solo esteja comprometido para as gerações futuras (Schertz, 1983).

Para Wischemeier \& Smith (1978) o termo "Tolerância de perda de solo" (T) indica o máximo nível de erosão de solo aceitável, mantendo um elevado nível de produtividade economicamente viável e indefinidamente.

Schertz (1983) cita como primeiro critério assumido pelos pesquisadores, para estabelecer valores de T, a taxa de formação natural dos solos. Surgindo a seguir novos critérios para a determinação de $T$, como a manutenção da produtividade ao longo de um certo período de tempo e a não formação de erosão linear.

Os cientistas afirmam que a tolerância de perda de solo varia com o tipo de solo, não podendo ser impostos limites fixos que sejam aplicáveis para solos semelhantes. Solos bastante profundos, permeáveis e bem drenados apresentam um valor de $\mathrm{T}$ maior do que solos rasos com subsolos desfavoráveis ao desenvolvimento do sistema radicular (Schhertz, 1983; Bertoni \& Lombardi Neto, 1993).

Os valores de $\mathrm{T}$ freqüentemente usado para áreas agrícolas é em torno de 2,5 até $12,5 \mathrm{Mg} \mathrm{ha}^{-1} \mathrm{ano}^{-1}$, mas o valor máximo tolerável de perdas de solo adotado em muitas partes do Estados Unidos é de $11,2 \mathrm{Mg} \mathrm{ha}^{-1}$ ano $^{-1}$, os pesquisadores justificam este valor pelas seguintes razões: 1) Valores de perda de solo superior a $11,2 \mathrm{Mg} \mathrm{ha}^{-1}$ ano $^{-1}$ afetam a manutenção, custos e eficiência das estruturas de controle de água devido aos sedimentos produzidos no processo erosivo; 2) Problemas relacionados com a formação de erosão linear causados pela excessiva perda de solo da superficie; 3) Perdas dos nutrientes necessário para o desenvolvimento das plantas, elevando os custos de produção e 4) A existência de práticas conservacionistas que podem ser empregadas com sucesso para manter as perdas de solo inferior a $11,2 \mathrm{Mg} \mathrm{ha}^{-1} \mathrm{ano}^{-1}$ (Brooks et al., 1991).

Segundo El-Swaify \& Dangler (1982) ainda não existe uma tolerância de perda de solo definida para as regiões tropicais, onde devem ser levadas em consideração alguns fatores para a sua determinação, segundo os autores estes valores devem ser maiores em solos tropicais do que aqueles utilizados para solos de regiões temperadas. Para Sparovek \& Jong van Lier (1993), apesar dos critérios estabelecidos para a 
definição da tolerância estarem bem estabelecidos, os limites geralmente usados não condizem com as condições naturais dos solos tropicais.

Lombardi Neto \& Bertoni (1975) estudaram 75 perfis de solos do Estado de São Paulo com o objetivo de estabelecer padrões de tolerância de perdas de solo para as unidades de solos, os critérios adotados levaram em consideração a sua profundidade e algumas propriedades fisicas. Os valores de tolerância média de perdas de solo variaram de 4,5 a 13,4 $\mathrm{Mg} \mathrm{ha}^{-1} \mathrm{ano}^{-1}$ e de 9,6 a $15,0 \mathrm{Mg} \mathrm{ha}^{-1} \mathrm{ano}^{-1}$, respectivamente, para solos com B textural e com B latossólico.

Sparovek et al. (1997) definiram um novo conceito para tolerância de perdas média de solo, o tempo de vida (tempo necessário para 50\% de uma área, com erosão maior que a formação do solo, atingir o mínimo de profundidade do solo), onde os critérios adotados são o uso do solo, sua profundidade e a taxa de erosão existente.

\subsection{As ações antrópicas e sua interferência no ambiente}

As interferências das ações antrópicas no meio ambiente, principalmente aquelas relacionadas com a retirada das matas nativas para a produção de alimentos, tem um importante papel no comportamento do solo diante do processo erosivo.

Para Dune \& Dietrich (1982), o uso do solo é a principal variável condicionante do processo erosivo. Os autores citam vários trabalhos onde foram observadas alterações importante nas taxas de erosão após o desmatamento. Estas alterações referem-se não somente a perda da proteção contra a ação direta da chuva no solo, mas principalmente a uma drástica alteração do meio físico, promovida pela eliminação da cobertura vegetal. Embora os autores reconheçam, que os dados de uso da terra não sejam levados em consideração na maior parte das análises regionais da produção de sedimentos, provavelmente devido a inexistência de dados que expliquem esta relação.

Prandini ${ }^{4}$ et al., citados por Oliveira (1994), consideram a formação arbórea densa o principal componente da floresta, nas ações específicas do comportamento hídrico do meio físico. Estas ações estão relacionadas com a interceptação e a proteção

\footnotetext{
${ }^{4}$ PRANDINI, F. L.; GUIDICINI, G.; BOTURRA, J.; PONÇANO, W.L.; SANTOS, A. R. Atuação da cobertura vegetalna estabilidade de encostas; uma resenha crítica. São Paulo, IPT. 22p. (IPT. Publicação,
} 
da incindência direta da chuva, raios solares e vento na superfície do solo; retenção de substancial volume de água de chuva na ampla superficie arbórea (copas das árvores) e ainda a eliminação de grande volume de água por meio da transpiração. Os autores ainda relatam a importância da serapilheira, camada de detritos vegetais que se forma na superfície do solo, na imobilização de boa parte da água da chuva que atinge o terreno, na promoção do escoamento sub superficial e em condições de máxima pluviosidade e na desaceleração do escoamento superficial.

O desmatamento proporciona incremento no escoamento superficial e na infiltração efetiva, levando a uma elevação do lençol freático. A elevação do lençol freático, restringe os horizontes não saturados que por ocasião das chuvas, favorece o desenvolvimento da erosão superficial e da subterrânea e podem ainda provocar alterações importantes nas estruturas dos solos que favorecem o processo erosivo.

Segundo Oliveira (1994) esta maior tendência do escoamento superficial e as irregularidades do terreno, proporcionam uma maior concentração das águas superficiais, favorecendo o desenvolvimento das feições erosivas lineares de grande porte, que sob as condições atenuantes da cobertura vegetal preservada não se manifestariam. $\mathrm{O}$ autor presumi que com o incremento nas taxas de erosão numa bacia desmatada, a sua produção de sedimentos será ainda maior, proporcionada devido à mudança qualitativa dos processos erosivos, de maior eficiência no transporte de sedimentos.

Os elementos físicos do uso do solo como as cercas, caminhos, carreadores, ruas, estradas entre outros podem também induzir de forma direta os processos erosivos, especialmente o desenvolvimento das erosões lineares, devido a concentração do escoamento superficial que favorecem a formação de sulcos e voçorocas. As áreas submetidas a movimentos de terraplanagem do solo com cortes aterros e bota-foras destacam-se como fontes muito produtivas de sedimentos (Oliveira, 1994).

Segundo Sparovek \& Lepsch (1998) grande parte da Região de Piracicaba encontra-se em processo degradação do solo, devido a super utilização dos solos dos solos arenosos e dos solos pouco profundos associado a relevos declivosos, aptidão de uso restrita e mesmo assim vem sendo utilizados para o plantio de cana-de-açúcar. 


\subsection{A degradação ambiental e a erosão do solo}

Nas últimas décadas as ações antrópicas tem participado como agente acelerador dos processos modificadores e de desequilíbrios da paisagem (Guerra \& Cunha, 1996). A ação do homem, principalmente na ocupação agrícola das terras, normalmente leva a um aumento muito grande da intensidade de erosão do solo e de suas conseqüências negativas no ambiente, como a degradação das terras e dos recursos hídricos (Lal,1990).

As características naturais: topografia, geologia, solos e clima podem contribuir para a erosão potencial das encostas e para os desequilibrios ambientais das microbacias hidrográficas, na maioria das vezes os fatores naturais iniciam os desequilíbrios que serão agravados pelas atividades humanas (Guerra \& Cunha, 1996).

O crescimento populacional e a pressão que este proporciona sobre o meio físico tem sido considerado por muitos a principal causa da degradação ambiental, para Guerra \& Cunha (1996) esta é uma posição simplista, visto que as áreas com forte concentração populacional nem sempre estão sujeitas à degradação. Segundo Morgan (1986), a principal causa da degradação ambiental se deve ao manejo inadequado do solo, tanto nas áreas rurais, como nas áreas urbanas.

O impactos ambientais decorrentes do uso de terras sem aptidão para atividades agrícolas e/ou com práticas de manejo inadequadas podem ser observadas nos vários compartimentos do ecossistema. $\mathrm{Na}$ atmosfera, as grandes queimadas que ocorrem nas extensas áreas de pastagens; na litosfera os efeitos são mais evidentes e permanentes, como a desertificação, a erosão, contaminação por agroquímicos e queda da fertilidade natural dos solos; na hidrosfera a contaminação do lençol freático e cursos d'água, assoreamento de rios, canais e represas tem ocorrido com freqüência reduzindo a biodiversidade e favorecendo a extinção de espécies (Flores, 1995).

A agricultura degrada os recursos hídricos, não com cargas orgânicas como é o caso da indústria e áreas urbanas, mas sim através da produção de sedimentos no processo de erosão do solo. Estes sedimentos são transportados para os cursos d'água podendo assoreá-los, aumentando os riscos de inundação, tornando os processos de 
bombeamento e tratamento de água mais caros, prejudicando a flora e fauna aquática, interferindo deste modo, na qualidade e quantidade de água (Clark II et al., 1985).

A agricultura é uma fonte não pontual de poluição. Os sedimentos carregam consigo os produtos químicos e fertilizantes aplicados no solo através do escoamento superficial, poluindo as águas superficiais, e podem através da infiltração no solo poluir até mesmo as águas subterrâneas, levando a degradação dos recursos hídricos.

A tecnificação da agricultura, e o uso intensivo e indiscriminado das terras para a produção agrícola, têm sido os grandes responsáveis pela erosão acelerada, resultando na queda da fertilidade natural do solo e por consequência maiores custos de produção. Surge deste modo, a necessidade de produzir cada vez mais alimentos em áreas cada vez menores, causando o mínimo de impacto possível no ambiente (Ehrlers, 1996).

O estudo da movimentação dos sedimentos em bacias hidrográficas tropicais, identificando-se sua origem e pontos de acúmulo, é essencial para o conhecimento da degradação do meio físico ligado a erosão do solo (Dune \& Dietrich, 1982).

Clark II et al. (1985) consideram os impactos causados pelos processos erosivos em duas categorias: os impactos a nível de propriedade rural, chamados pelos autores de "on farm", "on site", intrínsecos ou internos e os impactos verificados fora dos limites das explorações agrícolas: "off farm", "off site", extrínsecos ou externos.

Os impactos "off farm" constituem-se dos problemas causados pelos sedimentos levados pela água ao serem retirados das áreas agrícolas, pelo processo erosivo. Entre o início do processo e o destino final dos sedimentos, uma série de problemas são causados por estes, tanto nos cursos d'água diretamente ("in stream") quanto nos segmentos localizados fora dos cursos d'água ("on stream").

Os impactos causados nos corpos d'água estão relacionados com os sedimentos e outros contaminantes ligados ao solo erodido, que são transportados para os lagos, rios, reservatório e cursos d'água. Os impactos causados fora dos cursos d'água podem ocorrer antes que os sedimentos alcancem os corpos d'água e/ou depois, quando a água é usada diretamente no abastecimento urbano e industrial, na irrigação, na produção de energia elétrica e na recreação. 


\section{MATERIAL E MÉTODOS}

\subsection{Material}

\subsubsection{Localização da área}

A microbacia hidrográfica do córrego Ceveiro (MBHC), no Município de Piracicaba (SP), está situada $22^{\circ} 40^{\prime} \mathrm{S}$ e $47^{\circ} 47^{\prime} \mathrm{W}$. Possui uma área de contribuição de aproximadamente $2.200 \mathrm{ha}$, é limitada a montante pela Vila de Santana e a jusante pelo Distrito de Ártemis e pelo Rio Piracicaba (Figura 1).

A MBHC possui uma represa localizada no final do córrego do Ceveiro, que foi considerada neste estudo como limite inferior da área de estudo. A represa foi construída em 1978, para o abastecer o Distrito de Ártemis com água potável. Em 1995 a água captada pela represa deixou de abastecer a população do distrito, devido ao assoreamento que a represa sofreu nestes anos.

O limite considerado neste estudo é justificado pelo comportamento da represa em captar não somente a água mas também os sedimentos produzidos no processo erosivo que ocorre na microbacia, sendo testemunha do elevado grau de degradação que encontra-se a MBHC.

\subsubsection{Clima}

O clima, segundo o sistema de Köppen, é Cwa mesotérmico úmido, sub tropical com inverno seco e temperatura do mês mais quente superior a $22^{\circ} \mathrm{C}$ e a do mês mais frio não excede $18^{\circ} \mathrm{C}$ (Brasil, 1960). A distribuição das chuvas é caracterizada por um período chuvoso, que se estende de outubro a março e outro seco, de abril a setembro, com passagem abrupta de um período para outro. 
O regime térmico do solo é hipertérmico segundo Oliveira et al. (1976). Para os solos rasos como é o caso dos litólicos e podzólicos pouco profundo o regime térmico pode ser ústico.

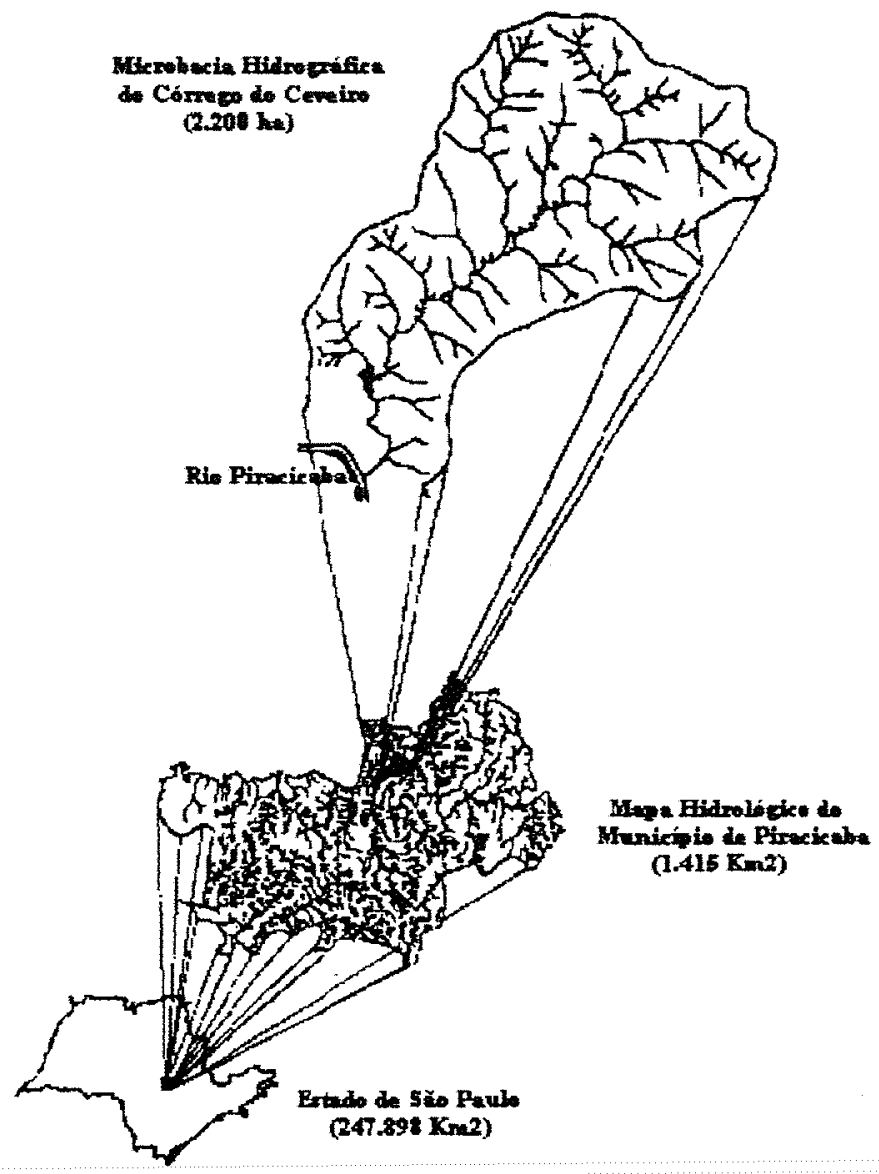

Figura 1: Localização da Microbacia Hidrográfica do Córrego do Ceveiro no Estado de São Paulo.

\subsubsection{Vegetação e Uso atual}

A vegetação natural é do tipo floresta mesófila semidecídua, sendo ripária nas margens dos cursos d'água. Esta vegetação é quase inexistente, aparecendo somente em 
algumas partes da rede de drenagem, e em áreas muito declivosas onde é impossível a prática agrícola.

Nas últimas décadas, a cobertura florestal nativa foi drasticamente reduzida devido ao avanço da agricultura, sendo hoje a cana-de-açúcar a principal cultura da área. A MBHC vem sendo explorada economicamente pela agricultura a muitas décadas, com o projeto Pró álcool, na década de setenta, houve um grande impulso da cultura canaviera na região de Piracicaba, caracterizado por uma elevada tecnificação.

Neste trabalho o uso do solo foi agrupado em sete tipos fisionômicos diferentes: mata, mata ciliar, reflorestamento, pasto sujo, pastagem, cana-de-açúcar, culturas anuais; a caracterização do uso da terra considerou ainda as áreas urbanas e as represas.

Fiorio (1998) fez uma avaliação cronológica do uso da terra na MBHC e o impacto deste na microbacia, os resultados obtidos pelo autor estão representados na tabela 1. A cana-de-açúcar foi a cultura que apresentou maior crescimento na área, passando de 16 para $66 \%$ a área cultivada, o autor cita como causas desta expansão o Programa Proalcool e a proximidade entre a área de estudo e a usina de moagem. No período estudado (1962, 1965, 1978 e 1995), o autor constatou uma diminuição de $99 \%$ da área cultivada com cultura anual, $48 \%$ da área com pastagens e de $42 \%$ da área de reflorestamento, principalmente entre 1978 e 1995, período este que coincide com a implantação do projeto Proalcool. Segundo Sparovek \& Lepsch (1998) na região de Piracicaba, a expansão da cultura canavieira entre 1962 e 1991, se deu principalmente principalmente nas áreas de pastagens.

A área urbana apresentou um crescimento de $7 \%$ passando de 2,6 para 39 ha na área de estudo, este crescimento ocorreu principalmente na Vila de Santana e nas proximidades ao reservatório. Analisando os dados da Tabela 2 observa-se que a área total da represa passou de 11,6 para 5,52 ha, o que representa um decréscimo de 50\% na área total, evidenciando o assoreamento ocorrido nestes 17 , nos devido a erosão das terras na MBHC. 
Tabela 2 : Evolução cronológica do uso da terra na MHC, para os anos de 1962,1965,1978 e 1995, com área total em hectares e área relativa.

\begin{tabular}{crrrrrrrrrr}
\hline Uso da Terra & \multicolumn{3}{c}{1962} & \multicolumn{3}{c}{1965} & \multicolumn{2}{c}{1978} & \multicolumn{2}{c}{1995} \\
\hline & \multicolumn{1}{c}{ ha } & \multicolumn{1}{c}{$\%$} & \multicolumn{1}{c}{ Ha } & \multicolumn{1}{c}{$\%$} & \multicolumn{1}{c}{ ha } & $\%$ & \multicolumn{1}{c}{ ha } & $\%$ \\
Cana-de-açúcar & 318,2 & 16,0 & 151,7 & 7,6 & 524,5 & 26,4 & 1319,6 & 66,3 \\
Cultura anual & 633,4 & 31,8 & 835,7 & 42,0 & 226,6 & 11,4 & 3,0 & 0,2 \\
Pastagem & 289,7 & 14,6 & 281,8 & 14,2 & 558,56 & 28,1 & 96,4 & 4,8 \\
Pasto sujo & 289,9 & 14,6 & 247,3 & 12,4 & 282,2 & 14,2 & 181,2 & 9,1 \\
Reflorestamento & 283,6 & 14,2 & 230,9 & 11,6 & 268,0 & 13,5 & 120,1 & 6,0 \\
Mata & 45,0 & 2,3 & 32,4 & 1,6 & 31,2 & 1,6 & 134,1 & 6,7 \\
Mata ciliar & 126,9 & 6,4 & 202,2 & 10,2 & 76,2 & 3,8 & 91,28 & 4,6 \\
Área urbana & 2,6 & 0,1 & 8,3 & 0,4 & 11,4 & 0,6 & 39,2 & 2,0 \\
Represa & 0 & 0,0 & 0 & 0,0 & 11,6 & 0,6 & 5,52 & 0,3 \\
\hline
\end{tabular}

Fonte: Fiorio (1998).

\subsubsection{Relevo}

O relevo é ondulado, com topografia apresentando morros em cotas variando entre 460 a $580 \mathrm{~m}$ de altitude, a declividade predominante nos topos é de $5 \%$ e nas encostas de 5 a $15 \%$. O mapa de declividade da MBHC, com seis classes de declives está representado na Figura 2. A MBHC possui $44 \%$ da área total com declividade superior a $10 \%$ (Tabela 3 ). As áreas com declives menores que $2 \%$ ocupam menos de $5 \%$ da área total da bacia, estando essa localizada em pequenas várzeas e nos topos de alguns morros (Figura 2). 


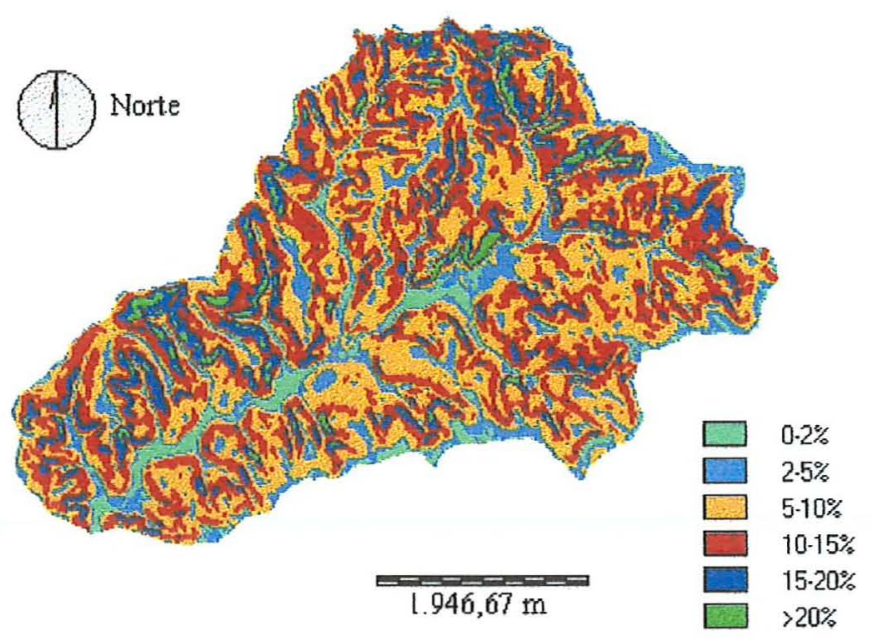

Figura 2: Mapa de declividade da MBHC, com seis classes de declive.

Tabela 3 : Áreas totais e relativas das classes de declividade da Microbacia Hidrográfica do Ceveiro.

\begin{tabular}{ccc}
\hline Declividade & Área total & Área relativa \\
\hline$\%$ & ha & $\%$ \\
$0-2$ & 83,72 & 4,2 \\
$2-5$ & 253,24 & 12,7 \\
$5-10$ & 772,44 & 38,8 \\
$10-15$ & 628,36 & 31,6 \\
$15-20$ & 210,84 & 10,6 \\
$>20$ & 41,80 & 2,1 \\
\hline Total & 1990,4 & 100 \\
\hline
\end{tabular}

\subsubsection{Geologia e material de origem}

A maior parte do Estado de São Paulo acha-se incluída bacia sedimentar do Paraná, que é uma unidade geotectônica estabelecida sobre a plataforma Sul-Americana a partir do Devoniano Inferior, a persistente subsidência desta bacia permitiu a acumulação de grande quantidade de sedimentos (Teramoto, 1995). A MHC está 
inserida na bacia do Paraná, e apresenta coluna estratigráfica representada por sedimentos dos grupos São Bento e Grupo Passa Dois (IPT, 1981).

O substrato geológico, segundo o mapa geológico do Estado de São Paulo - IPT (1981), escala 1:500.000, é representado por rochas relacionadas com arenitos da Formação Pirambóia e intrusivas básicas associadas da Formação Serra Geral, ambas do Grupo São Bento e pela formação Corumbataí do Grupo Passa Dois.

A formação Pirambóia recobre a formação Corumbataí, com contato por discordância erosiva, com destruição de espessura não estimável das camadas da Formação Corumbataí (IPT,1981). Na área de estudo ocorre locais onde a interface entre as duas formações aflora, podendo estar associada a bancos delgados de rochas de silex, ocorrendo em alguns locais o afloramento dos sills de diabásio(Figura 3).

A formação Pirambóia, possui idade não definida entre o Triássico Inferior e o Jurássico, litologicamente é caracterizada por uma sucessão de camadas arenosas, incluindo arenitos finos a médios avermelhados, siltitos argilosos com estratificação plano paralela, destacada pela alternância de lâminas mais ou menos ricas em argila ou silte, podendo apresentar estratificação cruzada, de dimensões média a grande, do tipo tangencial. Níveis de folhelhos e arenitos argilosos de cores variegadas (cinzas, arroxeadas e avermelhadas) e raras intercalações de natureza argilo-arenosas podem ser encontradas (IPT, 1981).

A Formação Corumbataí (Pc), pertence ao Permiano Superior, aflora continuamente até o divisor dos rios Tietê e Piracicaba para norte, até próximo de Minas Gerais, onde parece não se expor, podendo ser interrompida por sills de diabásio. É caracterizada por depósitos marinhos com estratificação plano paralelas, predominam siltitos e arenitos finos em parte concrecionados por calcário e sílex, de coloração vermelha arroxeada na base e esverdeada na base (IPT, 1981).

Os solos formados a partir de rochas da Formação Pirambóia encontra-se nas cotas mais elevadas do lado direito da MBHC (entende-se o sentido de observação do montante á jusante da microbacia), são representados pelos solos Podzólicos vermelhos amarelo e solos litosolos com textura arenosa a média, ocorrendo em aproximadamente $25 \%$ da área total. Cerca de $67 \%$ dos solos da área de estudo possuem a formação 
Corumbataí como material de origem (Sparovek et al., 1991), ocorrendo principalmente ás margens do Ceveiro e lado esquerdo da MBHC (sentido de observação do montante à jusante).

A Formação Serra Geral é caracterizada por intrusões básicas que recobrem a Formação Pirambóia, os solos oriundos destas intrusões ocorrem na cabeceira da MBHC do lado direito (mesmo sentido de observação) e uma pequena área no terço médio direito e são representados pelos solos Terras Roxa.

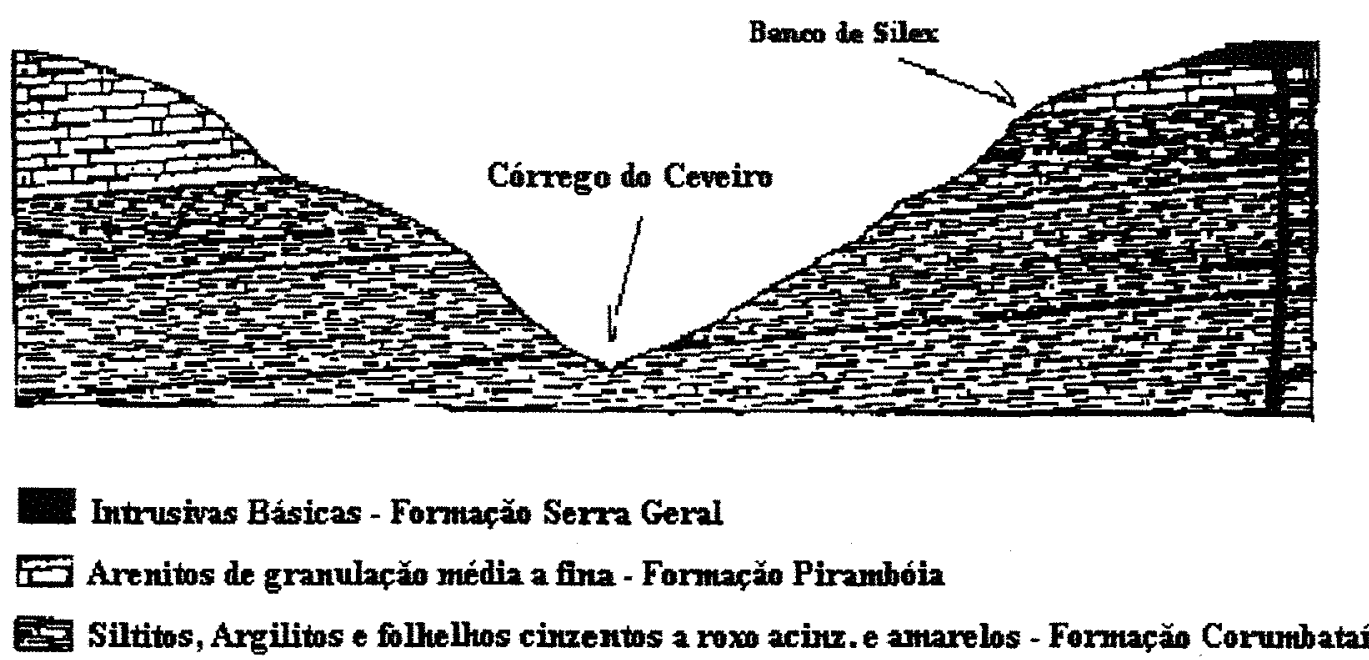

Figura 3: Corte transversal da MBHC mostrando a disposição das formações geológicas.

\subsubsection{Mapa de Solos}

Com base na legenda de solos proposta por Sparovek (1991), foi elaborada através dos dados de amostras de solos realizadas pelo laboratório de análise de solos do Departamento de Ciência do Solo da ESALQ, onde foram realizadas as seguintes determinações de rotina: $\mathrm{pH} \mathrm{CaCl}_{2}(0,01 \mathrm{M})$; teor de matéria orgânica (MO) oxidada por dicromato de sódio em $\mathrm{H}_{2} \mathrm{SO}_{4}$ e quantificada por colorimetria; fósforo disponível (P) e teores trocáveis de $\mathrm{K}^{+}, \mathrm{Ca}^{2+}$, e $\mathrm{Mg}^{2+}$, extraídos pela resina de troca iônica, sendo o $\mathrm{P}$ quantificado por colorimetria e $\mathrm{K}, \mathrm{Ca}$ e $\mathrm{Mg}$, por espectrofotometria de absorção atômica; teor trocável de $\mathrm{Al}^{3+}(\mathrm{Al})$, extraído por $\mathrm{KCl} 1 \mathrm{~N}$ e determinado por titulação ácido-base. 
A partir destes dados calculou-se a capacidade de troca de cátions, $(\mathrm{T})$, saturação por bases $(\mathrm{V} \%)$ e saturação por alumínio ( $\mathrm{m} \%$ ). Os métodos analíticos seguiram os procedimentos descritos por RAIJ et al. (1987). O teor de argila foi determinado pelo método de densímetro de Boyoucus sendo as frações de areia e silte obtidas por gravimetria após dispersão com hidróxido de sódio e calgon seguindo os métodos descritos por Camargo et al., 1986. A areia foi dividida em 3 frações granulométricas (grossa, média e fina).

O mapa de solos proposto por Sparovek (1991) está representado a seguir na Figura 4, e a área de ocorrência total e relativa na MBHC, das unidades de mapeamento estão relacionadas na Tabela 4. 


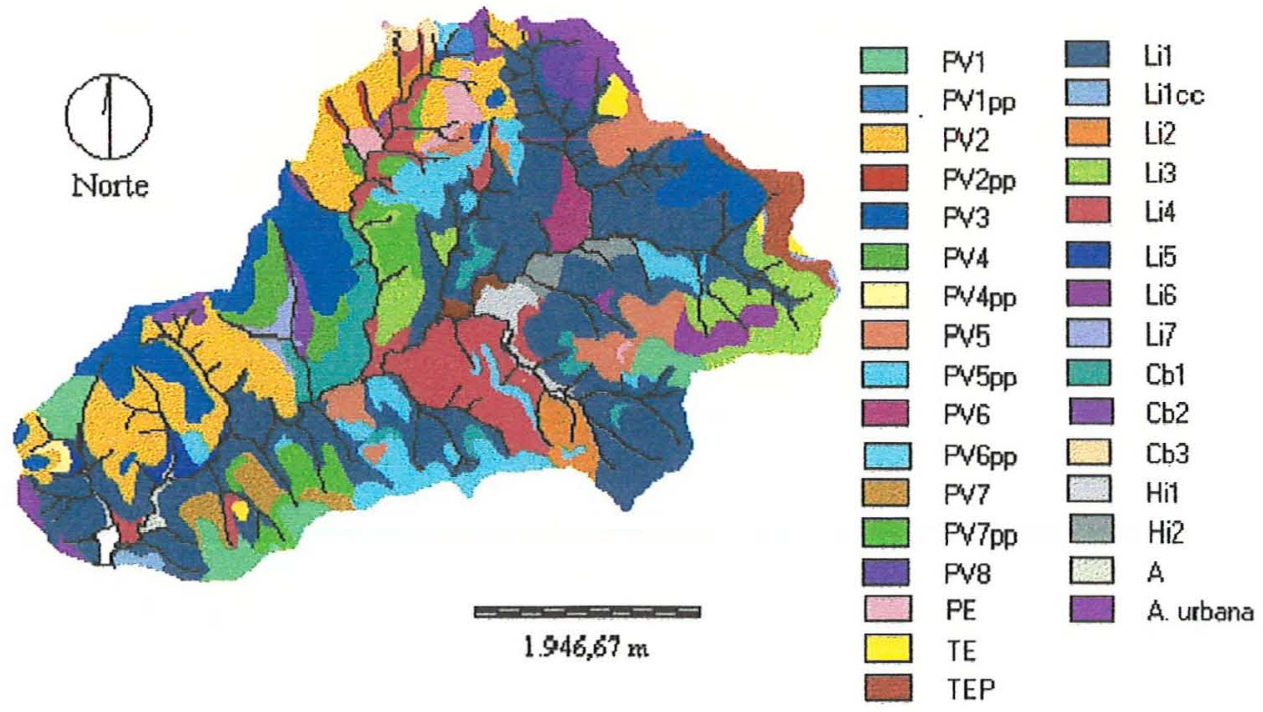

\section{Figura 4 : Mapa pedológico e unidades de mapeamento da Microbacia Hidrogáfica do}

Ceveiro.

\section{Unidades de Mapeamento}

\PV1 = Podzólico Vermelho Amarelo, álico, Tb, A moderado ou chernozêmico, textura arenosa/média

PV2 = Podzólico Vermelho Amarelo, álico, Ta, A moderado, textura arenosa/média

PV3 = Podzólico Vermelho Amarelo, álico Ta ou Tb, A moderado arênico, textura arenosa/média

PV4 = Podzólico Vermelho Amarelo, eutrófico, Tb, A moderado, textura arenosa/média

$\checkmark$ PV5 $=$ Podzólico Vermelho Amarelo, eutrófico, Tb, A moderado, textura média/argilosa

PV6 = Podzólico Vermelho Amarelo, eutrófico, Ta, A moderado, textura média/argilosa

PV7 = Podzólico Vermelho Amarelo, álico, Tb, A moderado, textura média/argilosa

PV8 = Podzólico Vermelho Amarelo, eutrófico, Ta ou Tb, A moderado (arênico), textura arenosa/argilosa

PV1pp = Podzólico Vermelho Amarelo, álico, Tb, A moderado ou chernozêmico, textura arenosa/média, fase pouco profunda PV2pp = Podzólico Vermelho Amarelo, álico, Ta, A moderado, textura arenosa/média fase pouco profunda

PV3pp = Podzólico Vermelho Amarelo, álico Ta ou Tb, A moderado arênico, textura arenosa/média fase pouco profunda

- PV4pp = Podzólico Vermelho Amarelo, eutrófico, Tb, A moderado, textura arenosa/média fase pouco profunda

- PV5pp = Podzólico Vermelho Amarelo, eutrófico, Tb, A moderado, textura média/argilosa fase pouco profunda

- PV6pp = Podzólico Vermelho Amarelo, eutrófico, Ta, A moderado, textura média/argilosa fase pouco profunda

PV7pp = Podzólico Vermelho Amarelo, álico, Tb, A moderado, textura média/argilosa fase pouco profunda

- PV8pp = Podzólico Vermelho Amarelo, eutrófico, Ta ou Tb, A moderado (arênico), textura arenosa/argilosa fase pouco profunda $\mathrm{PE}=$ Grupamento indiscriminado de Podzólico Vermelho Escuro, textura argilosa ou argilosa/muito argilosa com ou sem cascalho (Unidade Campestre)

( $\mathrm{TE}=$ Terra Roxa Estruturada, eutrófica, Tb, A moderado, textura argilosa (Unidade Estruturada)

TEpp $=$ Terra Roxa Estruturada, eutrófica, Tb, A moderado, textura argilosa (Unidade Estruturada) fase pouco profunda

TEP = Terra Roxa Estruturada Podzólica, eutrófica, Tb, A moderado, textura média/argilosa (Unidade Santana)

$\mathrm{Cb} 1$ = Cambissolo, eutrófico, Ta ou Tb, A moderado, textura média

$\mathrm{Cb} 2$ = Cambissolo, eutrófico ou distrófico, $\mathrm{Ta}$ ou Tb, A moderado, textura argilosa.

$\mathrm{Cb3}=$ Cambissolo, álico, Ta, A moderado, textura média.

$\mathrm{Cb} 4$ = Cambissolo, eutrófico, Ta, A moderado, textura média

$\mathrm{A}=$ Grupamento indiscriminado de solos aluviais.

Li 1 = Solo Litólico, eutrófico, Ta ou Tb, A moderado ou chernozêmico, textura média, substrato siltitos da For. Corumbataí

Li 2 = Solo Litólico, álico, Ta, A moderado, textura média, substrato siltitos da For. Corumbataí

Li 3 = Solo Litólico, eutrófico, Ta ou Tb, A moderado ou chernozêmico, textura argilosa, substrato folhelho da For. Corumbataí

Li 4 = Solo Litólico, álico, Ta, A moderado, textura argilosa, substrato folhelho da For. Corumbataí

Li 5 = Solo Litólico, distrófico, Tb, A moderado, textura média, substrato arenitos da For. Pirambóia

$\mathrm{Li} 6=$ Complexo Li3 + PV?+Cb2

$\mathrm{Li} 7$ = Complexo TEpp $+\mathrm{Cb} 5+\mathrm{Li} 7$

Hi 1 = Solo Hidromórfico, álico, Ta, A moderado, textura arenosa/média

Hi 2 = Solo Hidromórfico, eutrófico, Tb, A moderado, textura média/argilosa 
Tabela 4 : Áreas totais e relativas das unidades de mapeamento da Microbacia Hidrográfica do Ceveiro.

\begin{tabular}{ccc}
\hline Solo & Area total (ha) & Area relativa (\%) \\
\hline PV1 & 59,4 & 2,98 \\
PVlpp & 4,8 & 0,24 \\
PV2 & 222,3 & 11,17 \\
PV2pp & 4,6 & 0,23 \\
PV3 & 157 & 7,89 \\
PV4 & 35 & 1,76 \\
PV4pp & 5,3 & 0,27 \\
PV5 & 77,6 & 3,90 \\
PV5pp & 125,1 & 6,29 \\
PV6 & 20,5 & 1,03 \\
PV6pp & 23 & 1,16 \\
PV7 & 27,8 & 1,40 \\
PV7pp & 60,6 & 3,04 \\
PV8 & 18,4 & 0,92 \\
PE & 22,8 & 1,15 \\
TE & 11,7 & 0,59 \\
TEP & 29,9 & 1,50 \\
Li1 & 579,6 & 29,12 \\
Li1cc & 4,8 & 0,24 \\
Li2 & 31,3 & 1,57 \\
Li3 & 93,4 & 4,69 \\
Li4 & 143 & 7,18 \\
Li5 & 18,9 & 0,95 \\
Li6 & 20,8 & 1,05 \\
Li7 & 16,3 & 0,82 \\
Cb1 & 65 & 3,27 \\
Cb2 & 22,8 & 1,15 \\
Cb3 & 9,5 & 0,48 \\
Hi1 & 22,8 & 1,15 \\
Hi2 & 8,4 & 0,42 \\
A & 8,8 & 0,44 \\
Area urbana & 39,2 & 1,97 \\
\hline Total & 1990,4 & 100 \\
\hline & &
\end{tabular}

\subsubsection{Mapa geomorfológico}

A mapa geomorfológico (Figura 5) foi elaborada à partir de fotos aéreas na escala 1:25.000, do ano de 1995. O mapa final foi elaborado na escala 1:10.000, utilizando as técnicas de mapeamento propostas por Savigear (1965). Para a elaboração deste mapa, contou-se com a participação da aluna Marta Marujo Ferreira de doutorado do curso de pós graduação da Faculdade Geologia da Unesp - Campus Rio Claro. 
Foram mapeadas as rupturas de declividade, que é definida por Savigear (1965), como uma mudança gradativa de declive da vertente, podendo ser convexa e côncava. As rupturas convexa ou positivas são áreas de máxima energia, ou seja, áreas com grande potencial para serem áreas fontes de sedimentos no processo erosivo. As rupturas côncava ou negativa são áreas de baixa energia, onde os sedimentos produzidos no processo erosivo tendem a ser depositados, são áreas de baixadas e planas, onde a enxurrada não tem energia suficiente para transportar os sedimentos.

O mapa geomorfológico consegue traduzir a realidade da área quanto a tendência do processo erosivo, através da sua interpretação é possível identificar as áreas de perda, transporte e deposição dos sedimentos.

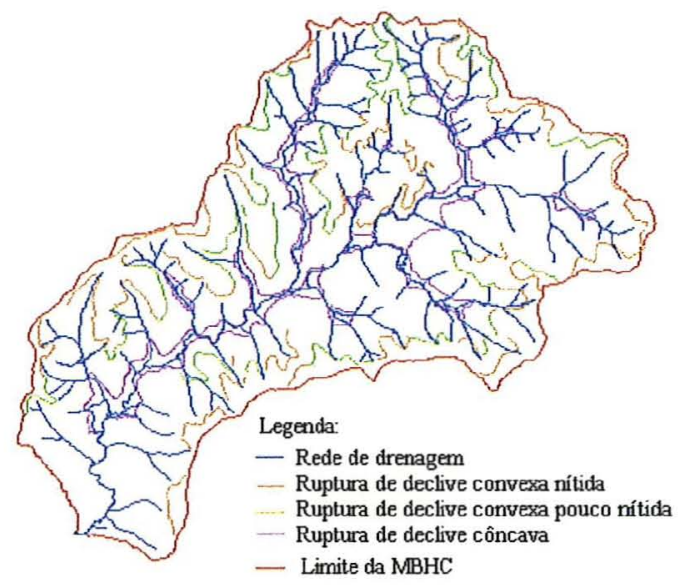

Figura 5 : Mapa Geomorfológico da área de estudo.

\subsection{Métodos de avaliação da erosão}

A MBHC foi dividida em sub bacias ao longo do córrego do Ceveiro, tendo com base o mapa planialtimétrico na escala 1:10.000. A erosão em sulcos e entre sulcos da MHC foi estimada em cada sub-bacia, estes dados foram levantados com o intuito de fornecer a ordem de grandeza do processo erosivo, não tendo como objetivo a sua q0uantificação precisa, mesmo porque isto é praticamente impossível quando se estuda os processos que ocorrem na natureza, onde muitas variáveis como a hidrologia, geomorfologia, pedologia, biologia e ações antrópicas estão envolvidas. 
O interesse principal deste estudo, em sub-bacia, é o entendimento da ordem de grandeza que os processos erosivos vem ocorrendo na MBHC e a compreensão destes, ou seja, identificação das áreas fontes de sedimentos e avaliação dos impactos ambientais causados pela erosão devido ao uso inadequado das terras agrícolas na MBHC, que servirão como subsídio para futuros estudos na área.

\subsubsection{Erosão areolar}

Para estimar a erosão areolar foram gerados mapas base dos seguintes materiais:

1) Mapa pedológico da MBHC, escala de 1:10.000, elaborados através de levantamento de campo por Sparovek (1991);

2) Mapas planialtimétrico do Instituto Brasileiro de Geografia e Estatística (IBGE), quadrícula de Piracicaba; escala 1:10.000, com curvas de nível de 5 em 5 metros;

3) Mapa de uso da terra elaborados através da interpretação de fotografias aéreas existentes do ano de 1995 (escala 1:25.000).

Para a estimativa de perda de solo foi utilizada a equação Universal de Perda de Solo (EUPS) segundo metodologia descrita por Ranieri (1996). Como forma de entrada de dados no SIG, utilizou-se o Autocad-12, os dados foram digitalizados via mesa digitalizadora. Para a geração e manipulação das imagens utilizou-se o programa IDRISI, Eastman (1992). A digitalização foi feita utilizando como base o sistema de coordenadas "Universal Transversa de Mercador"(UTM).

A taxa de erosão entre sulcos foi estimada através da sobreposição de vários mapas contendo os fatores da EUPS, os valores dos fatores foram retirados da literatura, com exceção do fator erodibilidade do solo $(\mathrm{K})$ que foi calculado para os solos que ocorrem na MBHC.

\section{Obtenção dos fatores da EUPS}

Fator erosividade da chuva $(R)$ - este fator foi considerado uniforme para toda a área da MHC, o valor da erosividade utilizado para a região de Piracicaba é de 
6.750MJ mm há ${ }^{-1} \mathrm{~h}^{-1} a^{-1}$ (Bertoni \& Lombardi Neto, 1993). Através do módulo "Assign" obteve-se o mapa de erosividade da chuva para MBHC.

Fator erodibilidade do solo (K) - Para o cálculo da erodibilidade foi utilizado o modelo matemático desenvolvido por Denardim (1990), baseado no nomograma de Wischemeier et al. (1971). Este modelo foi testado em solos dos EUA e do Brasil, os quais tinham valores de erodibilidade determinados diretamente no campo, apresentando coeficiente de determinação de 0,9767 e erro padrão estimado de 0,006 $\mathrm{Mg} \mathrm{ha} \mathrm{h} \mathrm{ha}^{-1} \mathrm{Mj}^{-1} \mathrm{~mm}^{-1}$ (teste F), permite que ela substitua as determinações de campo na grande maioria dos casos (Equação 4).

Equação $4: K=0,00000748(M)+0,00448059(P)-0,06311750(D M P)+0,01039567(R)$ onde: 2

$\mathrm{K}=$ valor estimado para o fator erodibilidade do solo, em $\left(\mathrm{Mg} \mathrm{ha} \mathrm{h} \mathrm{ha} \mathrm{aj}^{-1} \mathrm{Mj}^{-1} \mathrm{~mm}^{-1}\right)$, $\mathrm{M}=$ variável adimensional calculada a partir de parâmetros granulométricos, ou seja: \% novo silte $\mathrm{x}(\%$ novo silte $+\%$ nova areia $)$,

$\mathrm{P}=$ permeabilidade do solo conforme Wischmeier et al. (1971), no qual foram estabelecidas as seguintes classes de permeabilidade: $1=$ rápida; $2=$ moderada a rápida; $3=$ moderada; $4=$ lenta a moderada; $5=$ lenta; $6=$-muito lenta,

$\mathrm{DMP}=$ diâmetro médio ponderado das partícula menores que $2 \mathrm{~mm}(\mathrm{~mm})$, $\mathrm{R}=$ relação entre teor de matéria orgânica e o teor da nova areia (MO x \% nova areia)/100

Esta equação utiliza na sua maioria variáveis resultantes de análises de rotina, com exceção do parâmetro "M". Para o seu cálculo é necessária a subdivisão da fração areia em areia muito fina, areia fina, areia média, areia grossa e areia muito grossa.

O diâmetro médio das partículas foi calculado pela Equação 5, descrita por Bavel (1949), para diâmetro médio de agregados e aplicada neste caso para frações granulométricas.

Equação $5: D M P=\Sigma\left(C_{i} \times P_{i}\right)$

onde:

DMP = diâmetro médio das partículas; 
$\mathrm{Pm}=$ peso médio de cada fração granulométrica em relação ao total;

$\mathrm{C}=$ Centro de cada classe textural expresso em $\mathrm{mm}$.

Atribui-se o valor de erodibilidade encontrado para cada solo da MBHC e através do módulo "Assign" obteve-se o mapa de erodibilidade. Estes valores foram posteriormente agnupados em cinco classes.

Fator comprimento de rampa e grau de declividade (LS) - Para o cálculo deste fator foram necessário a combinação de vários módulos do IDRISI. Primeiramente gerou-se um modelo de elevação de terreno pela interpolação das curvas de nível feita pelo módulo do "Intercon", a partir da imagem de curvas de nível obtidas através do mapa planialtimétrico na escala 1:10.000. Por meio do módulo "Surface" e da imagem gerada no passo anterior foi feita a caracterização do terreno quanto às declividades $\mathrm{e}$ ao aspecto do terreno (orientação da vertente num raio de $0^{\circ}$ a $360^{\circ}$ ). O mapa de aspecto de terreno foi então reclassificado em oito faces, de $45 \mathrm{em} 45$ graus, dividindo as direções das vertentes em Norte, Sul, Leste, Oeste, Nordeste, Sudoeste e Noroeste. Foi feita a sobreposição de um mapa com cinco intervalos de declividade $(0-2 \%, 2-5 \%, 5-10 \%, 10-20 \%$ e $>20 \%)$ com o mapa de aspecto reclassificado e por meio do módulo "Crosstab" obteve-se todas as combinações possíveis entre estes dois mapas. Foi obtido um mapa de poligonos isolados através do módulo "Group", estes polígonos representam cada rampa homogênea da microbacia nas quais foram calculados os respectivos comprimentos (em metros), extraindo-se os valores máximos e mínimos da altura de cada polígono isolado (em metros) e também as declividades médias de cada rampa (em porcentagem). O comprimento de rampa foi calculado utilizando a Equação 6 :

Equação $6: c=h / s e m$

onde:

$\mathrm{c}=$ comprimento de rampa $(\mathrm{m})$;

$\mathrm{h}=$ diferença de altura da rampa $(\mathrm{m})$;

= declividade média do polígono $(\%)$. 
O mapa final do fator LS foi obtido através da Equação 7 desenvolvida por Bertoni \& Lombardi Neto (1993), e da utilização do módulo "Scalar":

Equação $7: \mathrm{LS}=0,00984 \mathrm{c}^{0,63} \mathrm{~d}^{1,18}$

Onde:

$\mathrm{LS}=$ fator topográfico;

$\mathrm{c}=$ comprimento de rampa $(\mathrm{m})$;

$\mathrm{d}=$ grau de declive $(\%)$

Cabe aqui salientar que o cálculo do fator LS feito desta maneira utiliza um gradiente médio de comprimento de rampa, considerando-o como uniforme, este procedimento pode subestimar as perdas de solo em declives convexos e superestimar em declives côncavos. Sendo este um dos maiores erros implícitos no uso desta equação.

Nas áreas ocupadas com cana-de-açúcar, o cálculo do fator LS foi feita de maneira diferentes. Estas áreas são cultivadas utilizando a prática de terraceamento, onde os terraços construídos com desnível vertical de 4,5 metros. O comprimento de rampa nestas áreas foi calculado a partir do mapa de classes de declividade, onde os valores correspondentes de cada classe esta representado à seguir:

a) $0-2 \%$ de declividade: $140 \mathrm{~m}$ de rampa;

b) $2-5 \%$ de declividade: $140 \mathrm{~m}$ de rampa;

c) $5-10 \%$ de declividade: $67 \mathrm{~m}$ de rampa;

d) $10-20 \%$ de declividade: $33 \mathrm{~m}$ de rampa;

e) $>20 \%$ de declividade: $25 \mathrm{~m}$ de rampa.

Fator uso e manejo (C) - Para a obtenção do parâmetro $\mathrm{C}$ foram utilizados os dados existente na literatura, foram adotados valores específicos para cada tipo de cobertura vegetal, sem levar em conta o estágio de desenvolvimento da cultura. Os valores encontrados para o fator $\mathrm{C}$ estão representados na Tabela 5 .

Elaborou-se um mapa de uso e manejo a partir das assinaturas do valor $\mathrm{C}$, obtidos através da interpretação de fotos aéreas na escala 1:25.000. 
Tabela 5 : Valores do fator uso e manejo (C) da EUPS e as referências bibliográficas de onde foram retirados.

\begin{tabular}{lcl}
\hline Mg.ha $^{-1}$.ano ${ }^{-1}$ Uso da Terra & Fator C & Referência \\
\hline Cana-de-açúcar & 0,11 & \multicolumn{1}{c}{ De Maria et al. (1994) } \\
Cultura anual & 0,55 & Informação pessoal De Maria (Dez/1995) \\
Pasto & 0,008 & Menk, 1993 \\
Pasto sujo & 0,008 & Menk, 1993 \\
Mata & 0,0001 & Seção de Conservação do Solo-IAC, adaptado por Santos (1993) \\
Mata ripária & 0,0001 & Seção de Conservaçã2o do Solo-IAC, adaptado por Santos \\
& & (1993) \\
Reflorestamento & 0,001 & \\
\hline
\end{tabular}

Fonte: Ranieri (1996)

Fator práticas conservacionistas $(\boldsymbol{P})$ - Segundo Fiorio (1998), verificou-se que as práticas conservacionistas, plantio em contorno, foram adotadas em larga escala em toda a área de cultivo, durante os anos observado. Desta forma atribui-se para as áreas de cana-de-açúcar e cultura anual o valor de 0,5 para $\mathrm{P}$ e para os demais usos o valor de 1,0 (Bertoni \& Lombardi Neto, 1993).

\subsubsection{Erosão linear}

A erosão linear foi estimada através de medidas realizadas no campo e interpretação de fotos áreas de 1995, escala 1:25.000, onde foram identificadas as suas ocorrências e medidas as profundidades e comprimentos dos sulcos que formam no processo de erosão linear no campo.

O critério adotado na caracterização dos sulcos foi a forma de ocorrência, ou seja, se os sulcos ocorrem de forma isolada ou freqüente, quando freqüentes mediu-se a largura de ocorrência e a distância entre os sulcos. Calculando deste modo, o volume de solo que foi transportado no processo de erosão linear. O volume de solo transportado observado para os sulcos frequientes foram divididos por quatro anos, isto se deve ao fato destes sulcos serem desfeitos com as práticas de cultivo que são efetuadas no período da 
reforma dos canaviais. Para a obtenção da perda de solo considerou-se o densidade do solo igual a $1,2 \mathrm{~g} \cdot \mathrm{cm}^{-3}$.

Os dados foram coletados no ano de 1996, durante a época da colheita da cana de açúcar, quando o solo se encontra praticamente sem cobertura vegetal, facilitando as observações no campo. As áreas onde não foi possível a observação, devido a cobertura do solo a erosão em sulcos foi estimada, utilizando os dados levantados nas áreas com o mesmo tipo de solo, a mesma declividade e o mesma cobertura vegetal. 


\section{RESULTADOS E DISCUSSÃO}

\subsection{Erodibilidade dos solos da MBHC}

O mapa de solos detalhado da MBHC (Figura 4), elaborado por Sparovek et al. (1991), possui 31 unidades de mapeamento que foram agrupadas segundo o valor do parâmetro erodibilidade do solo (fator K) da Equação Universal de Perda de Solo EUPS (Figura 6).

As unidades de mapeamento foram agrupadas em cinco classes, como critério para esta classificação foram utilizados os valores do fator $\mathrm{K}$ calculado para as unidades de mapeamento existentes na MBHC (Tabela 6), estes valores foram obtidos através da equação de Denardim (1990). Apesar do uso desta equação ser questionado por alguns autores (Silva et al., 1994; Marques et al., 1996), optou-se pela sua utilização por ter sido testado e adaptado para solos de regiões tropicais, mas especificamente solos do Brasil, e apresentar coeficiente de determinação de 0,9767 e erro padrão estimado de $0,006 \mathrm{Mg}$ ha h ha ${ }^{-1} \mathrm{MJ}^{-1} \mathrm{~mm}^{-1}$ (teste $\mathrm{F}$ ).

A ocorrência em área relativa das classes de erodibilidade, as unidades de mapeamento agrupadas em cada classe e a amplitude destas podem ser vistas na Tabela 7. Na classe 1, estão agrupados os quatro solos menos suscetíveis à erosão e que representam somente $7,6 \%$ da área total. A classe 2 possui cinco unidades de mapeamento e engloba $40,9 \%$ da área total da MBHC, nesta classe estão agrupados alguns dos solos que ocorrem com maior freqüência na microbacia, são eles: os Solos Litossolos, formados a partir das rochas da $\mathrm{F}$. Corumbataí, $\mathrm{Li}_{1}$ eutrófico, de textura média com ocorrência em $29 \%$ da área total e Li4 álico, de textura argilosa que ocorre em $7,18 \%$ da área e o Cambisolo ( $\mathrm{Cb} 1$ ), eutrófico de textura média com ocorrência em $3,27 \%$ da área total da MBHC.

As classes 3 e 4 são as que englobam a maior parte das unidades de mapeamento, com 10 e 8 tipos de solos respectivamente, porém com baixa área relativa, 
ocorrendo em pouco mais de $13 \%$ da área cada uma. A classe 5 ocupa $23 \%$ da área total da MBHC, inclui os solos mais suscetíveis à erosão, são eles os Podzólicos VermelhoAmarelo $\mathrm{PV}_{1}, \mathrm{PV}_{2}$ e $\mathrm{PV}_{3}$, álico ou endoálico, com textura arenosa no horizonte A sobre média no horizonte $\mathrm{B}$, e o $\mathrm{PV}_{8}$ Podzólico Vermelho Amarelo, eutrófico com o horizonte A de textura arenosa e espesso sobre o horizonte B argiloso.

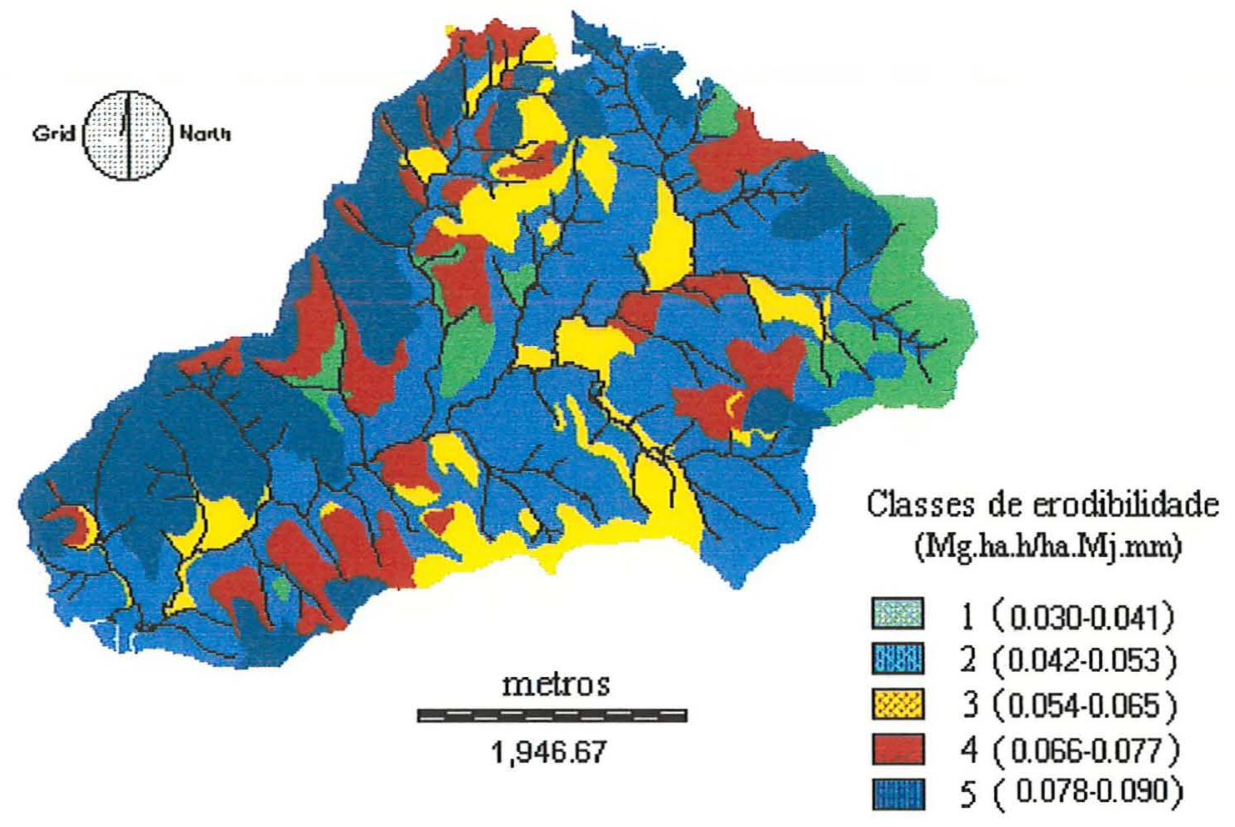

Figura 6 : Mapa de erodibilidade agrupado da MBHC. 
Tabela 6 : Unidades de mapeamento da MBHC, suas áreas relativas, valor da erodibilidade e classe de erodibilidade.

\begin{tabular}{|c|c|c|c|}
\hline $\begin{array}{l}\text { Unidade de } \\
\text { Mapeamento }\end{array}$ & $\begin{array}{c}\text { Área relativa } \\
\%\end{array}$ & $\begin{array}{c}\text { Fator } \mathrm{K} \\
\mathrm{Mg} \text { ha h ha } \mathrm{MJ}^{-1} \mathrm{~mm}^{-1}\end{array}$ & Classe do fator $K$ \\
\hline PV1 & 2,98 & 0,085 & 5 \\
\hline$P V 1_{p p}$ & 0,24 & 0,064 & 3 \\
\hline PV2 & 11,17 & 0,078 & 5 \\
\hline$P V 2_{p p}$ & 0,23 & 0,074 & 4 \\
\hline PV3 & 7,89 & 0,085 & 5 \\
\hline PV4 & 1,76 & 0,073 & 4 \\
\hline$P V 4_{p p}$ & 0,27 & 0,061 & 3 \\
\hline PV5 & 3,9 & 0,074 & 4 \\
\hline $\mathrm{PV}_{\mathrm{pp}}$ & 6,29 & 0,061 & 3 \\
\hline PVG & 1,03 & 0,060 & 3 \\
\hline $\mathrm{PV}_{\mathrm{pp}}$ & 1,16 & 0,066 & 4 \\
\hline PV7 & 1,40 & 0,070 & 4 \\
\hline$P V 7_{p p}$ & 3,04 & 0,069 & 4 \\
\hline PV8 & 0,92 & 0,089 & 5 \\
\hline PE & 1,15 & 0,061 & 3 \\
\hline TE & 0,59 & 0,037 & 1 \\
\hline TEP & 1,50 & 0,037 & 1 \\
\hline Li1 & 29,12 & 0,052 & 2 \\
\hline $\mathrm{Li1}_{c \mathrm{c}}$ & 0,24 & 0,052 & 2 \\
\hline $\mathrm{Li} 2$ & 1,57 & 0,054 & 3 \\
\hline $\mathrm{Li3}$ & 4,69 & 0,037 & 1 \\
\hline Li4 & 7,18 & 0,042 & 2 \\
\hline Li5 & 0,95 & 0,054 & 3 \\
\hline Li6 & 1,05 & 0,043 & 2 \\
\hline $\mathrm{Li7}$ & 0,82 & 0,031 & 1 \\
\hline $\mathrm{Cb} 1$ & 3,27 & 0,051 & 2 \\
\hline $\mathrm{Cb} 2$ & 1,15 & 0,074 & 4 \\
\hline $\mathrm{Cb} 3$ & 0,48 & 0,072 & 4 \\
\hline $\mathrm{Hi1}$ & 1,15 & 0,058 & 3 \\
\hline $\mathrm{Hi} 2$ & 0,42 & 0,063 & 3 \\
\hline A & 0,44 & 0,058 & 3 \\
\hline
\end{tabular}

A MBHC possui quase $50 \%$ da sua área total distribuídos entre as classes mais suscetíveis à erosão (classes 5,4 e 3 ), caracterizando-se como uma microbacia altamente suscetivel à erosão do solo (Tabela 7). Sparovek \& Lepsch (1998) obtiveram o mesmo resultado em estudo para fazer o diagnóstico de uso e aptidão das terras agrícolas do Municipio de Piracicaba, onde estudaram 47 microbacias. Segundo os autores a alta ocorrência dos solos Pdzólicos vermelho Amarelo, 856 ha (41,6\%), com elevado 
gradiente textura e com horizonte superficial de textura média a arenosa, tornam a MBHC uma área altamente suscetível a erosão.

Tabela 7 : Erodibilidade dos solos (K) agrupado em cinco classes, áreas relativas de ocorrência, unidades de mapeamento relacionadas e amplitude de variação na MBHC.

\begin{tabular}{cccc}
\hline Classe & Area relativa & Unidade de mapeamento & Valor de K \\
\hline & $\%$ & TE, Tep, LI3 e LI7 & Mg h ha ha $\mathrm{ha}^{-1} \cdot \mathrm{Mm}^{-1}$ \\
1 & 7,6 & LI1, LI1cc, LI4, LI6 e Cb1 & $0,030-0,041$ \\
2 & 40,9 & PV1pp, PV4pp, PV5pp, PV6, PE, LI2, LI5, Hi1, Hi2 e A & $0,042-0,053$ \\
3 & 13,5 & PV2pp, PV4, PV5, PV6pp, PV7, PV7pp, Cb2, e Cb3 & $0,066-0,077$ \\
4 & 13,1 & PV & $0,078-0,090$ \\
5 & 23,0 & PV1, PV2, PV3 e PV8 & \\
\hline
\end{tabular}

Resultado semelhante, foi encontrado por Silva et al. (1986) em seis solos do semi-árido do nordeste brasileiro, onde o solo Podzólico Vermelho-Amarelo com textura arenosa apresentou maior valor de $\mathrm{K}$ quando comparado com os baixos valores de $\mathrm{K}$ encontrados para os solos Litólicos. O mesmo não aconteceu em trabalhos realizados com os solos do Estado de Santa Catarina, onde Pundek (1994) obteve valores de erodibilidade menores para os Podzólicos Vermelho-Amarelo quando comparados com os solos litólicos.

Em trabalho sobre a sustentabilidade dos solos da região de Piracicaba, Levy (1995) classificou como baixa erodibilidade valores menores que $0,0247 \mathrm{Mg} \mathrm{ha} \mathrm{h} \mathrm{ha}^{-1} \mathrm{MJ}^{-1} \mathrm{~mm}^{-1}$; moderada erodibilidade valores de $0,0247 \mathrm{a}$ $0,0318 \mathrm{Mg}$ ha h ha ${ }^{-1} \mathrm{MJ}^{-1} \mathrm{~mm}^{-1} \mathrm{e}$ alta erodibilidade valores superiores que $0,0318 . \mathrm{Mg}$ ha h ha ${ }^{-1} \mathrm{MJ}^{-1} \mathrm{~mm}^{-1}$. Quando comparado com esta classificação, os solos da MBHC que ocorrem na classe $1\left(0,030\right.$ a $0,041 \mathrm{Mg}$ ha h ha $\left.{ }^{-1} \mathrm{MJ}^{-1} \mathrm{~mm}^{-1}\right)$, correspondem aos solos de alta erodibilidade, com exceção do $R_{7}$ que apresenta erodibilidade moderada (Tabela 6). Esta diferença entre os valores encontrados para a erodibilidade dos solos pode ser atribuído em partes às diferenças de escala dos dois trabalhos.

Levy (1995) estudou uma área de 176.000 ha, constituída por 78 microbacias hidrográficas, utilizando dados de solo da Carta Pedológica semi-detalhada do Estado de São Paulo (escala 1:100.000), onde segundo Sparovek \& Lepsch (1998), 21\% de área é 
representada por Latossolos, solos estes que não ocorrem na MBHC e que possuem baixo gradiente textural maior capacidade de infiltração da água, quando apresentam textura argilosa os valores da erodibilidade são baixos ou médio, e com textura média os valores da erodibilidade são altos. O levantamento pedológico da MBHC foi realizado na escala 1:10.000, na área de estudo não aparece os latossolos e $89 \%$ da área total é representada pelos podzólicos (profundos e pouco profundos) e litólicos, solos que em sua maioria apresentam valores médio a alto no levantamento utilizado por Levy (1995). Estes resultados mostram que a MBHC possui solos altamente suscetivel à erosão, quando somente a erodibilidade do solo é considerada.

\subsection{Sub-bacias da MBHC}

A MBHC foi divida em vinte e duas sub-bacias ao longo do córrego principal (Figura 7). A delimitação em sub-bacias (microbacias), permite a sua análise em separado, facilitando sobremaneira a interpretação dos dados e o planejamento conservacionista (Sparovek \& Lepsch, 1998). Este procedimento torna possível interagir os fatores relacionados com a erosão dos solos, a identificação das áreas problemas, aquelas onde o processo de erosão é favorecido, não só pelas propriedades do solo, mas também as relacionadas com o relevo, a declividade e o uso da terra.

A Figura 7 mostra o mapa da MBHC subdivido em vinte e duas sub-bacias e suas respectivas áreas (total e relativa) estão representadas na Tabela 8. As sub-bacias 7, 11,12 e 15 , possuem as maiores áreas com 312,7 ha $(15,7 \%), 239,8$ ha (12\%), 239,7ha $(12 \%)$ e 216,3 ha $(10,9 \%)$ respectivamente que somadas ocupam $50 \%$ da área total da MBHC, o restante da área de estudo está distribuído entre 18 sub-bacias, que não obedecem um padrão quanto ao tamanho. A MBHC possui um comportamento assimétrico quanto a distribuição das sub-bacias, o lado direito da MBHC (sentido de observação da montante para ajusante) e nas partes altas possui sub-bacias com áreas de captação maiores e rede de drenagem mais ramificadas, isto se deve ao material de origem.

Nestas áreas predominam os solos formados à partir do arenito Pirambóia, possuem rede de drenagem mais profunda e mais extensas, a granulometria do arenito 
favorece a infiltração da água, permitindo a formação de redes de drenagens mais profundas. As sub-bacias onde predominam os solos formados à partir da formação Corumbataí, com textura mais argilosa e solos menos profundos, apresentam rede de drenagem menos profunda e menos ramificada, estes solos ocorrem nas margens do córrego do Ceveiro e no lado esquerdo da microbacia.

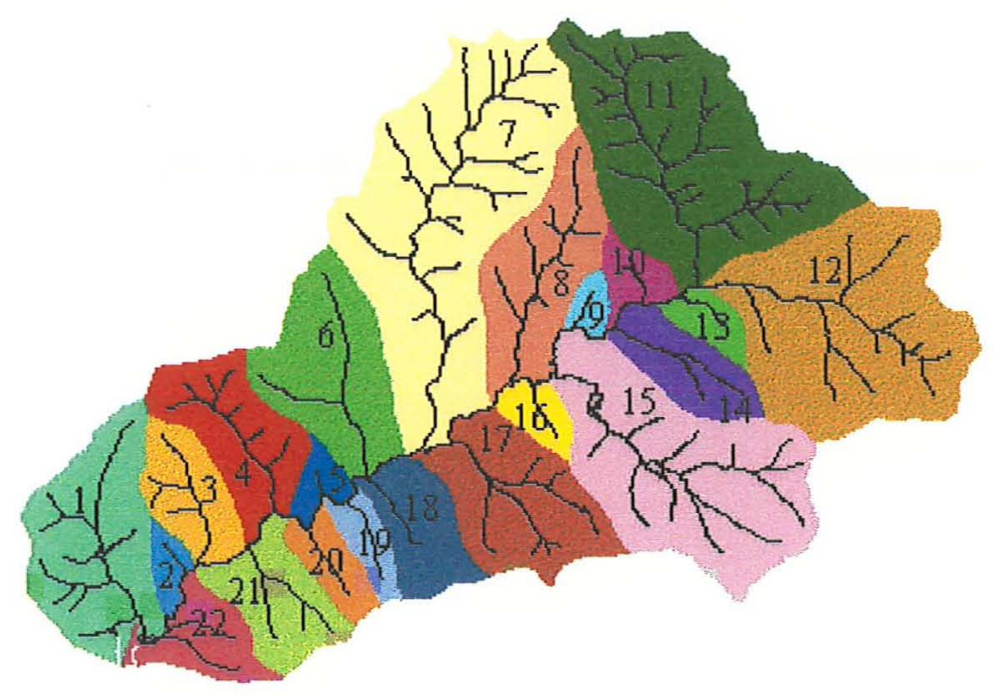

Figura 7: Mapa da MBHC subdividido em vinte e duas sub-bacias sub-bacias. 
Tabela 8 : Sub-bacias que compõem a MBHC e suas respectivas áreas total e relativa.

\begin{tabular}{cccccc}
\hline Sub-bacia & Área & Área relativa & Sub-bacia & Área & Área relativa \\
\hline & ha & $\%$ & & ha & $\%$ \\
1 & 133,2 & 6,7 & 12 & 239,72 & 12,0 \\
2 & 14,16 & 0,7 & 13 & 19,12 & 1,0 \\
3 & 55,76 & 2,8 & 214 & 50,24 & 2,5 \\
4 & 86,32 & 4,3 & 15 & 216,28 & 10,9 \\
5 & 16,68 & 0,8 & 16 & 21,44 & 1,1 \\
6 & 116,8 & 5,9 & 17 & 112,36 & 5,6 \\
7 & 312,72 & 15,7 & 18 & 56,52 & 2,8 \\
8 & 104 & 5,2 & 19 & 22,48 & 1,1 \\
9 & 11,72 & 0,6 & 20 & 29,56 & 1,5 \\
10 & 21,8 & 1,1 & 21 & 64,68 & 3,2 \\
11 & 239,84 & 12,0 & 22 & 45 & 2,3 \\
\hline
\end{tabular}

Em cada sub-bacia foi estimada a erosão areolar (entre sulcos) e linear (em sulcos), segundo metodologia citada no item 3.2. Os resultados obtidos fornecem o conhecimento da ordem de grandeza em que a erosão entre sulcos ocorreu na microbacia nos anos de 1962, 1978 e 1995, indicando as áreas fontes de sedimentos e as áreas mais impactantes na degradação do meio físico da $\mathrm{MBHC}$, relacionadas com o uso inadequados das terras.

\subsubsection{Erodibilidade}

A Tabela 9 mostra que a sub-bacias $1,2,3,4,5$ e 6 possuem mais de $40 \%$ de suas áreas relativas com solos agrupados na classe cinco (5) de erodibilidade, esta classe agrupa os solos que possuem valores do fator $\mathrm{K}$ entre 0,078 e $0,09 \mathrm{Mg} \mathrm{ha} \mathrm{h} \mathrm{ha}^{-1} \mathrm{MJ}^{-1} \mathrm{~mm}^{-1}$. Sendo que as sub-baxias 3 e 4 apresentam respectivamente $74,2 \%$ e $78,3 \%$ de suas áreas com classe de erodibilidade 5. Estas sub-bacias estão localizadas no lado direito da MBHC (sentido de observação montante para a jusante), na parte do terço médio para as partes baixas e apresentam perdas de solo altas, quando somente a erodibilidade dos solos é analisada, a erodibilidade do solo é o fator que representa o efeito integrado dos processos que regulam o comportamento do solo frente aos agentes erosivos (Lal, 1994). 
Este fato teve uma forte contribuição no processo de assoreamento da represa, uma vez que estas áreas localizam-se nas proximidades do reservatório, e os sedimentos aí produzidos facilmente chegam ao reservatório e ali se depositam.

A classe de erodibilidade 1 ocorre com maior freqüência na sub-bacia 12 , ocupando $39,6 \%$ da área total desta, nas outras sub-bacias sua ocorrência é bem baixa não ultrapassando $11 \%$ e aparecendo somente em seis sub-bacia.

As sub-bacias que apresentaram menor suscetibilidade à erosão, quando os outros fatores relacionados com o processo erosivo não são analisados, foram as subbacias 12 que possui $76,1 \%$ de sua área total com solos na classe de erodibilidade 1 e 2 , a 16 com $91,8 \%$ da área na classe 2 e $8,2 \%$ na classe 3 e a sub-bacia 22 com $70,1 \%$ de sua área total na classe 2 de erodibilidade.

É importante lembrar que mesmo os valores mais baixos de erodibilidade calculados neste trabalho apresentam-se elevados quando comparados como os encontrados na literatura (Silva et al., 1986; Levy, 1995). Mostrando ser a MBHC uma microbacia que possui solos altamente suscetiveis à erosão. 
Tabela 9 : Área de ocorrência das classes de erodibilidades dos solos e as respectivas porcentagem em área total em cada sub-bacia.

\begin{tabular}{|c|c|c|c|c|c|c|c|c|c|c|c|}
\hline \multirow{3}{*}{$\begin{array}{l}\text { Sub- } \\
\text { bacia }\end{array}$} & \multirow{3}{*}{$\begin{array}{l}\text { Area } \\
\text { ha }\end{array}$} & \multicolumn{10}{|c|}{ Classes de erodibilidade } \\
\hline & & \multicolumn{2}{|c|}{1} & \multicolumn{2}{|c|}{2} & \multicolumn{2}{|c|}{3} & \multicolumn{2}{|c|}{4} & \multicolumn{2}{|c|}{5} \\
\hline & & $\mathrm{Ha}$ & $\%$ & ha & $\%$ & ha & $\%$ & ha & $\%$ & ha & $\%$ \\
\hline 1 & 133,2 & 0 & 0 & 47,8 & 35,9 & 5.8 & 4,4 & 5,32 & 4,0 & 66,6 & 50,0 \\
\hline 2 & 14,16 & 0 & 0 & 5,92 & 41,8 & 2.4 & 16,7 & 0 & 0 & 5,9 & 41,5 \\
\hline 3 & 55,76 & 0 & 0 & 0,1 & 0,1 & 14.3 & 25,7 & 0 & 0 & 41,4 & 74,2 \\
\hline 4 & 86,32 & 0 & 0 & 8,0 & 9,2 & 3,0 & 3,5 & 7,7 & 9,0 & 67,6 & 78,3 \\
\hline 5 & 16,68 & 0 & 0 & 9,1 & 54,7 & 0 & 0 & 0 & 0 & 7,56 & 45,3 \\
\hline 6 & 116,8 & 13 & 11,1 & 17,1 & 14,7 & 0 & 0 & 39,6 & 33,9 & 47,0 & 40,3 \\
\hline 7 & 312,72 & 24,3 & 7,8 & 68,1 & 21,8 & 52.5 & 16,8 & 58,8 & 18,8 & 107,1 & 34,2 \\
\hline 8 & 104 & 6,6 & 6,4 & 67,9 & 65,3 & 22,4 & 21,5 & 3,8 & 3,7 & 3,2 & 3,1 \\
\hline 9 & 11,72 & 0 & 0 & 11,5 & 98,3 & 0.2 & 1,7 & 0 & 0 & 0 & 0 \\
\hline 10 & 21,8 & 0 & 0 & 14,8 & 68,1 & 6,4 & 29,4 & 06 & 2,6 & 0 & 0 \\
\hline 11 & 239,84 & 10,8 & 4,5 & 105,3 & 43,9 & 19,4 & 8,1 & 25,4 & 10,6 & 49,4 & 20,6 \\
\hline 12 & 239,72 & 49,9 & 39,6 & 87,4 & 36,5 & 14,4 & 6,0 & 17,3 & 7,2 & 25,9 & 10,7 \\
\hline 13 & 19,12 & 12,8 & 67 & 6,3 & 33 & 0 & 0 & 0 & 0 & 0 & 0 \\
\hline 14 & 50,24 & 0 & 0 & 29,1 & 58 & 1.7 & 3,3 & 18,7 & 37,3 & 0,6 & 1,3 \\
\hline 15 & 216,28 & 0 & 0 & 136,0 & 62,9 & 62.2 & 28,8 & 9,2 & 4,3 & 8,8 & 4,1 \\
\hline 16 & 21,44 & 0 & 0 & 19,7 & 91,8 & 1.7 & 8,2 & 0 & 0 & 0 & 0 \\
\hline 17 & 112,36 & 0 & 0 & 77,2 & 68,7 & 34 & 30,3 & 1,2 & 1,1 & 0 & 0 \\
\hline 18 & 56,52 & 0 & 0 & 21,0 & 37,2 & 16.6 & 29,4 & 18,9 & 33,4 & 0 & 0 \\
\hline 19 & 22,48 & 0 & 0 & 9,2 & 40,9 & 0,4 & 1,8 & 12,3 & 54,6 & 0,6 & 2,7 \\
\hline 20 & 29,56 & 0 & 0 & 8,4 & 28,6 & 0,7 & 2,3 & 14,1 & 47,6 & 6,4 & 21,5 \\
\hline 21 & 64,68 & 1,7 & 3,7 & 25,1 & 55,8 & 04 & 1,0 & 24,4 & 54,1 & 13,1 & 29,1 \\
\hline 22 & 45 & 0 & 0 & 31,6 & 70,1 & 4,8 & 10,6 & 2,6 & 5,8 & 6,1 & 13,5 \\
\hline
\end{tabular}

\subsubsection{Declividade}

A declividade é uma característica importante no estudo da erosão do solo. Áreas muito íngremes favorecem o aumento da velocidade das enxurradas aumentando a sua força erosiva. As perdas de solo são sempre crescentes com o aumento da declividade. $O$ comprimento do declive, também tem grande importância no processo 
erosivo. Declives de comprimento mais longo estão sempre sujeito a maior perda de solo, estas perdas estão relacionadas com a permeabilidade do solo e a intensidade das precipitações (César, 1952).

A classe de declive predominante na $\mathrm{MBHC}$ é a $\mathrm{D}$ que corresponde às áreas com 5 a $10 \%$ de declividade (Tabela 3 ) e ocupa 772,4 ha ou $31,6 \%$, nesta classe ainda não há limitações sérias para a mecanização, mas solos mais suscetíveis à erosão já requerem práticas conservacionistas bastante eficientes ( Sparovek \& Lepsch, 1998). As classes de maior declividade C, D e E ocupam 881 ha o que representa $44,3 \%$ da área de estudo, estas áreas constituem-se nas terras de maior limitações para a mecanização e estão associadas a sérios riscos de degradação, quando utilizadas além da sua capacidade de uso.

A ocorrência das classes de declive em cada sub-bacia pode ser vista na Tabela 10. As sub-bacias que apresentam maior limitação quanto a declividade são as $2,3,4,6$, 9, 10 e 11 com mais de $20 \%$ de suas áreas com declividade superior a $15 \%$ (classes D e F). Nestas áreas estão as terras onde a utilização é de risco para o cultivo da cana-deaçúcar, sendo somente viável com medidas extremas de controle à erosão, possuindo um risco razoável de degradação, principalmente quando ocorrem em solos altamente suscetiveis à erosão como é o caso da área de estudo. Para culturas anuais estas áreas possuem grande risco potencial de degradação (Sparovek \& Lepsch, 1998).

Todas estas sub-bacias estão localizadas no lado direito da bacia, coincidindo com as áreas onde ocorre a maior porcentagem de solos com classe de erodibilidade 5, altamente suscetíveis à erosão. A sub-bacia 9 é a que apresenta maior limitação devido a declividade, pois $42 \%$ de sua área total apresenta declividade superior a $15 \%$, porém esta é a menor sub-bacia que compõe a MBHC com apenas 11,72 ha.

Nos solos de baixa permeabilidade, muito comuns na MBHC (solos Podzólicos e solos Litossolos), independente do comprimento de declive as perdas de solo são sempre maiores, pois nestes solos a água não infiltra facilmente em todo o perfil do solo e com o aumento da intensidade das chuvas tendem a formar enxurradas. 
Tabela 10 : - Classes de declive e as áreas totais e relativas que ocorrem em cada sub-bacia da MBHC.

\begin{tabular}{|c|c|c|c|c|c|c|c|c|c|c|c|c|c|}
\hline \multirow{3}{*}{ SB } & \multirow{3}{*}{$\begin{array}{c}\text { Área } \\
\text { ha }\end{array}$} & \multicolumn{12}{|c|}{ Classes de declive } \\
\hline & & \multicolumn{2}{|c|}{$A(0-2 \%)$} & \multicolumn{2}{|c|}{ B $(2-5 \%)$} & \multicolumn{2}{|c|}{ C (5-10\%) } & \multicolumn{2}{|c|}{$D(10-15 \%)$} & \multicolumn{2}{|c|}{$E(15-20 \%)$} & \multicolumn{2}{|c|}{$F(>20 \%)$} \\
\hline & & ha & $\%$ & & $\%$ & ha & $\%$ & ha & $\%$ & ha & $\%$ & ha & $\%$ \\
\hline 1 & 133,2 & 4,5 & 3,4 & 18,8 & 14,1 & 48,8 & 36,6 & 48,0 & 36,0 & 12,6 & 9,5 & 0,5 & 0,4 \\
\hline 2 & 14,16 & 1,1 & 7,9 & 1,3 & 9,0 & & & 4,2 & 29,7 & 3,1 & 22,0 & & 4,8 \\
\hline 3 & 55,76 & 2,9 & 5,2 & 5,0 & 8,9 & 18,4 & & 17,5 & 31,4 & 11,1 & 19,9 & 0,8 & 1,5 \\
\hline 4 & 86,32 & 1,7 & 1,9 & 6,0 & 7,0 & 25,4 & & 27,4 & 31,8 & 9,3 & 22,4 & & 7,5 \\
\hline 5 & 68 & 0,8 & 4,8 & 3,4 & 20,6 & 0 & & 4,0 & 24,0 & & 11, & & 3,4 \\
\hline 6 & 116,8 & 2,8 & 2,4 & 11,8 & 10,1 & 37,7 & 32,3 & 38,1 & 32,6 & 21,9 & 18,8 & 4,5 & 3,8 \\
\hline 7 & 312,72 & 8 & 2,6 & 31,7 & 10,1 & 123,9 & & 112,9 & 36,1 & 2 & 10 , & 4, & 1,5 \\
\hline 8 & 34,0 & 4,8 & 4,7 & 9 & 9,1 &, 4 & & 41,4 & 39,8 & 5 & 10, & 1,4 & 1,3 \\
\hline 9 & 11,72 & 0 & 0 & 0,3 & 2,4 & 3,5 & 30,0 & 3,2 & 27,3 & 2,4 & 20,1 & 2,4 & 20,1 \\
\hline 10 & 21,8 & 0,5 & 2,4 & 2,1 & 9,7 & 7,8 & & 6,8 & 31,4 & 2,3 & 10 & 2 & 10,5 \\
\hline 11 & 239,84 & 5,1 & 2,1 & 26,8 & 11,2 & 79,8 & & 4,7 & 6,1 & 41,6 & 17,3 & 12,0 & 5,0 \\
\hline 12 & 239,72 & 6,2 & 2,6 & 31,2 & 13,0 & 99,7 & & 80,6 & 33,6 & 20,0 & 8,3 & 2,1 & 0,9 \\
\hline 13 & 19,12 & 0,4 & 2,3 & 2,6 & 13,6 & 9,8 & & 6,2 & 32,2 & 0,2 & 0,8 & 0 & 0 \\
\hline 14 & 50,24 & 1,0 & 2,0 & 10,7 & 21,3 & 21,4 & & 13,1 & 26,0 & 4,1 & 8 & 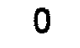 & 0 \\
\hline 15 & 216,28 & 12,1 & 5,6 & 37,1 & 17,1 & 90,7 & & 63,6 & 29,4 & 11,5 & 5,3 & 1,3 & 0,6 \\
\hline 16 & 21,44 & 1,4 & 6,5 & 3,0 & 13,8 & 10,4 & & 6,1 & 28,4 & 0,6 & 3,0 & 0 & 0 \\
\hline 17 & 112,36 & 9,8 & 8,7 & 17,6 & 15,7 & 54,6 & 48 & 23,4 & 20,9 & 6,5 & 5,8 & 0,4 & 0,4 \\
\hline 18 & 56,52 & 5,2 & 9,3 & 11,1 & 19,6 & 26,6 & 47,1 & 10,2 & 18,0 & 2,4 & 4,2 & 1,0 & 1,7 \\
\hline 19 & 22,48 & 3,2 & 14,2 & 2,8 & 12,3 & 9,0 & & 5,7 & 25,3 & 1,8 & 7,8 & 0,1 & 0,5 \\
\hline 20 & 29,56 & 0,9 & 3,0 & 4,6 & 15,7 & 14,6 & & 7,9 & 26,8 & 1,1 & 3,7 & 0,4 & 1,5 \\
\hline 21 & 64,68 & 6,1 & 9,4 & 8,5 & 13,1 & 27,8 & & 19,5 & 30,2 & 2,7 & 4,1 & 0,1 & 0,2 \\
\hline 22 & 45 & 5,0 & 11,2 & 7,5 & 16,7 & 16,5 & 36,7 & 13,9 & 30,8 & 2,0 & 4,5 & 0 & 0 \\
\hline
\end{tabular}

\subsubsection{Uso do solo}

Para melhor entender o processo de perda de solo na $\mathrm{MBHC}$ é necessário conhecer a evolução do uso da terra. As atividades que o homem exerce na ocupação do solo tem grande influência no processo erosivo, à partir do momento que o homem retira a mata para a implantação de outras culturas, ocorre uma série de interferências não somente na proteção do solo contra o impacto da chuva, na formação dos deflúvios e na taxa de produção de sedimentos, mas principalmente no ciclo hidrológico da microbacia hidrográfica.

Para Dunne \& Dietrich (1982) o uso do solo é a principal responsável pela degradação do solo e dos recursos hídricos, principalmente quando a área de estudo está 
sendo explorada pela agricultura e pecuária por um longo período de tempo, como é o caso da MBHC.

Estas mudanças no ciclo hidrológico provocam uma alteração no equilíbrio do meio fisico da microbacia, e os processos erosivos que ocorriam naturalmente tendem a sofre alterações, procurando um novo equilíbrio. Dune \& Dietrich (1982) citam a importância do uso da terra na produção de sedimentos e vários trabalhos onde foi verificada alterações significativas nas taxas de erosão do solo após o desmatamento.

É importante lembrarmos que as ações do homem na ocupação das terras, não é a única responsável pela degradação da MBHC, pois esta possuí características naturais que favorecem o processo erosivo das encostas, entre elas podemos citar a descontinuidade litológica, que pode ser observado no afloramento do contato entre a Formação Corumbataí e a Formação Pirambóia; descontinuidade pedológica (31 unidades de solos mapeadas); o contato solo-rocha abrupto, que ocorre em 903,16ha ( $45 \%$ da área total) nos solos litólicos juntamente com as interferências que o homem vem provocando no meio ambiente levaram a $\mathrm{MBHC}$ a atingir tal nivel de degradação.

$\mathrm{Na}$ Tabela 2 está representada a evolução do uso da terra na MBHC, quando comparamos o uso da terra de 1962 com 1978 e 1995, podemos observar que houve uma expansão da cultura canaviera na área de estudo, passando de 318,2 ha (16\%) para 524,5 ha $(26 \%)$ e 1319,6 ha $(66 \%)$ respectivamente; este fato tem sido observado por alguns pesquisadores na região de Piracicaba (Borges et al.,1993; Sparovek et al., 1995; Fiorio, 1998).

O aumento da cultura canavieira se deu principalmente nas áreas de cultura anual, que em 1962 ocupavam 633,4 ha (32\% da área total da MBHC), 226,6ha (11,4\%) em 1978 sendo praticamente extinta da área em 1995 quando ocupava uma área de 3,0 ha $(0,2 \%)$, as outras áreas que cederam espaço para a cultura canavieira foram as de pastagem, reflorestamento e mata ciliar.

Ocorreu um aumento de $33,5 \%$ na área de mata ciliar, vegetação que aparecem ao longo das redes de drenagem, este acréscimo é um importante controlador do processo erosivo, pois além de terem fundamental importância na proteção do solo contra o impacto da gota da chuva, ainda ocorre a formação da serapilheira (camada 
composta de restos de vegetais) que propicia aumento da taxa de infiltração de água no solo e diminuição da velocidade das enxurradas que se formam durante os eventos erosivos, deste modo elas contribuem para que os sedimentos produzidos pela erosão nas áreas a montantes se depositem, podendo novamente serem transportados quando ocorrer outro evento erosivo. A mata ainda tem um papel importante na liberação de água para a atmosfera, através da evapo-transpiração das copas das árvores.

A área urbana apresentou uma expansão de 6,5\%, passando de 2,6 ha em 1962 para 11,4 ha em 1978 chegando a 39,2 ha em 1995 (Fiorio, 1998), as áreas urbanas diminuem a taxa de infiltração da água no solo, através do sistema de pavimentação das ruas, e cobertura do solo para as construções, concentrando as águas que saem da área urbana, isto provoca um aumento na erosão em sulcos, e quando os esgotos não são tratados, constituem um importante poluentes das águas.

Os resultados apresentados acima também foram encontrados por Sparovek \& Lepsch (1998), que observaram uma expansão da cultura canavieira na MBHC e uma redução nas áreas ocupadas por pastagens e mata natural. Segundo os autores houve uma redução do uso adequado e subutilização, com um aumento significativo das áreas utilizadas com risco na MBHC, que em 1962 ocupava 50,5\% da área passando em 1991 para $76,3 \%$ da área total. Os autores concluíram que no ano de 1991 a MBHC apresentava praticamente $3 / 4$ de suas terras sendo superutilizadas, ou seja, com utilização acima da sua capacidade, apresentando grandes riscos de degradação.

O reservatório foi construído em 1978, nesta época a lâmina d'água ocupava 10,7 ha e em 1995 a lâmina d'água ocupava 5,5 ha, reduzindo pela metade. $O$ comportamento do reservatório de captar a água e com ela os sedimentos que são produzidos e transportados durante a erosão, e a sua localização possui especial importância neste estudo, pois ele é o mais importante testemunho do impacto que o uso do solo vem causando na MBHC.

No anexo A é possivel visualizar a evolução do uso da terra nas sub-bacias que compõem a MBHC. As sub-bacias localizadas nas proximidades da Vila de Santana apresentaram maior persistência quando ao cultivo de culturas anuais no decorrer dos anos estudados, uma das explicações para tal fato é a situação fundiária destas áreas, que 
se caracteriza pela maior ocorrência de pequenos proprietários. Nas áreas à jusante da MBHC prevalece as grandes propriedades onde podemos observar que a cana aparece mais intensamente em 1995 (Tabela 11), devido ao arrendamento das terras e as vantagens financeiras que este oferece aos proprietários.

No ano de 1995, todas as sub-bacias possuíam cana-de-açúcar como a principal cultura com exceção da sub-bacia 19 que nesta época apresentou 19,3 ha $(85,8 \%$ da área total) com pastagens (pastagem e pasto sujo) e somente 2,9 ha $(13,2 \%)$ com cana-deaçúcar (Tabela 11). 
Tabela 11 : Uso do solo e a porcentagem da área ocupada em cada sub-bacia da MBHC, no ano de 1995.

\begin{tabular}{|c|c|c|c|c|c|c|c|c|c|}
\hline \multirow{2}{*}{$\begin{array}{l}\text { Sub- } \\
\text { Bacia }\end{array}$} & \multirow{2}{*}{$\begin{array}{l}\text { Area } \\
\text { ha }\end{array}$} & \multicolumn{8}{|c|}{ Uso do solo } \\
\hline & & Cana & Past, & P. sujo & $\begin{array}{r}\text { C. Anual } \\
\%\end{array}$ & Reflor. & Mata & M. Ripária & A. urb. \\
\hline 1 & 133,60 & 71,6 & & 4,7 & & & & 16,5 & 5,81 \\
\hline 2 & 14,16 & 71,8 & 0,8 & 2,8 & 15,0 & & 5,6 & 4,0 & \\
\hline 3 & 55,76 & 72,7 & & 6,2 & & & 3,8 & 17,4 & \\
\hline 4 & 86,32 & 72,4 & & & 6,3 & & 11,8 & 9,5 & \\
\hline 5 & 16,68 & 57,1 & & 39,1 & & & 3,8 & & \\
\hline 6 & 116,80 & 73,0 & & 0,9 & & 13.4 & 12,6 & & \\
\hline 7 & 312,72 & 71,1 & 0,03 & 3,3 & & 1.3 & 12,6 & 11,1 & 0,60 \\
\hline 8 & 104,00 & 76,1 & 10,6 & 2,0 & & 0.5 & 4,4 & 6,4 & \\
\hline 9 & 11,72 & 63,1 & 36,9 & & & & & & \\
\hline 10 & 21,80 & 78.5 & & & & 1.7 & 19,8 & & \\
\hline 11 & 239,84 & 60,5 & 0,30 & 10,0 & 0,4 & 9.6 & 3,8 & 3,2 & 12,3 \\
\hline 12 & 239,72 & 72,2 & & 6,8 & & 21.0 & & & \\
\hline 13 & 19,12 & 82,6 & & & & 16,5 & 0,8 & & \\
\hline 14 & 50,24 & 93,2 & & & & & 6,8 & & \\
\hline 15 & 216,28 & 50,7 & 11,4 & 24,10 & & 10,7 & 2,5 & & \\
\hline 16 & 21,44 & 42,7 & 21,3 & 9,5 & & & 26,5 & & \\
\hline 17 & 112,36 & 64,7 & & 15,4 & & & 19,9 & & \\
\hline 18 & 56,52 & 40,1 & 51,3 & 3,2 & & & 5,4 & & \\
\hline 19 & 22,48 & 13,2 & 65,5 & 20,3 & & & & & \\
\hline 20 & 29,56 & 63,5 & & 36,5 & & & & & \\
\hline 21 & 64,68 & 81,9 & & 12,2 & & & 5,8 & 0,1 & \\
\hline 22 & 45,00 & 45,9 & 25,5 & 19,4 & & & 0,4 & 4,3 & \\
\hline
\end{tabular}

\subsection{Quantificação da erosão entre sulcos na MBHC}

A perda média de solo (A) na MBHC, foi calculada para os anos de 1962, 1978 e 1995 (Tabela 12), posteriormente calculou-se o valor de A nas vinte e duas sub-bacias, isto possibilitou a identificação das áreas que mais contribuíram na produção de sedimentos durante os anos estudados, o maior entendimento da relação entre os fatores envolvidos no processo erosivo (uso do solo, erodibilidade dos solos e o relevo) em cada área, fornecendo subsidio necessários para o planejamento e implantação de práticas conservacionistas adequadas e facilitando futuros planejamentos para o uso racional das terras da MBHC. Não sendo objetivo deste trabalho propor tais práticas, mesmo porque estas propostas já foram feitas por Sparovek (1991), cabendo aos órgãos governamentais e municipais implantá-las. 
Quando comparamos a perda média de solos para os anos estudados, podemos observar que em 1962 a MBHC apresentou o maior valor de A, perdendo $123,6 \mathrm{Mg}$ de solo por hectare neste ano, este valor é extremamente grande quando comparamos com os considerados como tolerantes encontrados na literatura (Wischemeier \& Smith, 1978; Brooks et al., 1991; Bertoni \& Lombardi Neto, 1993; Mellerowicz, 1994). Neste ano a MBHC possuía quase 633,4 ha $(32 \%$ da área total) cultivada com cultura anual, chegando a ocupar 226,6ha (11,4\%) em 1978 caindo para somente 3ha em 1995.

Tabela 12 : Perda média de solo da MBHC para os anos de 1962, 1978 e 1995.

\begin{tabular}{cc}
\hline Ano & Preda média de solo (A) \\
\hline & $\mathrm{Mg}^{-1} \cdot \mathrm{ha}^{-1} \cdot \mathrm{ano}^{-1}$ \\
1962 & 123,6 \\
1978 & 59,0 \\
1995 & 26,7 \\
\hline
\end{tabular}

Houve uma grande expansão da cultura da canavieira na área de estudo, passando 318ha (16\%) em 1962 para 524,5ha em 1978 e chegando a ocupar 1319,6 ha $(66,3 \%)$ em 1995, estes números vão de encontro com os resultados obtidos por Sparovek \& Lepsch (1998), ao verificarem que a expansão da cultura de cana-de-açúcar na região de Piracicaba se deu principalmente nas áreas próximas das unidades processadoras, áreas onde o sistema viário e fundiário é favorecido. A superutilização das terras de baixa aptidão agrícola, com uso intenso para o cultivo de cana-de-açúcar é qualificado pelos autores como uma situação muito preocupante, devido ao processo de degradação a que estas terras estão expostas. A presença da cultura de cana-de-açúcar em 1962 e a sua expansão devido ao projeto Pró-álcool, nos solos de baixa capacidade de uso (superior a classe III) da MBHC, se deve principalmente a sua localização próxima da Usina Costa Pinto.

Em 1962 cerca de $44 \%$ da área cultivada com culturas anuais ocupava áreas com declives entre 10 e $20 \%$, e $5 \%$ em áreas com declives superior a $20 \%$ (Fiorio, 
1998). Esta utilização de solos com elevada declividade favorece o processo erosivo contribuindo para o elevado valor de A obtido neste ano.

Em 1978 a perda média de solo foi da ordem de $59 \mathrm{Mg} \mathrm{ha}^{-1}$ ano $^{-1}$ (Tabela 12), neste ano é interessante observar que houve uma expansão das áreas de pastagens e pasto sujo, em 1962 estas áreas somavam 569,3ha (28\%), passando para 840,7ha (42\%) em 1978 (Tabela 2), este crescimento das áreas com pastagens se deu em detrimento das áreas com culturas anuais, isto se deve principalmente a baixa capacidade de uso e aptidão agrícola das terras de $\mathrm{MBHC}$, que não suportam usos intensivos com agricultura convencional por um longo periodo de tempo sem que haja uma queda na fertilidade natural dos solos, isto porque o processo de erosão transporta os nutrientes e a matéria orgânica da camada superficial do solo.

Quando comparamos o valor de A em 1978 com 1995, observamos que este valor decresceu de $59 \mathrm{Mg} \mathrm{ha}^{-1}$ ano $^{-1}$ para $26 \mathrm{Mg} \mathrm{ha}^{-1}$ ano $^{-1}$ (Tabela 12). Porém este fato não torna a situação menos crítica, pois os valores de $\mathrm{A}$ continuam elevados, quando comparamos com os valores toleráveis encontrados na literatura, Bertoni \& Lombardi Neto (1993) que consideram como valores toleráveis de A entre 4,5 a 13,4 $\mathrm{Mg} \mathrm{ha}^{-1}$ ano $^{-1}$ para solos com B textural e igual 4,2 $\mathrm{Mg} \mathrm{ha}^{-1}$ ano ${ }^{-1}$ para solos litólicos.

Fiorio (1998), utilizou o programa SAMPRA (Köffler, 1992) na geração de mapas de adequação dos usos da terra para a MBHC e concluiu que apenas 16,2ha $(0,8 \%)$ de suas terras possuem alta aptidão para o cultivo de culturas anuais e que $1.313,4$ ha $(66 \%)$ possuem baixa aptidão para este uso, para as culturas semi-perenes, como é o caso da cana-de-açúcar, apenas 30 ha $(1,5 \%)$ possuem alta aptidão, 1261,26ha apresentam aptidão média. A queda de $21 \%$ da perda média de solo que ocorreu na MBHC deve-se em grande parte às mudanças que ocorreram no uso da terra, ou seja, fator uso e manejo (C) da EUPS. O valor do fator C, utilizado para a cultura anual é de 0,55 (De Maria ${ }^{5}$, informação pessoal) e para a cana-de-açúcar de 0,11 (De Maria et al., 1994), este aumento expressivo na cultura de cana de açúcar ocupando as áreas de cultura anual contribuíram para que as perdas de solo fossem menor.

\footnotetext{
${ }^{5}$ DE MARIA, I.C. Comunicação pessoal, 1995.
} 
O mapa da MBHC com as perdas médias de solo classificada em seis classes está representado na Figura 8, e na Tabela 13 estão relacionadas as classes de perda média de solo com as áreas de ocorrência. As áreas com perdas de solo inferiores a 5 Mg.ha ${ }^{-1} \cdot$ ano $^{-1}$ ocupam 621,72 ha, o que eqüivale corresponde a $31 \%$ da área total, estas geralmente ocorrem nas baixadas, ao longo da rede da drenagem vegetadas e também em algumas áreas do lado esquerdo da MBHC (sentido de observação a montante para a jusante), onde os solos apresentam menores erodibilidade e menores classe de declive. A MBHC apresenta uma área de1092,52 ha, aproximadamente $55 \%$ da área total, com perdas média de solo por erosão entre sulcos entre 20 e $80 \mathrm{Mg} \mathrm{ha}^{-1} \mathrm{ano}^{-1}$.

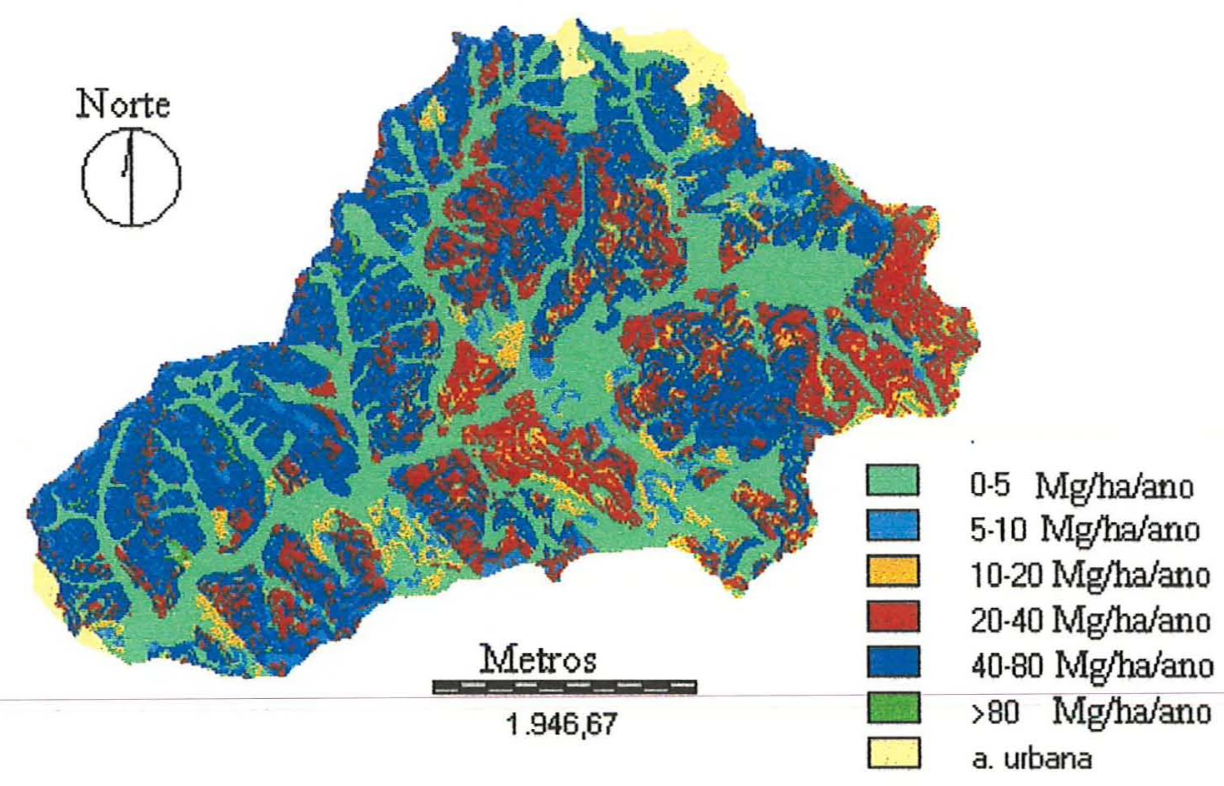

Figura 8: : Mapa da MBHC com as seis classes de perda média de solo. 
Tabela 13 : Classes de perda de solo, as amplitudes e as respectivas área de ocorrência na MBHC.

\begin{tabular}{ccc}
\hline Classe & Amplitude & Arrea \\
\hline & $\mathrm{Mg} \mathrm{ha}^{-1}$ ano $^{-1}$ & ha \\
1 & $0-5$ & 621,72 \\
2 & $5-10$ & 138,44 \\
3 & $10-20$ & 98,56 \\
4 & $20-40$ & 399,48 \\
5 & $40-80$ & 681,92 \\
6 & $>80$ & 11,12 \\
\hline
\end{tabular}

A área de estudo apresenta taxas de erosão entre sulcos elevadas, o que vai de encontro com os resultados obtidos por Sparovek et al. (1997) que definiram um novo conceito para tolerância de perdas média de solo, o tempo de vida (tempo necessário para 50\% de uma área, com erosão maior que a formação do solo, atingir o mínimo de profundidade do solo), considerando o uso do solo, sua profundidade e a taxa de erosão existente. Os autores aplicaram este conceito de tolerância de perda de solo na $\mathrm{MBHC}$ e concluíram que somente em $24 \%$ da área total da MBHC o solo é preservado como um recurso natural, onde a taxa de erosão é menor do que a taxa de formação do solo. Nas áreas cultivadas com cana-de-açúcar, $66 \%$ da área total, as taxas de erosão são maiores do que as taxas de formação e em $42 \%$ desta o impacto da erosão do solo é irreversível. Esta situação é sustentável por aproximadamente 100 anos, quando a degradação das terras da microbacia sofrerá aumentos significativos, se persistir esta situação o tempo de vida para a microbacia será de 350 anos, ou seja, o tempo necessário para que 50\% da área possua taxas de erosão superior a taxas de formação do solo atingindo o mínimo de profundidade do solo para manter a produção economicamente viável.

É importante lembrar que o fato da EUPS ter sido desenvolvida para ser usada em parcelas unitárias e uniformes e não em microbacias hidrográficas, pode ter contribuido para que a perda média de solo fosse superestimada na MBHC. Deste modo, os resultados obtidos não são refinados, mas servem para mostrar a ordem de grandeza em que o processo erosivo vem ocorrendo e o grau de degradação atual da MBHC. 


\subsection{Quantificação da erosão em sulcos na MBHC}

Para a estimativa da erosão em sulcos da MBHC, percorreu-se toda a área de estudo, os sulcos freqüentes e isolados foram cuidadosamente medidos e anotados no mapa de campo (escala 1:10,000), o anexo $\mathrm{C}$ contém os resultados obtidos por subbacia. As áreas onde não foi possível a observação a erosão, devido ao fato do solo encontrar-se coberto, esta foi estimada tomando como padrão as áreas onde o solo, o uso da terra e a declividade eram semelhantes.

As estradas e carreadores não foram considerados no presente estudo, embora admita-se que estes tenham uma grande contribuição no processo erosivo da área. A área de estudo é relativamente grande (1990,4 ha) e a cultura da cana-de-açúcar exige um grande número de carreadores para o escoamento da produção até a Usina processadora e devido a falta de tempo necessária para o levantamento de toda a rede viária da área, mesmos os dados levantados foram omitidos no presente trabalho.

A MBHC apresentou taxa de erosão em sulcos da ordem de $58,7 \mathrm{Mg} \mathrm{ha}^{-1}$ ano $^{-1}$, apesar deste valor ter sido maior do que o estimado para a erosão entre sulcos e destas feições erosivas serem mais feias no campo, elas são menos prejudiciais para a queda da fertilidade natural do solo (Bertoni \& Lombardi Neto, 1993), sua ocorrência é localizada enquanto que a erosão entre sulcos ocorre na área toda e é responsável pelo transporte do horizonte superficial e mais fértil do solo.

A sub-bacia 11, foi a que apresentou maior perda de solo por erosão entre sulcos, sendo da ordem de $12,6 \mathrm{Mg} \mathrm{ha}^{-1}$ ano $^{-1}$ (Tabala15), localiza-se na cabeceira da MBHC, com aproximadamente $12 \%$ de sua área urbanizada, pela Vila de Santana, a urbanização geralmente favorece o desenvolvimento da erosão em sulcos, pois a água da chuva pouco infiltra nas ruas e são escoadas de modo concentrado, pontualmente, outro fator que contribui para este valor alto é o fato de nesta área estar localizado grande parte dos pequenos produtores, que praticam agricultura como os seus avós praticavam, utilizando pouca tecnologia e degradando o solo.

A erosão em sulcos é um processo que vem sendo desenvolvida ao longo do tempo. Em alguns casos ela pode ter o seu início na erosão entre sulcos, que em estágio mais desenvolvido não proporciona um desgaste absolutamente uniforme por toda a 
superficie do solo, proporcionando a concentração das enxurradas nos locais onde a erosão entre sulcos mais se manifestou, determinando a formação dos sulcos.

\subsection{Quantificação da erosão nas sub-bacias da MBHC}

A tabela 14 contém as vinte e duas sub-bacias e as perda média de solo por ano. As sub-bacias que apresentaram maiores perdas médias de solo estão localizadas do lado direito da MBHC, coincidindo com as áreas onde ocorre a maior erodibilidade do solo.

A MBHC vem apresentando perdas de solo muito elevadas deste 1962, sendo este o período mais crítico quanto aos valores de perdas de solo encontrados. $O$ fato que mais chama a atenção, quando analisamos a Tabela 11 é que em 1962 algumas subbacias apresentaram perdas de solo extremamente elevadas.

As áreas que apresentaram maiores perdas médias de solo no ano de 1962 foram as sub-bacias $7,8,10,11,12,15,16$ e 21 todas com perdas de solo bem superiores a $100 \mathrm{Mg} \mathrm{ha}^{-1}$ ano $^{-1}$, nestas áreas a maior parte de suas terras estão sendo utilizada além da sua capacidade, solos altamente suscetíveis à erosão ocorrendo em declividade que limitam o seu uso para a agricultura intensiva e com práticas de conservação e manejo tradicionais. Analisando o anexo A podemos observar que áreas relativamente grandes (mais de 40\%) de cultura anual aparecem nestas sub-bacias, com exceção da sub-bacia 7 que apresentou apenas $23,5 \%$ de sua área cultivada com cultura anual, mas que possui $53 \%$ de seu solo na classe 4 e 5 de erodibilidade e $48 \%$ de sua área com declividade superior a $10 \%$.

Outro fato que chama a atenção é que as quatro maiores sub-bacias $(7,11,12 \mathrm{e}$ 15) apresentaram maiores perdas média de solo em 1962 , ou seja que $50 \%$ da área total da MBHC está perdendo em média mais de $178 \mathrm{Mg} \mathrm{ha}^{-1} \mathrm{ano}^{-1}$, um valor extremamente grande. As sub-bacias 1, 9, 13, 14, 17, 18 e 22 apresentaram perdas médias de solo entre 42 e $88 \mathrm{Mg} \mathrm{ha}^{-1}$.ano ${ }^{-1}$, o que não deixa de ser um valor elevado. As sub-bacias 19 e 20 que apresentaram menores valores de perdas média de solo com 8,3 e $9 \mathrm{Mg} \mathrm{ha}^{-1}$ ano $^{-1}$, respectivamente, mais de $90 \%$ de suas terras eram ocupadas por pastagens e pasto sujo.

Em 1978, a MBHC apresentou perdas média de solo por sub-bacia bem menores, apesar da perda média de solo da MBHC ter sido elevada este ano, mas a 
situação mais crítica encontra-se em apenas seis sub-bacia, que somadas as suas áreas ocupam aproximadamente $40 \%$ da área total da MBHC (Tabela 14). Nestas sub-bacias as perdas médias de solo foram entre $87 \mathrm{e} 194 \mathrm{Mg} \mathrm{ha}^{-1} \mathrm{ano}^{-1}$. Quando comparamos os resultados obtidos na tabela $14 \mathrm{com} \mathrm{o}$ anexo $\mathrm{A}$, podemos observar que as menores perdas de solo ocorreram nas áreas onde predominaram as pastagens e matas, mostrando esta ser a maior aptidão agricola das terras da MBHC.

As sub-bacias com maiores perdas média de solo por hectare por ano em 1995 foram as sub-bacias $2,4,3$ e 1 com perdas médias de 50,5, 38,6, 35,6 e 34,5 $\mathrm{Mg} \mathrm{ha}^{-1}$ ano $^{-1}$ (Tabela 14) que localizam-se na parte baixa da MBHC, do lado direito (sentido de observação a montante para a jusante), coincidindo com as áreas onde o solo são mais suscetíveis à erosão.

Neste ano a cana-de-açúcar predominou em todas as sub-bacias, e apesar da perda média de solo ter sido menor quando comparamos com os outros anos estudados, perdas relativamente altas podem ser observadas quando comparamos com os números encontrados na bibliografia considerados como tolerantes para as perdas média de solo. 
Tabela 14 : Sub-bacias da MBHC, suas áreas e as perdas médias de solo devido a erosão entre sulcos.

\begin{tabular}{ccccc}
\hline Sub-bacia & Area & \multicolumn{3}{c}{ Erosão areolar } \\
& \multicolumn{4}{c}{1978} \\
\hline & 1962 & Mg/ha/ano & 1995 \\
\hline & ha & 65,38 & 11,27 & 34,465 \\
3 & 133,6 & 15,26 & 9,53 & 50,456 \\
4 & 14,16 & 27,48 & 27,71 & 35,650 \\
5 & 55,76 & 34,35 & 21,54 & 38,582 \\
6 & 86,32 & 35,28 & 9,77 & 28,464 \\
7 & 16,68 & 13,61 & 7,10 & 33,912 \\
8 & 116,8 & 129,7 & 140,33 & 29,660 \\
9 & 312,72 & 153,9 & 194,10 & 29,922 \\
10 & 104,0 & 42,58 & 141,78 & 23,377 \\
11 & 11,72 & 139,95 & 43,91 & 26,617 \\
12 & 21,8 & 218,22 & 87,93 & 29,195 \\
13 & 239,84 & 198,9 & 18,35 & 21,459 \\
14 & 239,72 & 88,03 & 21,46 & 26,235 \\
15 & 19,12 & 62,12 & 24,94 & 31,423 \\
16 & 50,24 & 168,63 & 16,45 & 17,156 \\
17 & 216,28 & 117,32 & 13,93 & 11,970 \\
18 & 21,44 & 47,22 & 15,37 & 18,077 \\
19 & 112,36 & 65,10 & 11,14 & 15,874 \\
20 & 22,48 & 8,33 & 7,63 & 11,438 \\
21 & 29,56 & 9,32 & 7,47 & 27,766 \\
22 & 64,68 & 215,72 & 100,40 & 31,429 \\
\hline & 45 & 69,84 & 102,48 & 19,174 \\
\hline
\end{tabular}

As sub-bacias localizadas do lado esquerdo da MBHC que apresentaram maiores perdas média de solo foram as 20 e 22 , com $31,4 \mathrm{Mg} / \mathrm{ha} /$ ano cada uma. As subbacias 1,2 e 22 localizam-se próximas à represa, que funciona como receptora de água e de sedimentos produzidos e transportados durante o processo erosivo. As sub-bacias com menores perdas média de solo devido a erosão entre sulcos foram as 19 e 16 , com perdas respectivas de $11,4 \mathrm{Mg} \mathrm{ha}^{-1}$ ano $^{-1}$ e $12 \mathrm{Mg} \mathrm{ha}^{-1} \mathrm{ano}^{-1}$ (Tabela 14).

$\mathrm{Na}$ Tabela 15, estão relacionadas as 22 sub-bacias e as perdas de solo por erosão em sulcos. As sub-bacias 1, 2, 3, 4 e 6 localizam-se nas terras baixas da MBHC, do lado esquerdo onde ocorrem os solos mais suscetíveis à erosão, possuindo aproximadamente $50,41,74,78$ e $40 \%$ de suas áreas com os solos na classe 5 de erodibilidade, respectivamente e um pouco mais de $70 \%$ das áreas cultivadas com cana- 
de-açúcar, estas perdas de solo elevada, mostram mais uma vez que as terras destas subbacias estão sendo super utilizadas, e que no presente estas áreas são as que estão causando maior impacto na MBHC.

Em algumas sub-bacias quase não foi identificada a ocorrência de sulcos, isto ocorre em sub-bacias que a muito tempo vem sendo utilizada para pastagens, caso da sub-bacia 19 onde não foi observado a presença de sulcos de erosão, ou casos onde os solos são rasos (Litosolos), e não favorecem ao aparecimento de sulcos profundos, onde ocorre a maior perda de solo. As grandes erosões lineares (em sulcos) são decorrência de ações antrópicas isoladas e não tem nada com o manejo geral da área.

Tabela 15: Sub-bacias da MBHC e as perdas médias de solo por ano devido a erosão em sulcos.

\begin{tabular}{|c|c|c|c|}
\hline Sub-bacia & Area & $\begin{array}{l}\text { Erosão em } \\
\text { sulcos }\end{array}$ & $\begin{array}{l}\text { Erosão em } \\
\text { sulcos }\end{array}$ \\
\hline & ha & Mg/ha & $\mathrm{Mgha}^{-1}$ ano $^{-1}$ \\
\hline 1 & 133,6 & 44,4 & 11.10 \\
\hline 2 & 14,16 & 31,0 & 7,75 \\
\hline 3 & 55,76 & 40,4 & 10,10 \\
\hline 4 & 86,32 & 21,7 & 5,43 \\
\hline 5 & 16,68 & 12,4 & 3,10 \\
\hline 6 & 116,8 & 3,3 & 0,83 \\
\hline 7 & 312,72 & 6,5 & 1,63 \\
\hline 8 & 104 & 1,3 & 0,33 \\
\hline 9 & 11,72 & 1,5 & 0,38 \\
\hline 10 & 21,8 & 0,7 & 0,18 \\
\hline 11 & 239,84 & 50,6 & 12,65 \\
\hline 12 & 239,72 & 2,7 & 0,68 \\
\hline 13 & 19,12 & 0,7 & 0,18 \\
\hline 14 & 50,24 & 1,4 & 0,35 \\
\hline 15 & 216,28 & 1,6 & 0,40 \\
\hline 16 & 21,44 & 5,4 & 1,35 \\
\hline 17 & 112,36 & 0,7 & 0,18 \\
\hline 18 & 56,52 & 2,5 & 0,63 \\
\hline 19 & 22,48 & 1,0 & 0,25 \\
\hline 20 & 29,56 & 0,0 & 0,00 \\
\hline 21 & 64,68 & 1,6 & 0,40 \\
\hline 22 & 45 & 3,3 & 0,83 \\
\hline
\end{tabular}




\section{CONCLUSÕES}

Os resultados obtidos neste estudo nos leva a concluir que a degradação da MBHC está diretamente relacionada com as interferências antrópicas no meio ambiente, mas precisamente o uso da terra para a agricultura, não sendo este o único fator relacionado, pois a área de estudo apresenta características naturais do meio fisico que favorecem o processo erosivo.

As taxas de erosão encontradas neste estudo podem estar superestimada, mas elas nos fornecem informações das áreas onde o processo erosivo vem ocorrendo com maior intensidade e o solo encontra-se em estágios mais avançados de degradação.

Em 1962, a MBHC apresentava uma elevada perda média de solo por toda a área, isto se deve principalmente ao cultivo de culturas anuais, as sub-bacias que mais contribuíram para a produção de sedimentos foram as $7,8,910,11,12,15,16$ e 21 . Sendo está a pior situação encontrada entre os anos estudados.

Em 1978, as principais áreas produtoras de sedimentos foram as sub-bacias 7 , $8,9,21$ e 22 , o restante da área apresentou menores taxas de erosão entre sulcos nos anos estudados, sendo que somente duas sub-bacias 10 e 11 apresentaram perdas média de solo maiores do que em 1995. A represa construída neste ano, passou a reter os sedimentos produzidos devido ao uso inadequado do solo acelerando o processo de erosão e que antigamente eram exportados para o Rio Piracicaba, sendo uma testemunha do impacto do uso do solo na MBHC.

A menor perda de solo estimada para a microbacia foi no ano de 1995, mas diferente das situações antigas toda a MBHC apresenta taxas de erosão de solo relativamente altas, as maiores taxas de erosão entre sulcos foram encontradas nas subbacias 1, 2, 3 e 4 onde os solos apresentam maior suscetibilidade à erosão. As sub-bacias que possuem maiores perdas de solo devido a erosão em sulcos são as $1,2,3,4,5$ e 11 . 
Sendo estas as áreas que mais têm contribuem para a produção de sedimentos na MBHC.

A área de estudo ainda está longe das condições ideais para manter o solo como um recurso natural que poderá ser utilizado indefinidamente pelas gerações futuras. Estes dois processos de erosão (entre sulcos e em sulcos) são os responsáveis pela intensa degradação dos solos e dos recursos hídricos da MBHC.

Futuros estudos devem ser realizados na MBHC, a fim de compreender como ocorre o transporte e a deposição dos sedimentos produzidos no processo erosivo durante o percurso destes ao longo da área até atingirem os cursos d'água, e causarem a degradação dos recursos hídricos. 


\section{REFERÊNCIAS BIBLIOGRÁFICAS}

BAVEL, C.H.M. Mean weight diameter of soil aggregates as a statistical index of agregation. Soil Science of Society of America Procedings, v. 14, p. 20-23, 1949.

BEASLY, R.P. Erosion and sediment pollution control. Ames: Iowa State University Press. 1974. 320p.

BERTOLINI, D.; LOMBARDI NETO, F.; DRUGOWICH, M.I. Programa estadual de microbacias hidrográficas. Campinas: CATI, 1993. 16p.

BORGES, M.H.; PFEIFER, R.M.; DEMATTÊ, J.A.M. Evolução e mapeamento do uso da terra, através de imagens aerofotogramétricas e orbitais em Santa Bárbar D'oeste (SP). Sciencia Agricola, v.50, n.3, p. 365-371, out./dez. 1993.

BRASIL, 1960 Ministério da Agricultura Comissão de Solos. Levantamento de reconhecimento de solos do Estado de São Paulo. Rio de Janeiro, Ministério da Agricultura, CNEPA, 634p. 1969 (Boletim 12).

BROOKS, K.N.; FFOLLIOTT, P.F.; GREGERSEN, H.M.; THAMES, J.L. Surface erosion and control of erosion on upland watersheds. In: Hidrology and the manegement of watersheds. Ames: Iowa State University Press, 1991. cap.7, p. $129-152$ 
CAMARGO, O.A.; MONIZ, A.C. JORGE, J.A.; VALADARES, J.M.A.S. Métodos de análise química, mineralógica e física de solos do Instituto Agronômico do Estado de São Paulo. Campinas: IAC, 1986. 94p. (IAC. Boletim Técnico, 106).

CÉSAR, C.M. Contribuição para o estudo da erosão e de seus principais determinantes.Piracicaba. 1952. 76p. Tese (Professor) - Escola Superior de Agricultura "Luiz de Queiroz", Universidade de São Paulo.

CHRISTOLOLETTI, A. Geomorfologia. 2.ed. São Paulo: Edgard Blücher, 1974. 188p.

CLARK II, E.H.; HAVERKAMP, J.A.; CHAPMAN, W. Eroding soils: the off-farm impacts. Washington: The Conservation Foundation, 1985. $252 \mathrm{p}$.

De MARIA, I.C.; LOMBARDI NETO, F.; DECHEN, S.C.F.; CASTRO, O.M. Fator da equação universal de perdas de solo (EUPS) para a cultura de cana-de-açúcar. In: REUNIÃO BRASILEIRA DE MANEJO E CONSERVAÇÃO DA ÁGUA E DO SOLO, 10., Florianópolis, 1994. Resumos. Florianópolis, 1994. p.148-149.

DENARDIN, J.E. Erodibilidade do solo estimada por meio de parâmetros físicos e químicos. Piracicaba, 1990. 114 p. Tese (Doutorado) - Escola Superior de Agricultura "Luiz de Queiroz", Universidade de São Paulo.

DUNE, T; DIETRICH, W. Sediment sources in tropical drainage basins. In: : Kral, D.M. Soil erosion and conservation in the tropics. Madison: American Society of Agronomy, Soil Science Society of America, 1982. cap. 3, p.41-55. (ASA. Special Publication, 43).

EASTMAN, J.R. IDRISI : user's guide. Worcester: Clark University, 1992. 
EHRLERS, E. Agricultura sustentável: origens e perspectivas de um novo paradigma. São Paulo: Livro da Terra., 1996. 178p.

EL-SWAIFY, S.A.; DANGLER, E.W. Rainfaall erosion in the tropics: a state-of-the-art. In: Kral, D.M. Soil erosion and conservation in the tropics. Madison: American Society of Agronomy, Soil Science Society of America, 1982. cap. 1, p.1-25. (ASA. Special Publication, 43).

FAO. La erosion del suelo por el água; algunas medidas para combartila en las tierras de cultivo. Roma, 1967. 204p. (FAO. Coleccion FAO. Fomento de Tierras y Aguas, 7).

FIORIO, P.R. Avaliação cronológica do uso da Terra e seu impacto no ambiente da Microbacia Hidrográfica do Córrego do Ceveiro da região de Piracicaba, SP. Piracicaba, 1998. 114p. Dissertação (Mestrado) - Escola Superior de Agricultura "Luiz de Queiroz", Universidade de São Paulo.

FLORES, M.X. Uso agrícola do solo: Principais tipos de solo, potencial de utilização e impactos ambientais. In: TAUK-TORNISIELO, S.M.; GOBBI, N.; FORESTI, C. et al. Análise ambiental estratégias e ações. T.A. Queiroz, 1995. Cap.7, p. 280-290.

FOSTER, G.R.; MOLDENHAUER, W.C.; WISCHEMEIER W.H. Transferability of US technology for predicition and control of erosion in the tropics. . In: Kral, D.M. Soil erosion and conservation in the tropics. Madison: American Society of Agronomy, Soil Science Society of America, 1982. cap. 8. p.135-149. (ASA. Special Publication, 43). 
FOSTER, G.R.; YOUNG, R.A.; RÖMKENS, M.J.M.; OSTANAD, C.A. Processes of soil erosion by water. In: FOLLET,R.F.; STWART, B.A. (Ed.) Soil erosion and crop producitivity. Madison: American Society of Agronomy, Crop Soil Society of America, Soil Science Society of America, 1985. cap. 9, p.137-162.

GRISSINGER, E.H. Rill and gullys erosion. In: AGASSI, M. Erosion, conservation and rehabilitation. New York: Marcel Dekker, 1995. cap.8, p. 153-167.

GUERRRA, A.J.T.; CUNHA, S.B. Geomorfologia e meio ambiente. Rio de Janeiro: Bertrand Brasil, 1996. 394p.

HAMLETT, J.L.; MILLER, D.A.; DAY,R.L.; PETERSON,G.W.; BAUMER, G.M.; RUSSO,J. Statewide GIS - based ranking of watersheds for agricultural pollution prevention. Journal of Soil and Water Conservation, v.47, n.5, p.399-404, Sept./Oct. 1992.

INSTITUTO DE PESQUISAS TECNOLÓGICAS. Mapa geológico do Estado de São Paulo. São Paulo, 1981. (Esc. 1:1.000.000).

KöFFLER, N.F. Sistema de análise ambiental para planejamento agrícola: versão 1.0. Rio Claro: CEAPLA, 1992, $41 \mathrm{p}$.

LAL, R. Soil erosion and land degradation: the global risks. Advances in Soil Science, v.7, p.129-172, 1990.

LAL, R. Soil erosion by wind and water: problems and prospects. In: LAL, R. Soil erosion and research methods. 2 ed. Delray Beach: St. Lucie Press, 1994. cap. 1, p.1-9. 
LANE, L.J.; NEARING, M.A. (Ed.) Water erosion prediction project: landscape profile model documentation. Washington: USDA, National Soil Erosion Research Laboratory, Agricultural Research Service, 1989. (NSERL Report, 2).

LEPSCH, I.F; BELLINAZZI, R.R.; BERTOLINI, D.; ESPÍNDOLA, C.R. Manual para levantamento utilitário do meio físico e classificação de terras no sistema de classificação de uso. Campinas: SBCS, 1983. 175p.

LEVY, M.C.T.C. Avaliação da sustentabilidade das terras de Piracicaba (SP) por comparação de cenários. Piracicaba, 1995. 104p. Dissertação (Mestrado) - Escola Superior de Agricultura "Luiz de Queiroz", Universidade de São Paulo.

LOMBARDI NETO, F.; BERTONI, J. Tolerância de perdas de terra para solos do Estado de São Paulo. Campinas: IAC, 1975. P.12 (IAC Boletim Técnico, 28).

MARQUES, J.F. Efeito da erosão do solo na geração de energia elétrica: uma abordagem da economia ambiental. São Paulo, 1995. 257p. Tese (Doutorado) Faculdade de Economia Administração e Contabilidade, Universidade de São Paulo.

MARQUES, J.J.G.S.M.; CURI, N.; FERREIRA, M.M.; LIMA, J.M.; SILVA, M.L.N.; SÁ, M.A. C. de. Adequação de métodos indiretos para a estimativa de erodibilidade de solos com horizonte B textural no Brasil. Revista Brasileira de Ciência do Solo, v. 21, n. 3, p. $447-456,1997$. 
MELLEROWICZ, K.T.; REES, H.J.; CHOW, T.L.; GHANEM, I. Soil conservation planning at watershed level using the Universal Soil Loss Equation and GIS and microcomputer technologies: a case study. Journal of Soil and Water Conservation, v.49, n.2, p.194-199, 1994.

MEYER, L.D.; WILLOUGHBY, W.E; WHISLER, F.D.; RHOTON, F.E. Prediciting size distributions od sediment eroded from aggregated soils. Transection of the ASAE, v.26, n.2, p.486-490, 1983.

MOLDAN, B.; CERNÝ, J.C. Small catchment research. In: MOLDAN, B.; CERNY, J. Biogeochemistry of small catchments: a tool for environmental research. New York: John Wiley, 1994. p. 1-29.

MORGAN, R.P.C. Soil erosion and its control . New York: Van Nostrand Reinhold, 1986. $311 \mathrm{p}$.

OLIVEIRA, A.M.S. Depósitos tecnogênicos e assoreamento de reservatórios. Exemplo do reservatório de Capivara, Rio Paranapanema, SP/PR. São Paulo, 1994. 2 v. Tese (Doutorado) - Faculdade de Filosofia, Letras e Ciências Humanas, Universidade de São Paulo.

OLIVEIRA, J.B. de; ALFONSI, R.R. \& PEDRO JÚNIOR, M.J. Regimes hídricos e térmicos do Estado de São Paulo. In: Congresso Brasileiro de Ciência do Solo, Campinas, 1976. Anais. Campinas: Sociedade Brasileira de Ciência do solo, 1976. P359-362. 
PARANÁ (Estado). Programa de manejo integrado dos solos e da água em microbacias. Curitiba, 1987. 34p.

PROCHONOW, M.C.R. Recursos hídricos e metodologia de pesquisa. Geografia, v.10, n. 19, p.187-202, 1985.

PUNDEK, M. Utilização prática da equação universal de perdas de solo para as condições de Santa Catarina. In: Secretaria de Estado da Agricultura e Abastecimento. Manual de uso, manejo e conservação do solo e da água; Projeto de recuperação, conservação e manejo dos recursos naturais em microbacias hidrográficas. 2. Ed. Florianópolis: EPAGRI, 1994. cap.2 parte 2.6, p. $99-129$.

RAIJ, B. van; QUAGGIO, J.A.; CANTARELLA, H.; FERREIRA, M.E.; LOPES, A.S.; BATAGLiA, O.C. Análise química de solos para fins de fertilidade. Campinas: Fundação Cargill, 1987. 170p.

RANIERI, S.B.L. Avaliação de métodos e escalas de trabalho para a determinação de risco de erosão em bacia hidrográfica utilizando Sistema de Informações Geográficas (SIG). São Carlos, 1996. 128p. Dissertação (Mestrado) - Escola de Engenharia de São Carlos, Universidade de São Paulo.

RENARD, K.G.; FOSTER, G.R.; YODER, D.C.; McCOOL, D.K. RUSLE revised: status, questions, answers and the future. Journal of Soil and Water Conservation, v.49, p.213-220, 1994. 
SCHERTZ, D.L. The basis for soil loss tolerances. Journal of Soil and Water Conservation, v. 38, n.1, p. 10-14, 1983.

SHARMA, P.P. Interril erosion. In: AGASSI, M. Erosion, conservation and rehabilitation. New York: Marcel Dekker, 1995 cap.7. p. 125-151.

SILVA, I.F.; ANDRADE, A.P.; CAMPOS FILHO, O.R.; OLIVEIRA, F.A.P. Erodibilidade de seis solos do semi-árido paraibano obtida com chuva simulada e método nomográfico. Revista Brasileira de Ciência do Solo, v. 10, n.3, p.289-292, 1986.

SILVA, M.L.N.; CURI, N.; OLIVEIRA, M.S.; FERREIRA, M.M.; LOMBARDI NETO,F. Comparação de métodos direto e indiretos para a determinação da erodibilidade em latossolos sob cerrado. Pesquisa Agropecuária brasileira, v.29, 1751-1761, 1994.

SILVA, A.C.; LIMA,J.M.; CURI, N. Relação entre voçorocas, usos da terra, solos e materiais de origem na região de Lavras (MG). Revista Brasileira de Ciência do Solo, v. 17, n.4, p. 459-464, 1993.

SPAROVEK, G. Plano diretor da Microbacia do Córrego do Ceveiro. Piracicaba: ESALQ, 1991. 286 p. v.1: Diagnóstico da situação, levantamento de problemas e propostas de solução.

SPAROVEK, G.; JONG van LIER, Q. Estimativa de tolerância de perdas de terra por erosão. In: CONGRESSO BRASILEIRO DE CIÊNCIA DO SOLO, 24. Goiânia, 1993. Resumos. Goiânia: SBCS, 1993. v.3, p.165-166. 
SPAROVEK, G.; LESPCH, I.F. Diagnóstico de uso e aptidão das terras agricolas de Piracicaba. 2.ed. Piracicaba: ESALQ, 1998. 99 p.

SPAROVEK, G.; WEILL, M.M.; RANIERI, S.B.; SCHNUG, E.; SILVA, E.F.; The life-time concept as a tool for erosion tolerance definition. Sci. Agric., Piracicaba, 54 (número especial): p. 130-135, 1997.

TERAMOTO, E.R. Relações solos substrato geológico e superficies geomorfológicas na Microbacia do Ribeirão Marins. Piracicaba, 1995. 93p. Dissertação (Mestrado) Escola Superior de Agricultura "Luiz de Queiroz", Universidade de São Paulo.

WISCHMEIER, W.H.; MANNERING, J.V. Relation of soil properties to its erodibility. Soil Science Society of America Proceedings, v.33, p. 131-137. 1969.

WISCHMEIER, W.H.; SMITH, D.D. Predicting rainfall erosion losses from cropland east of the Rocky mountain: Guide for selections of pratices for soil and water conservation. Washington: USDA, 1965. 47p. (USDA. Agricultural Handbook, 282).

WISCHMEIER, W.H.; SMITH, D.D. Predicting rainfall erosion losses: a guide to conservation planning. Washington: USDA, 1978. 58p. (USDA. Agricultural Handbook, 537).

WISCHEMEIER, W H.; JOHNSON, C.B.; CROSS, B.V. A erodibility nomograph for farmland and construction sites. Journal of Soil and Water Conservation, v.26, n.6, p. $189-93,1971$. 


\section{ANEXOS}


Anexo A

\begin{tabular}{|c|c|c|c|c|c|c|c|c|c|c|c|}
\hline \multirow{2}{*}{\begin{tabular}{|l|} 
Sub- \\
bacia \\
\end{tabular}} & \multicolumn{3}{|c|}{ Uso da terra 1962} & \multirow{2}{*}{\begin{tabular}{|l|} 
Sub- \\
bacia \\
\end{tabular}} & \multicolumn{3}{|c|}{ Uso da terra 1978} & \multirow{2}{*}{\begin{tabular}{|l|} 
Sub- \\
bacia \\
\end{tabular}} & \multicolumn{3}{|c|}{ Uso da terra 1995} \\
\hline & & ha & & & & ha $1 \%$ & $\%$ & & & ha & $\%$ \\
\hline & 1Cana & 71,52 & $\overline{53,7}$ & & mata ciliar & 10,16 & 7,6 & & Cana & 95,32 & 71,6 \\
\hline & cult.anual & 21,8 & 16,4 & & pastagem & 116,12 & 87,2 & & Pasto sujo & 6,32 & 4,7 \\
\hline & 1 Mata & 15,2 & 11,4 & & pasto sujo & 1,80 & 1,4 & & mata ciliar & 21,96 & 16,5 \\
\hline & Pastagem & 3,48 & 2,6 & & represa & 5,12 & 3,8 & 1 & a. urbana & 7,76 & 5,8 \\
\hline 1 & pasto sujo & 13,8 & 10,4 & & & & & & Represa & 1,84 & 1,4 \\
\hline & Reflorestamento & 7,4 & 5,6 & & & & & & & & \\
\hline & & & & & & & & & & & \\
\hline & 2 Cana & 2,2 & 15,5 & 2 & mata ciliar & 0,56 & 4,0 & & Cana & 10,16 & 71,8 \\
\hline & Mata & 0,04 & & 2 & pastagem & 13,56 & 95,8 & & Pastagem & 0,12 & 0,8 \\
\hline 2. & 2 mata ciliar & 0,32 & & & represa & 0,04 & 0,3 & & Pasto sujo & 0,4 & 2,8 \\
\hline & Pastagem & 10,4 & & & & & & & c.anual & 2,12 & 15,0 \\
\hline 2 & 2 pasto sujo & 1,2 & & & & & & & Mata & 0,8 & 5,6 \\
\hline & & & & & & & & 2 & mata ciliar & 0,56 & 4,0 \\
\hline & & & & & & & & & & & \\
\hline 3 & Cana & 26,72 & 47,9 & 3 & cult.anual & 4,40 & 7,9 & & Cana & 40,52 & 72,7 \\
\hline 3 & 3 Mata & 4,96 & 8,9 & 3 & mata & 0,16 & 0,3 & & Pasto sujo & 3,44 & 6,2 \\
\hline 3 & mata ciliar & 6,28 & 11,3 & 3 & mata ciliar & 7,00 & 12,6 & & Mata & 2,12 & 3,8 \\
\hline 3 & Pastagem & 15,84 & 28,4 & 3 & pastagem & 44,20 & 79,3 & & mata ciliar & 9,68 & 17,4 \\
\hline 3 & 3Reflorestamento & 1,96 & 3,5 & & & & & & & & \\
\hline & & & & & & & & & & & \\
\hline 4 & 4 Cana & 51,48 & 59,6 & 4 & cult.anual & 1,40 & 1,6 & & Cana & 62,52 & 72,4 \\
\hline & $4 \longdiv { \text { Mata } }$ & 1,24 & 1,4 & 4 & mata ciliar & 9,48 & 11,0 & & c.anual & 5,48 & 6,3 \\
\hline & mata ciliar & 15,96 & 18,5 & & pastagem & 75,44 & 87,4 & & Mata & 10,16 & 11,8 \\
\hline 4 & Pastagem & 10,2 & 11,8 & & & & & 4 & mata ciliar & 8,16 & 9,5 \\
\hline 4 & pasto sujo & 3,48 & 4,0 & & & & & & & & \\
\hline 4 & Reflorestamento & 3,96 & 4,6 & & & & & & & & \\
\hline & & & & & & & & & & & \\
\hline 5 & 5 Cana & 14,2 & 85,1 & & mata ciliar & 1,16 & 7,0 & & Cana & 9,52 & 57,1 \\
\hline 5 & 5 mata ciliar & 1,96 & 11,8 & & pastagem & 15,52 & 93,0 & & Pastagem & 6,52 & 39,1 \\
\hline 5 & 5 Pastagem & 0,08 & 0,5 & & & & & & Mata & 0,64 & 3,8 \\
\hline 5 & pasto sujo & 0,44 & 2,6 & & & & & & & & \\
\hline & & & & & & & & & & & \\
\hline 6 & Cana & 25,68 & 22,0 & & pastagem & 44,80 & 38,4 & & Cana & 85,28 & 73,0 \\
\hline 6 & Mata & 9,56 & 8,2 & & pasto sujo & 1,80 & 1,5 & 6 & Pasto sujo & 1,08 & 0,9 \\
\hline 6 & mata ciliar & 0,08 & 0,1 & & reflorest. & 70,20 & 60,1 & & reflor. & 15,68 & 13,4 \\
\hline 6 & Pastagem & 11,2 & 9,6 & & & & & & Mata & 14,76 & 12,6 \\
\hline 6 & pasto sujo & 11 & 9,4 & & & & & & & & \\
\hline 6 & Reflorestamento & 59,28 & 50,8 & & & & & & & & \\
\hline & & & & & & & & & & & \\
\hline 7 & Cana & 78,32 & 25,0 & & A. urbana & 0,52 & 0,2 & & Cana & 222,4 & 71,1 \\
\hline 7 & cult.anual & 73,4 & 23,5 & & Cana & 56,00 & 17,9 & & Pastagem & 0,08 & 0,0 \\
\hline 7 & 7 Mata & 6.08 & 1,9 & & 7 cult.anual & 83,60 & 26,7 & & Pasto sujo & 10,44 & 3,3 \\
\hline 7 & mata ciliar & 14,4 & 4,6 & & mata & 5,84 & 1,9 & & reflor. & 4 & 1,3 \\
\hline 7 & Pastagem & 37,56 & 12,0 & & 7 pastagem & 32,80 & 10,5 & & Mata & 39,32 & 12,6 \\
\hline 7 & pasto sujo & 21,4 & 6,8 & & 7 pasto sujo & 58,40 & 18,7 & 7 & mata ciliar & 34,64 & 11,1 \\
\hline $7 \mid 1$ & 7Reflorestamento & 81.56 & 26,1 & & 7 reflorest. & 75,56 & 24,2 & & a. urbana & 1,88 & 0,6 \\
\hline
\end{tabular}




\begin{tabular}{|c|c|c|c|c|c|c|c|c|c|c|}
\hline \multirow{2}{*}{\begin{tabular}{|l|} 
Sub- \\
bacia
\end{tabular}} & \multicolumn{3}{|c|}{ Uso da terra 1962} & \multirow{2}{*}{\begin{tabular}{|l|} 
Sub- \\
bacia \\
\end{tabular}} & \multicolumn{3}{|c|}{ Uso da terra 1978} & \multicolumn{3}{|c|}{ Sub- $\quad$ Uso da terra 1995} \\
\hline & Categoria & ha 10 & $\%$ & & Categoria & ha $\%$ & $\%$ & bacia Categoria & ha $[\%$ & $\%$ \\
\hline & Cana & 37,64 & 36,2 & & Cana & 1,72 & 1,7 & 8ícana & 79,12 & 76,1 \\
\hline 80 & cult.anual & 36,72 & 35,3 & 8 & Cult.anual & 49,16 & 47,3 & 8iPastagem & 11,04 & 10,6 \\
\hline & mata ciliar & 12,24 & 11,8 & 8 & mata & 0,48 & 0,5 & 8)Pasto sujo & 2,04 & 2,0 \\
\hline 8$] \mathrm{F}$ & Pastagem & 11,72 & 11,3 & $8 \mid$ & mata ciliar & 7,16 & 6,9 & 8|Reflor. & 0,56 & 0,5 \\
\hline 811 & Reflorestamento & 5,68 & 5,5 & $8 \mid$ & pastagem & 39,20 & 37,7 & 8) Mata & 4,6 & 4,4 \\
\hline & & & & 81 & pasto sujo & 2,28 & 2,2 & Mata ciliar & 6,64 & 6,4 \\
\hline & & & & 81 & reflorest. & 4,00 & 3,8 & & & \\
\hline & & & & & & & & & & \\
\hline 9 & Cana & 2,28 & 19,5 & 9 & Cana & 1,12 & 9,6 & 9/Cana & 7,4 & 63,1 \\
\hline 9 & cult.anual & 1,04 & 8,9 & 9 & cult.anual & 4,16 & 35,5 & 9|Pastagem & 4,32 & 36,9 \\
\hline $9 / 1$ & Mata & 2,2 & 18,8 & 9 & mata & 3,20 & 27,3 & & & \\
\hline $9 /$ & mata ciliar & 0,72 & 6,1 & 9 & pastagem & 2,56 & 21,8 & & & \\
\hline 9 & Pastagem & 5,28 & 45,1 & 9 & pasto sujo & 0,68 & 5,8 & & & \\
\hline 95 & pasto sujo & 0,2 & 1,7 & & & & & & & \\
\hline & & & & & & & & & & \\
\hline $10 \mid c$ & cult.anual & 8,96 & 41,1 & 10 & Cana & 12,28 & 56,3 & 10ICana & 17,12 & 78,5 \\
\hline 101 & Mata & 1,92 & 8,8 & 10 & cult.anual & 3,60 & 16,5 & 10|Reflor. & 0,36 & 1,7 \\
\hline 10 & mata ciliar & 0,24 & 1,1 & 10 & mata & 0,36 & 1,7 & 10/Mata & 4,32 & 19,8 \\
\hline 10 & Pastagem & 9,44 & 43,3 & 10 & pastagem & 5,04 & 23,1 & & & \\
\hline 10 & pasto sujo & 1,24 & 5,7 & 10 & pasto sujo & 0,52 & 2,4 & & & \\
\hline 11 & área urbana & 2,6 & 1,1 & 11 & A. urbana & 10,92 & 4,6 & 11Cana & 145,1 & 60,5 \\
\hline 11 & cult.anual & 136 & 56,7 & 11) & Cana & 93,28 & 38,9 & 11 Pastagem & 0,72 & 0,3 \\
\hline $11 \mid$ & Mata & 5,28 & 2,2 & 11 & cult.anual & 51,20 & 21,3 & 11)Pasto sujo & 24 & 10,0 \\
\hline 11 & mata ciliar & 21,44 & 8,9 & 11 & mata & 10,60 & 4,4 & 11|c.anual & 0,84 & 0,4 \\
\hline 11 & Pastagem & 27,52 & 11,5 & 11 & mata ciliar & 10,68 & 4,5 & 11|Reflor. & 22,96 & 9,6 \\
\hline 11 & pasto sujo & 37,04 & 15,4 & 11 & pastagem & 0,68 & 0,3 & 11) Mata & 9,04 & 3,8 \\
\hline 11 & Reflorestamento & 9,92 & 4,1 & 11 & pasto sujo & 50,12 & 20,9 & 11/Mata ciliar & 7,68 & 3,2 \\
\hline & & & & 11 & reflorest. & 12,36 & 5,2 & 11) a. urbana & 29,52 & 12,3 \\
\hline 12 & cult.anual & 136 & 56,7 & 12 & Cana & 139,20 & 58,1 & 12 Cana & 173,1 & 72,2 \\
\hline 12 & Mata & 0,04 & 0,0 & 12 & pasto sujo & 26,60 & 11,1 & 12/Pasto sujo & 16,32 & 6,8 \\
\hline 12 & mata ciliar & 1,84 & 0,8 & 12 & reflorest. & 73,92 & 30,8 & 12/Reflor. & 50,32 & 21,0 \\
\hline 12 & Pastagem & 7,04 & 2,9 & & & & & & & \\
\hline 12 & pasto sujo & 27,44 & 11,4 & & & & & & & \\
\hline 12 & Reflorestamento & 67,4 & 28,1 & & & & & & & \\
\hline & & & & & & & & & & \\
\hline 13 & cult.anual & 6,48 & 33,9 & 13 & Cana & 12,56 & 65,7 & 13:Cana & 15,8 & 82,6 \\
\hline 13 & Pastagem & 2,28 & 11,9 & 13 & mata & 0,04 & 0,2 & 13/Reflor. & 3,16 & 16,5 \\
\hline 13 & pasto sujo & 8,8 & 46,0 & 13 & pastagem & 1,24 & 6,5 & 13 Mata & 0,16 & 0,8 \\
\hline 13 & Reflorestamento & 1,56 & 8,2 & 13 & pasto sujo & 1,24 & 6,5 & & & \\
\hline & & & & 13 & reflorest. & 4,04 & 21,1 & & & \\
\hline & & & & & & & & & & \\
\hline 14 & cult.anual & 13,28 & 26,4 & 14 & Cana & 30,88 & 61,5 & 14 Cana & 46,84 & 93,2 \\
\hline 14 & Mata & 2,52 & 5,0 & 14 & mata & 2,20 & 4,4 & 14 Mata & 3,4 & 6,8 \\
\hline 14 & Pastagem & 16,84 & 33,5 & 14 & pastagem & 13,44 & 26,8 & & & \\
\hline 14 & pasto sujo & 17,16 & 34,2 & 14 & pasto sujo & 3,72 & 7,4 & & & \\
\hline 14 & Reflorestamento & 0,44 & 0,9 & & & & & & & \\
\hline
\end{tabular}




\begin{tabular}{|c|c|c|c|c|c|c|c|c|c|c|c|}
\hline \multirow{2}{*}{\multicolumn{2}{|c|}{\begin{tabular}{|l|} 
Sub- \\
bacia \\
\end{tabular}}} & ra 1962 & & \multirow{2}{*}{\multicolumn{2}{|c|}{$\frac{\text { Sub- }}{\text { bacia }}$}} & rra 1978 & & \multirow{2}{*}{\begin{tabular}{|l|} 
Sub- \\
bacia
\end{tabular}} & \multicolumn{3}{|c|}{ Uso da terra 1978} \\
\hline & & ha & $\%$ & & & ha & $\%$ & & & ha & \\
\hline \multicolumn{2}{|c|}{ 15/cana } & 5,92 & 2,7 & \multicolumn{2}{|c|}{ 15 Cana } & 90,56 & 41,9 & \multicolumn{2}{|c|}{ 15 Cana } & 109,7 & 50,7 \\
\hline \multicolumn{2}{|c|}{15 cult.anual } & 100,3 & 46,4 & \multicolumn{2}{|c|}{ 15 mata } & 2,60 & 1,2 & 15 & Pastagem & 24,68 & 11,4 \\
\hline & & 5,12 & 2,4 & \multicolumn{2}{|c|}{ 15/mata ciliar } & 5,20 & 2,4 & 15 & pasto sujo & 52,12 & 24,1 \\
\hline \multicolumn{2}{|c|}{$\begin{array}{l}\text { 15 } \text { mata } \\
15 \text { mata ciliar }\end{array}$} & 22,04 & 10,2 & \multicolumn{2}{|c|}{15 pastagem } & 41,12 & 19,0 & 15 & reflor. & 23,08 & 10,7 \\
\hline \multicolumn{2}{|c|}{15 pastagem } & 47,96 & 22,2 & \multicolumn{2}{|c|}{15 pasto sujo } & 53,16 & 24,6 & 15 & Mata & 5,4 & 2,5 \\
\hline \multicolumn{2}{|c|}{15 pasto sujo } & 34,92 & 16,1 & \multirow{2}{*}{\multicolumn{2}{|c|}{$\begin{array}{l}\text { 15|reflorest. } \\
15 \mid \text { represa }\end{array}$}} & 22,72 & 10,5 & 15 & Represa & 1,32 & 0,6 \\
\hline & & & & & & 0,92 & 0,4 & & & & \\
\hline & & & & & & & & & & & \\
\hline 16 & cult.anual & 14,08 & 65,7 & \multicolumn{2}{|c|}{ 16|Cana } & 9,76 & 45,5 & \multicolumn{2}{|c|}{$\begin{array}{l}\text { Cana } \\
\end{array}$} & 9,16 & 42,7 \\
\hline 16 & mata & 0,4 & 1,9 & \multicolumn{2}{|c|}{ 16/mata ciliar } & 0,84 & 3,9 & 16 & Pastagem & 4,56 & 21,3 \\
\hline 16 & mata ciliar & 3,2 & 14,9 & & pastagem & 4,28 & 20,0 & 16 & pasto sujo & 2,04 & 9,5 \\
\hline 16 & pastagem & 2,32 & 10,8 & & pasto sujo & 5,48 & 25,6 & 16 & Mata & 5,68 & 26,5 \\
\hline 16 & pasto sujo & 0,6 & 2,8 & & Sreflorest. & 1,08 & 5,0 & & & & \\
\hline 16 & reflorestamento & 0,84 & 3,9 & & & & & & & & \\
\hline & & & & & & & & & & & \\
\hline 17! & cult.anual & 23,08 & 20,5 & 17 & Cana & 53,24 & 47,4 & 17 & Cana & 72,68 & 64,7 \\
\hline 17 & Cult.anual & 4,08 & 3,6 & 17 & mata & 3,24 & 2,9 & 17| & pasto sujo & 17,28 & 15,4 \\
\hline 17 & mata ciliar & 0,32 & 0,3 & & 7 mata ciliar & 0,04 & 0,0 & 17 & Mata & 22,4 & 19,9 \\
\hline 17 & pastagem & 11 & 9,8 & 17 & 7 pastagem & 4,40 & 3,9 & & & & \\
\hline 17 & pasto sujo & 34,16 & 30,4 & 17 & 7pasto sujo & 48,04 & 42,8 & & & & \\
\hline 17 & reflorestamento & 39,72 & 35,4 & 17 & 7 reflorest. & 3,40 & 3,0 & & & & \\
\hline & & & & & & & & & & & \\
\hline 18 & cana & 0,36 & 0,6 & 18 & Cana & 10,08 & 17,8 & 18 & Cana & 22,68 & 40,1 \\
\hline 18 & cult.anual & 15,72 & 27,8 & & 8 mata & 0,56 & 1,0 & 18 & Pastagem & 29 & 51,3 \\
\hline 18 & mata & 1,72 & 3,0 & 18 & 8 mata ciliar & 5,12 & 9,1 & 18 & pasto sujo & 1,8 & 3,2 \\
\hline 18 & pastagem & 15,08 & 26,7 & & 8 pastagem & 40,08 & 70,9 & 18 & Mata & 3,04 & 5,4 \\
\hline 18 & pasto sujo & 19,76 & 35,0 & & 8 reflorest. & 0,68 & 1,2 & & & & \\
\hline 18 & reflorestamento & 3,88 & 6,9 & & & & & & & & \\
\hline & & & & & & & & & & & \\
\hline 19 & cana & 0,48 & 2,1 & & 9 mata & 0,04 & 0,2 & 19 & Cana & 2,96 & 13,2 \\
\hline 19 & mata ciliar & 0,6 & 2,7 & & 9|mata ciliar & 3,64 & 16,2 & $19 \mid$ & Pastagem & 14,72 & 65,5 \\
\hline 19 & pastagem & 10 & 44,5 & & 9 pastagem & 18,80 & 83,6 & 19 & pasto sujo & 4,56 & 20,3 \\
\hline 19 & pasto sujo & 11,4 & 50,7 & & & & & 19 & Represa & 0,24 & 1,1 \\
\hline & & & & & & & & & & & \\
\hline 20 & cana & 1,44 & 4,9 & & Olmata ciliar & 3,68 & 12,4 & 20 & Cana & 18,76 & 63,5 \\
\hline 20 & mata ciliar & 1,2 & 4,1 & & Olpastagem & 25,88 & 87,6 & 20 & pasto sujo & 10,8 & 36,5 \\
\hline 20 & pastagem & 17,8 & 60,2 & & & & & & & & \\
\hline 20 & pasto sujo & 9,12 & 30,9 & & & & & & & & \\
\hline & & & & & & & & & & & \\
\hline 21 & 1) cult.anual & 39,24 & 60,7 & & 1) cult.anual & 19,24 & 29,7 & 21 & Cana & 53 & 81,9 \\
\hline 21 & mata & 0,32 & 0,5 & & 1 mata & 0,24 & 0,4 & $21 \mid$ & pasto sujo & 7,88 & 12,2 \\
\hline 21 & 1 mata ciliar & 4,48 & 6,9 & & 1 mata ciliar & 10,20 & 15,8 & 21 & Mata & 3,76 & 5,8 \\
\hline 21 & 1) pastagem & 9,44 & 14,6 & & 1 pastagem & 13,44 & 20,8 & 21 & mata ciliar & 0,04 & 0,1 \\
\hline 21 & 1) pasto sujo & 11,2 & 17,3 & 21 & 1 pasto sujo & 21,56 & 33,3 & & & & \\
\hline
\end{tabular}




\begin{tabular}{|c|c|c|c|c|c|c|c|c|c|c|c|}
\hline \multirow{2}{*}{$\begin{array}{l}\text { Sub- } \\
\text { bacia }\end{array}$} & \multicolumn{3}{|c|}{ Uso da terra 1962} & \multirow{2}{*}{$\begin{array}{l}\text { Sub- } \\
\text { bacia }\end{array}$} & \multicolumn{3}{|c|}{ Uso da terra 1978} & \multirow{2}{*}{$\begin{array}{l}\text { Sub- } \\
\text { bacia }\end{array}$} & \multicolumn{3}{|c|}{ Uso da terra 1995} \\
\hline & & ha & $\%$ & & & ha & $\%$ & & & ha & $\%$ \\
\hline 22 & cult.anual & 7,32 & 16,3 & 22 & Cana & 13.80 & 30,7 & 22 & Cana & 20.6 & 45,8 \\
\hline 22 & mata & 1,48 & 3,3 & 22 & cult.anual & 9,88 & 22,0 & 22 & Pastagem & 11,48 & 25,5 \\
\hline 22 & mata ciliar & 4,4 & 9,8 & 22 & mata & 1,68 & 3,7 & 22 & pasto sujo & 8,72 & 19,4 \\
\hline 22 & pastagem & 7,24 & 16,1 & 22 & mata ciliar & 1,32 & 2,9 & 22 & Mata & 0,16 & 0,4 \\
\hline 22 & pasto sujo & 24,56 & 54,6 & 22 & pastagem & 5,96 & 13,2 & 22 & mata ciliar & 1,92 & 4,3 \\
\hline & & & & 22 & pasto sujo & 6,80 & 15,1 & 22 & Represa & 2,12 & 4,7 \\
\hline & & & & 22 & represa & 5,56 & 12,4 & & & & \\
\hline & & & & & & & & & & & \\
\hline
\end{tabular}


Anexo B Análises químicas das unidades de mapeamento da área de estudo.

\begin{tabular}{|c|c|c|c|c|c|c|c|c|c|c|c|c|c|c|c|}
\hline \multirow{2}{*}{$\begin{array}{l}\text { Solo } \\
\text { Sigla }\end{array}$} & \multirow{2}{*}{$\begin{array}{l}\text { Hori- } \\
\text { zonte }\end{array}$} & \multicolumn{3}{|c|}{$\mathrm{pH}$} & \multirow{2}{*}{$\begin{array}{l}\mathrm{MO} \\
\mathrm{gkg}^{-1}\end{array}$} & \multirow{2}{*}{$\begin{array}{c}\mathrm{P} \\
\mathrm{mg} / \mathrm{kg}\end{array}$} & \multirow[t]{2}{*}{$K$} & \multirow[t]{2}{*}{$\mathrm{Ca}$} & \multirow[t]{2}{*}{$\mathrm{Mg}$} & $\mathrm{Al}$ & $\mathrm{H}+\mathrm{Al}$ & \multirow[t]{2}{*}{$\mathrm{S}$} & \multirow[t]{2}{*}{$\mathrm{T}$} & \multirow{2}{*}{$\% \%$} & \multirow[t]{2}{*}{$\mathrm{m} \%$} \\
\hline & & $\mathrm{H}_{2} \mathrm{O}$ & $\mathrm{KCl}$ & $\mathrm{CaCl}_{2}$ & & & & & & o & & & & & \\
\hline \multirow[t]{2}{*}{$\mathrm{PVI}$} & $\mathrm{A}$ & 5,0 & 4,2 & 4,4 & 13,2 & 25,8 & 1.7 & 9,6 & 2,5 & 8,8 & 17,4 & 14,0 & 31,4 & 43,2 & 24,6 \\
\hline & B & 4,5 & 3,7 & 3,9 & 10,0 & 2,0 & 1.9 & 16,4 & 4,7 & 28,4 & 45,8 & 28,0 & 68,9 & 32.5 & 55,5 \\
\hline \multirow[t]{2}{*}{ PV2 } & A & 4,4 & 3,9 & 3,9 & 12,2 & 2,6 & 1.7 & 8,3 & 8,8 & 13,0 & 32,2 & 12,9 & 45,1 & 26,4 & 55,4 \\
\hline & $\mathrm{B}$ & 4,8 & 3,6 & 3,6 & 9,0 & 1,4 & 1.2 & 12,0 & 5,9 & 53,2 & 146,8 & 19,0 & 166,0 & 15,9 & 16,9 \\
\hline \multirow[t]{2}{*}{ PV3 } & A & 5,4 & 4,8 & 4,8 & 12,4 & 39,0 & 2.5 & 17,6 & 4,9 & 1,8 & 13,2 & 25,3 & 38,5 & 61,4 & 10,4 \\
\hline & $\mathrm{B}$ & 4,5 & 3,8 & 3,0 & 10,2 & 3,0 & 1.6 & 11,7 & 5,9 & 50,8 & 102,2 & 18,5 & 120,8 & 18,6 & 60.9 \\
\hline PV4 & $A$ & 5,7 & 5,1 & 5,8 & 12,0 & 4,0 & 1,3 & 15,4 & 3,3 & 0,8 & 7,0 & 20,0 & 27,0 & 74,0 & 4,0 \\
\hline & $\mathrm{B}$ & 5,4 & 4,6 & 4,9 & 9,0 & 2,0 & 1.0 & 27,3 & 13,5 & 2,2 & 15,0 & 12,0 & 37,0 & 74,0 & 5,0 \\
\hline PV5 & A & 3,5 & 4,2 & 4,0 & 17,5 & 10,0 & 3.0 & 20,2 & 5,4 & 2,6 & 26,8 & 20,5 & 54,7 & 52,5 & 10,9 \\
\hline & B & 5,4 & 4,8 & 4,0 & 11,7 & 4,3 & 3.0 & 34,5 & 6,5 & 4,3 & 29,3 & 43,9 & 72,9 & 60,9 & 7,3 \\
\hline PV6 & A & 5,0 & 4,4 & 4,4 & 17,0 & 35,0 & 3.0 & 25,3 & 6,5 & 6,0 & 32,0 & 34,7 & 66,7 & 47,3 & 21,8 \\
\hline & B & 4,0 & 3,5 & 3,5 & 10,0 & 4,7 & 1.9 & 18,1 & 5,1 & 16,9 & 204,8 & 20,1 & 124,5 & 14,2 & 34,6 \\
\hline PV7 & A & 4,7 & 4,1 & 4,2 & 20,2 & 9,8 & 1.8 & 23,1 & 5,6 & 11,4 & 51,6 & 30,5 & 82,1 & 39,3 & 26,1 \\
\hline & $B$ & 4,6 & 3,7 & 3,7 & 13,6 & 1,4 & 2.4 & 19,3 & 11,2 & 41,2 & 157,6 & 38,1 & 190,7 & 52,4 & 58,1 \\
\hline PVS & $A$ & 5,8 & 4,9 & 5,2 & 15,7 & 10,6 & 0.1 & 59,9 & 8,9 & 0,9 & 18,3 & 71,9 & 90,3 & 66,4 & 3,4 \\
\hline & B & 6,5 & 5,5 & 5,5 & 12,3 & 12,0 & 1.7 & 1,0 & 13,0 & 9,0 & 19,7 & 95,7 & 115,4 & 78,8 & 1,3 \\
\hline $\mathrm{PE}$ & A & 5,7 & 4,8 & 5,1 & 24,3 & 60,3 & 2.7 & 41,6 & 7,1 & 1,5 & 29,3 & 51,1 & 80,5 & 57,8 & 3,3 \\
\hline & $\mathrm{B}$ & 6,0 & 5,3 & 3,7 & 15,0 & 4,8 & 0.6 & 37,1 & 9,4 & 1,0 & 19,0 & 47,2 & 66,2 & 71,2 & 2,1 \\
\hline $\mathrm{TE}$ & A & 6,2 & 5,5 & 5,6 & 31,2 & 32,6 & 6.4 & 76,2 & 32,5 & 1,4 & 32,4 & 115,1 & 147,5 & 71,9 & 1,8 \\
\hline & B & 6,3 & 5,6 & 5,6 & 20,0 & 24,4 & 3,5 & 50,1 & 16,5 & 1,1 & 57,8 & 70,1 & 127,9 & 63,7 & 1,5 \\
\hline TEP & $A$ & 5,6 & 5,1 & 0,1 & 20,5 & 8,8 & 1.8 & 41,7 & 6,3 & 1,3 & 26,5 & 51,7 & 28,2 & 34,9 & 1,9 \\
\hline & B & 6,0 & 5,3 & 5,5 & 18,5 & 17,8 & 5.6 & 40,1 & 2,8 & 1,6 & 23,0 & 69,3 & 92,8 & 49,0 & 8,2 \\
\hline $\mathrm{Cb} 2$ & A & 5,4 & 4,7 & 5,1 & 23,4 & 19,7 & 2.9 & 54,0 & 16,8 & 4,5 & 26,9 & 74,5 & 101,5 & 75,9 & 6,9 \\
\hline & B & 5,2 & 4,2 & 4,6 & 15,3 & 6,6 & 1,9 & 48,1 & 15,4 & 10,7 & 47,1 & 60,4 & 107,5 & 57,4 & 30,1 \\
\hline $\mathrm{Cb} 3$ & A & 7,8 & 6,8 & 7,2 & 36,0 & 72,0 & 7.3 & 39,2 & 11,3 & 1,4 & 10,0 & 148,0 & 158,0 & 94,0 & 1,0 \\
\hline & $B$ & 5,1 & 3,8 & 3,7 & 8,0 & 1,0 & 4,8 & 12,7 & 9,1 & 65,8 & 228,0 & 26,0 & 231,0 & 10,0 & 78,0 \\
\hline $\mathrm{Cb} 4$ & A & 4,8 & 4,0 & 4,3 & 15,0 & 2,0 & 1.6 & 28,7 & 3,1 & 7,8 & 31,0 & 33,0 & 34,0 & 52,0 & 15,0 \\
\hline & B & 5,3 & 4,4 & 4,7 & 11,0 & 4,0 & 1.5 & 48,8 & 4,5 & 2,8 & 10,0 & 50,0 & 68,0 & 73,0 & 4,0 \\
\hline $\mathrm{Lil}$ & A & 5,4 & 4,7 & 4,9 & 33,6 & 33,2 & 4.4 & 60,6 & 14,9 & 4,7 & 37,2 & 77,9 & 117,1 & 66,1 & 7,1 \\
\hline & $C$ & 5,3 & 4,5 & 4,7 & 16,7 & 27,4 & +.0 & 66,0 & 14,5 & 0,9 & 45,7 & 36,6 & 32,4 & 67.5 & 9,3 \\
\hline $\mathrm{Li} 2$ & A & 5,2 & 4,6 & 5,0 & 20,0 & 30,5 & 2.6 & 68,3 & 29,9 & 12,1 & 52,0 & 101,8 & 153,8 & 64,2 & 15,4 \\
\hline & $\mathrm{C}$ & 4,4 & 3,5 & 3,6 & 17,0 & 5,0 & 2.4 & 35,3 & 12,2 & 61,6 & 276,0 & 49,8 & 325,8 & 16,7 & 35,9 \\
\hline $\mathrm{Li} 3$ & A & 5,5 & 4,7 & 5,0 & 25,4 & 68,3 & 6.3 & 59,7 & 14,6 & 5,0 & 39,5 & 80,5 & 120,0 & 63,0 & 9,3 \\
\hline & C & 6,0 & 4,9 & 5,2 & 14,7 & 2,4 & 2.7 & 94,6 & 19,2 & 5,3 & 34,4 & 117,4 & 151,8 & 74,8 & 5,2 \\
\hline $\mathrm{Li} 4$ & A & 4,9 & 4,2 & 4,8 & 25,5 & 51,0 & 3,2 & 47,5 & 13,3 & 18,8 & 60,5 & 60,9 & 150,2 & 52,2 & 10,5 \\
\hline & $\mathrm{C}$ & 4,1 & 3,6 & 3,7 & 13,0 & 3,8 & 2,6 & 21,2 & 11,2 & 50,4 & 249,5 & 35,0 & 204,5 & 22.6 & 55,3 \\
\hline Li 5 & A & 5,0 & 4,3 & 4,6 & 28,0 & 0,7 & 2.8 & 27,7 & 9.6 & 6,8 & 41,0 & 41,1 & 82,1 & 47,8 & 14,3 \\
\hline & C & 4,7 & 3,6 & 3,9 & 12,0 & 4,0 & 2.5 & 31,9 & 10,7 & 31,2 & 121,0 & 48,0 & 166,0 & 27,0 & 11,0 \\
\hline $\mathrm{Li} 6$ & $A$ & 5,9 & 5,3 & 5,4 & 3,5 & 30,0 & 36,7 & 60,7 & 16,7 & 0,9 & 23,5 & 92,0 & 115,5 & 77,1 & 1,3 \\
\hline & $\mathrm{C}$ & 5,5 & 4,5 & 5,0 & 17,0 & 4,5 & 4,0 & 102,1 & 21,7 & 4,8 & 32,3 & 127,8 & 160,3 & 79,7 & 3,4 \\
\hline $\mathrm{Li} 7$ & $A$ & 5,8 & 5,3 & 4,9 & 32,0 & 29,0 & 8.6 & 82,8 & 29,9 & 1,0 & 13,0 & 122,0 & 35,0 & 90,0 & 1,0 \\
\hline $\mathrm{Hi} 1$ & A & 4,4 & 3,9 & 4,1 & 17,0 & 19,0 & 2.2 & 15,6 & 3,6 & 13,8 & 51,0 & 21,3 & 72,3 & 30,5 & 39,2 \\
\hline & $B$ & 4,4 & 3,3 & 3,5 & 8,0 & 2,0 & 2,3 & 21,6 & 7,0 & 30,4 & 201,5 & 30,9 & 232,4 & 13.2 & 63,3 \\
\hline Hi 2 & $A$ & 4,6 & 3,0 & 4,1 & 15,0 & 18,0 & 1,0 & 11,1 & 5,9 & 9,2 & 42,0 & 19,0 & 61,0 & 31,0 & 33,0 \\
\hline & $\mathrm{B}$ & 5,5 & 4,1 & 4,4 & 7,0 & 5,0 & 1.6 & 31,7 & 14,3 & 5,4 & 24,0 & 40,0 & 82,0 & 50,0 & 10,0 \\
\hline PV1 raso & A & 4,9 & 4,1 & 4,0 & 18,0 & 2,0 & 0,7 & 16,0 & 2,2 & 5,4 & 28,0 & 19,0 & 47,0 & 40,0 & 22,0 \\
\hline & B & 4.0 & 4,3 & 3,8 & 14,0 & 3,0 & 0.4 & 6,9 & 1,7 & 7,0 & 34,0 & 9,0 & 43,0 & 21,0 & 46,0 \\
\hline
\end{tabular}


Análises químicas das unidades de mapeamento da área de estudo (continuação).

\begin{tabular}{|c|c|c|c|c|c|c|c|c|c|c|c|c|c|c|c|}
\hline \multirow{2}{*}{$\begin{array}{l}\text { Solo } \\
\text { Sigla }\end{array}$} & \multirow{2}{*}{$\begin{array}{l}\text { Hor- } \\
\text { zonte }\end{array}$} & \multicolumn{3}{|c|}{$\mathrm{pH}$} & MO & $\mathrm{P}$ & \multirow[t]{2}{*}{$\mathrm{K}$} & \multirow[t]{2}{*}{$\mathrm{Ca}$} & \multirow[t]{2}{*}{$\mathrm{Mg}$} & \multirow[t]{2}{*}{ Al } & \multirow{2}{*}{\multicolumn{2}{|c|}{$\begin{array}{l}\mathrm{H}+\mathrm{Al} \quad \mathrm{S} \\
\mathrm{mmol}_{c} \mathrm{dm}\end{array}$}} & \multirow[t]{2}{*}{$\mathrm{T}$} & \multirow{2}{*}{$\mathrm{V} \%$} & \multirow[t]{2}{*}{$\mathrm{m}^{\mathrm{o}} \mathrm{o}$} \\
\hline & & $\mathrm{H}_{2} \mathrm{O}$ & $\mathrm{KCL}$ & $\mathrm{CaCl}_{2}$ & $\mathrm{gkg}^{-1}$ & $\mathrm{mg} / \mathrm{kg}$ & & & & & & & & & \\
\hline \multirow[t]{2}{*}{ PV4 raso } & $A$ & 4,5 & 3,8 & 3,9 & 10,0 & 4,0 & 1,0 & 6,8 & 1,7 & 8,4 & 25,0 & 10,0 & 35,0 & 28,0 & 47.0 \\
\hline & B & 4,7 & 3,9 & 4,2 & 7,0 & 1,0 & 1,9 & 24,3 & 11,8 & 9,4 & 31,0 & 30,0 & 69,0 & 55,0 & 20,0 \\
\hline \multirow[t]{2}{*}{ PVS raso } & $A$ & 5,2 & 4,6 & 4,7 & 19,3 & 19,8 & 2,7 & 31,3 & 7,4 & 4,5 & 27,9 & 41,6 & 69,5 & 37,1 & 11,7 \\
\hline & B & 5,2 & 4,2 & 4,4 & 19,1 & 5,4 & 8,3 & 40,3 & 12,5 & 14,9 & 61,6 & 51,5 & 116,6 & 50,3 & 22,0 \\
\hline \multirow[t]{2}{*}{ PV6 raso } & $A$ & 4,9 & 4,4 & 4,6 & 16,0 & 22,0 & 1,3 & 46.9 & 5,0 & 7,2 & 34,0 & 54,0 & 38,0 & 61,0 & 12.0 \\
\hline & B & 4,8 & 3,7 & 4,0 & 13,0 & 2,0 & 1,9 & 42,7 & 7,4 & 34,8 & 98,0 & 32,0 & 150,0 & 36,0 & 38,0 \\
\hline \multirow[t]{2}{*}{ PV7 raso } & $A$ & 4,5 & 3,8 & 3,9 & 18,0 & 9,0 & 2,4 & 8,5 & 3,0 & 13,4 & 42,0 & 13,0 & 55,0 & 21,0 & 47,0 \\
\hline & B & 5,2 & 4,1 & 4,2 & 15,0 & 8,0 & 1,5 & 34,4 & 31,4 & 17,4 & 10,2 & 54,0 & 48,0 & 54,0 & 27,0 \\
\hline \multirow[t]{2}{*}{ PV8 raso } & $A$ & 3,2 & 4,5 & 4,9 & 8,0 & 5,0 & 0,4 & 9,4 & 0,1 & 0,8 & 12,0 & 10,0 & 32,0 & 45,0 & 7,0 \\
\hline & $B$ & 6,1 & 5,3 & 5,3 & 7,0 & 4,0 & 0,7 & 36,7 & 4,7 & 0,8 & 15,0 & 42,0 & 57,0 & 74,0 & 2.0 \\
\hline
\end{tabular}

Análises granulométricos das unidades de mapeamento da área de estudo.

\begin{tabular}{|c|c|c|c|c|c|c|c|}
\hline \multirow[t]{2}{*}{ Solo/Sigla } & \multirow[t]{2}{*}{ Horizonte } & Argila & Silte & Areia & Areia Grossa & Areia Média & Areia Fina \\
\hline & & \multicolumn{6}{|c|}{$\mathrm{gkg}^{-1}$} \\
\hline \multirow[t]{2}{*}{ PVI } & A & 70 & 96 & 834 & $\overline{8}$ & 54 & 772 \\
\hline & B & 280 & 94 & 626 & 4 & 42 & 580 \\
\hline \multirow[t]{2}{*}{ PV2 } & A & 102 & 126 & 772 & 20 & 62 & 690 \\
\hline & B & 298 & 120 & 620 & 14 & 42 & 564 \\
\hline \multirow[t]{2}{*}{ PV3 } & A & 50 & 96 & 854 & 10 & 104 & 740 \\
\hline & B & 228 & 88 & 688 & 6 & 88 & 594 \\
\hline \multirow[t]{2}{*}{ PV4 } & $A$ & 50 & 100 & 850 & 10 & 170 & 670 \\
\hline & $\mathrm{B}$ & 340 & 70 & 590 & 30 & 170 & 390 \\
\hline \multirow[t]{2}{*}{ PV5 } & $A$ & 160 & 185 & 655 & 13,3 & 36,7 & 605 \\
\hline & $\mathrm{B}$ & 436,7 & 135 & 426,3 & 10.8 & 17,5 & 400 \\
\hline \multirow[t]{2}{*}{ PV6 } & $\mathrm{A}$ & 293,3 & 396,7 & 320 & 20 & 36,7 & 263,3 \\
\hline & B & 523,3 & 286,7 & 190 & 11,7 & 18,3 & 160 \\
\hline \multirow[t]{2}{*}{ PV7 } & A & 232 & 256 & 512 & 8 & 16 & 488 \\
\hline & B & 638 & 161 & 196 & 1 & 11 & 184 \\
\hline \multirow[t]{2}{*}{ PV8 } & A & 113,3 & 140 & 746,7 & 13,3 & 23,3 & 710 \\
\hline & B & 373,3 & 126,7 & 500 & 13,3 & 10 & 476,7 \\
\hline \multirow[t]{2}{*}{$\mathrm{PE}$} & A & 326,7 & 203,3 & 470 & 10 & 23,3 & 436,7 \\
\hline & B & 526,7 & 160 & 313 & 6.7 & 13,3 & 293,3 \\
\hline \multirow[t]{2}{*}{$T E$} & A & 508 & 206 & 286 & 90 & 26 & 168 \\
\hline & B & 692 & 164 & 144 & 44 & 12 & 88 \\
\hline \multirow[t]{2}{*}{ TEP } & A & 330 & 277,5 & 397,5 & 212.5 & 30 & 155 \\
\hline & B & 597,5 & 190 & 212,5 & 145 & 11,3 & 56,3 \\
\hline \multirow[t]{2}{*}{$\mathrm{Cb} 2$} & A & 322,2 & 357,8 & 320 & 4.4 & 24,4 & 271,1 \\
\hline & B & 375,6 & 395,6 & 230 & 23.9 & 27,2 & 176.9 \\
\hline \multirow[t]{2}{*}{$\mathrm{Cb} 3$} & A & 70 & 210 & 720 & 10 & 60 & 650 \\
\hline & B & 130 & 220 & 650 & 10 & 40 & 600 \\
\hline \multirow[t]{2}{*}{ Cb4 } & A & 140 & 220 & 640 & 10 & 30 & 600 \\
\hline & B & 130 & 250 & 620 & 0 & 10 & 610 \\
\hline \multirow[t]{2}{*}{ Li1 } & A & 327,7 & 406 & 267,7 & 31 & 27 & 208.3 \\
\hline & $\mathrm{C}$ & 382,2 & 400 & 207,2 & 27 & 27,2 & 152,2 \\
\hline \multirow[t]{2}{*}{$\mathrm{Li} 2$} & $\mathrm{~A}$ & 230 & 500 & 270 & 40 & 30 & 200 \\
\hline & $\mathrm{C}$ & 315 & 430 & 235 & 175 & 35 & 45 \\
\hline
\end{tabular}


Análises granulométricos das unidades de mapeamento da área de estudo (continuação).

\begin{tabular}{cccccccc}
\hline \multirow{2}{*}{ Solo/Sigla } & Horizonte & Argila & Silte & Areia & Areta Grossa & Areia Média & Areia Fina \\
\cline { 2 - 8 } & & \multicolumn{7}{c}{$\mathrm{gkg}^{-1}$} \\
\hline \multirow{2}{*}{ Li3 } & A & 405 & 407,5 & 187,5 & 40 & 30 & 117,5 \\
& C & 421,6 & 356 & 196 & 62 & 48 & 86 \\
\multirow{2}{*}{ Li4 } & A & 377,5 & 342,5 & 260 & 12.5 & 17,5 & 230 \\
& Lis & 537,5 & 297,5 & 165 & 5 & 7,5 & 152,5 \\
& C & 336,7 & 490 & 173,3 & 23.3 & 23,3 & 126,7 \\
& A & 420 & 470 & 110 & 10 & 20 & 80 \\
\hline
\end{tabular}


Anexo C 
Sub-bacia 1

SB AR Tipo

1 A S. gr. $\quad 80 \quad 0,8 \quad 0,2$ Tri.

1 A S. gr. $\quad \begin{array}{llll}100 & 0,4 & 0,1 & \text { Tri. }\end{array}$

1 A S. gr. $20 \quad 1,1 \quad 0,9$ Tri.

$1 \mathrm{~A}$ S. gr. $20 \quad 2 \quad 1,3 \mathrm{Tri}$.

1 A S.gr. $20 \quad 1,5 \quad 1$ Tri.

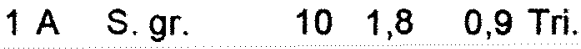

1 A S. gr. $\quad 30 \quad 4 \quad 0,4$ Tri.

1 A S. gr. $\quad 25 \quad 1,7 \quad 1,2$ Tri.

1 A S.gr. $25 \quad 1,7 \quad 1,4$ Tri.

1 A S.gr. $40 \quad 2,5 \quad 0,5$ Tri.

1 A S.gr. $\quad 10 \quad 2,2 \quad 0,2$ Tri.

$1 \mathrm{~A}$ S. gr. 2010,15 Tri.

$1 \mathrm{~A}$ S.gr. $\quad 40 \quad 2,3 \quad 0,4$ Tri.

$1 \mathrm{~A}$ S.gr. $\quad 142,60,15$ Tri.

$1 \mathrm{~A}$ S.gr. $20 \quad 2,5 \quad 0,3$ Tri.

$1 \mathrm{~A}$ S.gr. $30 \quad 3,3 \quad 0,3$ Tri.

$1 \mathrm{~A}$ S.gr. $20 \quad 2 \quad 0,7$ Tri.

$1 \mathrm{~A}$ S.gr. $\quad 40 \quad 0,6 \quad 0,1$ Tri.

$1 \mathrm{~A}$ S.gr. $\quad 40 \quad 1,7 \quad 0,4$ Tri.

$1 \mathrm{~A}$ S.gr. $\quad 10 \quad 6 \quad 1,3$ Tri.

$1 \mathrm{~A}$ S.gr. 2210,15 Tri.

$1 \mathrm{~A}$ S.gr. $10 \quad 3 \quad 0,3$ Tri.

1 A S.gr. $20 \quad 4 \quad 0,3$ Tri.

$1 \mathrm{~A}$ S.gr. $20 \quad 4 \quad 1$ Tri.

$1 \mathrm{~A}$ S.gr. $\quad 15 \quad 3 \quad 1,1$ Tri.

$1 \mathrm{~A}$ S.gr. $\quad 3510,2$ Tri.

1 A S.gr. $\quad 10 \quad 2,5 \quad 1,2$ Tri.

$1 \mathrm{~A}$ S.gr. 25221,4 Tri.

$1 \mathrm{~A}$ S.gr. $10 \quad 6 \quad 0,5$ Tri.

$1 \mathrm{~A}$ S.gr. $30 \quad 1 \quad 0,1$ Tri.

1 A S.gr. $25 \quad 3 \quad 0,4$ Tri.

$1 \mathrm{~A}$ S.gr. $\quad 20 \quad 0,6 \quad 0,1$ Tri.

$1 \mathrm{~A}$ S.gr. $\quad 20 \quad 0,6 \quad 0,1$ Tri.

1 A S.gr. $40 \quad 0,6 \quad 0,1$ Tri.

1 A S.gr. $20 \quad 0,6 \quad 0,1$ Tri.

$1 \mathrm{~A}$ S. gr. 2030,6 Tri.

$1 \mathrm{~A}$ S.gr. $40 \quad 6 \quad 0,6$ Tri.

$1 \mathrm{~A}$ S.gr. $30 \quad 1 \quad 0,2$ Tri.

1 A S.gr. $30 \quad 6 \quad 0,6$ Tri.

$1 \mathrm{~A}$ S.gr. $\quad 30 \quad 4 \quad 0,4$ Tri.

1 A S.gr. $20 \quad 1 \quad 0,4$ Tri.

$1 \mathrm{~A}$ S.gr. $\quad 30 \quad 3 \quad 1,5$ Tri.

1 A S.gr. $40 \quad 6 \quad 0,5$ Tri.
Dist. Lar.
$m$

.

$\begin{array}{llrrr}\text { PV1 } & \text { CAN } & 0,4 & 6,4 & 6 \\ \text { PV1 } & \text { CAN } & 0,4 & 2,0 & 8 \\ \text { PV1 } & \text { CAN } & 0,4 & 9,9 & 18 \\ \text { PV1 } & \text { CAN } & 0,4 & 26,0 & 44 \\ \text { PV1 } & \text { CAN } & 0,4 & 15,0 & 59\end{array}$

$\begin{array}{lllll}\text { PV1 CAN } & 0,4 & 8,1 & 67 & 10\end{array}$

$\begin{array}{llllll}\text { PV1 } & \text { CAN } & 0,4 & 24,0 & 91 & 29\end{array}$

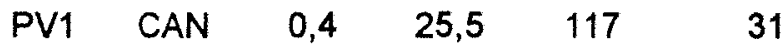

$\begin{array}{lllll}\text { PV1 CAN } & 0,4 & 29,8 & 147 & 36\end{array}$

$\begin{array}{lllll}\text { PV1 CAN } & 0,4 & 25,0 & 172 & 30\end{array}$

$\begin{array}{llll}\text { PV1 CAN } & 0,4 & 2,2 & 174\end{array}$

$\begin{array}{llll}\text { PV1 CAN } & 0,4 & 1,5 & 175\end{array}$

$\begin{array}{lllll}\text { PV1 CAN } & 0,4 & 18,4 & 194 & 22\end{array}$

$\begin{array}{llll}\text { PV1 CAN } & 0,4 & 2,7 & 196\end{array}$

$\begin{array}{llll}\text { PV1 CAN } & 0,4 & 7,5 & 204\end{array}$

$\begin{array}{llll}\text { PV1 CAN } & 0,4 & 14,9 & 219\end{array}$

PV1 CAN $0,4 \quad 14,0 \quad 233$

$\begin{array}{llll}\text { PV1 CAN } & 0,4 & 1,2 & 234\end{array}$

PV1 CAN $0,4 \quad 13,6 \quad 248$

PV1 CAN $0,3 \quad 39,0 \quad 287$

$\begin{array}{llll}\text { PV1 CAN } & 0,3 & 1,7 & 288\end{array}$

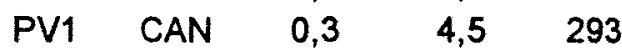

PV1 CAN $0,3 \quad 12,0 \quad 305$

$\begin{array}{llll}\text { PV1 CAN } & 0,3 & 40,0 & 345\end{array}$

PV1 CAN $0,3 \quad 24,8 \quad 370$

$\begin{array}{llll}\text { PV1 CAN } & 0,3 & 3,5 & 373\end{array}$

$\begin{array}{llll}\text { PV1 CAN } & 0,3 & 15,0 & 388\end{array}$

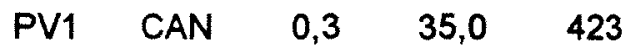

$\begin{array}{llll}\text { PV1 CAN } & 0,3 & 15,0 & 438\end{array}$

PV1 CAN $0,3 \quad 1,5 \quad 440$

$\begin{array}{llll}\text { PV1 CAN } & 0,3 & 15,0 & 455\end{array}$

$\begin{array}{llll}\text { PV1 CAN } & 0,3 & 0,6 & 455\end{array}$

$\begin{array}{llll}\text { PV1 CAN } & 0,3 & 0,6 & 456\end{array}$

PV1 CAN $0,3 \quad 1,2 \quad 457$

$\begin{array}{llll}\text { PV1 CAN } & 0,3 & 0,6 & 458\end{array}$

$\begin{array}{lllll}\text { PV3 } & \text { CAN } & 0,3 & 18,0 & 476\end{array}$

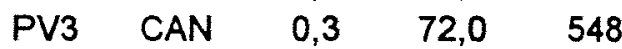

PV3 CAN $0,3 \quad 3,0 \quad 551$

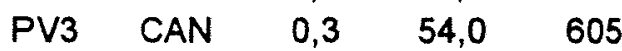

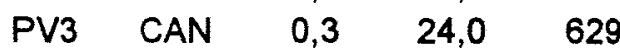

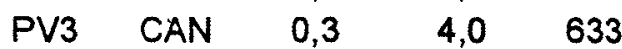

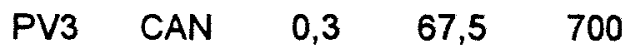

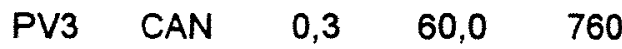

$8 \quad 8$

210

$12 \quad 22$

$31 \quad 53$

$8 \quad 71$

81

$\quad 110$

176

206

209

$2 \quad 210$

233

$3 \quad 236$

$9 \quad 245$

$18 \quad 263$

17

1

16

47

2

5

14

48

30

4

18

42

18

2

18

1

1

1

1

22

86

4

65

29

5

81

72
279

281

297

344

346

351

366

414

443

448

466

508

526

527

545

546

547

548

549

571

657

661

725

754

759

840

912 
SB AR Tipo

$1 \mathrm{~A}$ S. gr.

$1 \mathrm{~A}$ S.gr.

$1 \mathrm{~A}$ S.gr.

$1 \mathrm{~A}$ S.gr.

$1 \mathrm{~A}$ S. gr.

$1 \mathrm{~A}$ S.gr.

$1 \mathrm{~A}$ S. gr.

$1 \mathrm{~A}$ S. gr.

$1 \mathrm{~A}$ S. gr.

$1 \mathrm{~A}$ S. peq.

$1 \mathrm{~B}$ S.gr.

$1 \mathrm{~B}$ S. gr.

$1 \mathrm{~B}$ s. gr.

$1 \mathrm{~B}$ S.gr.

$1 \mathrm{~B}$ S. gr.

$1 \mathrm{~B}$ S. gr.

$1 \mathrm{~B}$ S. gr.

$1 \mathrm{~B}$ S.gr.

$1 \mathrm{~B}$ S.gr.

$1 \mathrm{~B}$ S.gr.

$1 \mathrm{~B}$ S. peq.

$1 \mathrm{~B}$ Dren.

$1 \mathrm{C}$ S.gr.

$1 \mathrm{C}$ S.gr.

$1 \mathrm{C}$ S.gr.

$1 \mathrm{C}$ S.gr.

$1 \mathrm{C}$ s.gr.

$1 \mathrm{C}$ s.gr.

$1 \mathrm{C}$ S. peq.

$1 \mathrm{C}$ Dren.

$1 \mathrm{x}-1$ S. gr.

$1 x-1$ s. gr.

$1 x-1$ s. gr.

$1 \mathrm{x}-1$ s. gr.

$1 \mathrm{x}-1$ s. gr.

$1 x-1$ S. gr.

$1 \mathrm{x}-1$ s. gr.

$1 x-1$ s. gr.

$1 \mathrm{x}-1$ s. gr.

$1 X-1$ s. peq.

$1 \mathrm{x}-2$ S. gr.

$1 \mathrm{x}-2$ S. gr.

$1 X-2$ S. peq.

$1 \mathrm{X}-2$ Dren.

$1 \times-3$ s. gr.

$1 \mathrm{x}-3 \mathrm{~s}$. gr.

$1 \times-3$ s. gr.

$1 \mathrm{X}-3$ s. gr.
Com. Lar. Prof Form. Dist. Lar. Solo $m \mathrm{~m} \mathrm{~m}$ $\begin{array}{lll}20 & 3,5 & 0,4 \\ & \text { Tri. }\end{array}$ 30331,2 Tri. $80 \quad 0,6 \quad 0,15$ Tri. $\begin{array}{lll}30 & 0,8 & 0,2 \\ 30 & 0,8 & 0,2\end{array}$ $\begin{array}{lll}30 & 0,8 & 0,2\end{array}$ Tri. $\begin{array}{lll}260 & 7 & 1\end{array}$ $\begin{array}{lll}40 & 2 & 0,4 \\ \text { Tri. }\end{array}$ \begin{tabular}{lll}
60 & 1 & 0,3 \\
\hline & Tri.
\end{tabular} $\begin{array}{lll}20 & 0,8 & 0,2 \\ 30 & 0,3 & 0,1\end{array}$ $\begin{array}{lll}30 & 0,3 & 0,1\end{array}$ Tri. $\begin{array}{lll}60 & 2 & 1\end{array}$ Tri. $30 \quad 1,5 \quad 0,4$ Tri. $\begin{array}{lll}60 & 2,5 & 1\end{array}$ Tri. $\begin{array}{lll}30 & 1 & 0,3 \\ \text { Tri. }\end{array}$ $\begin{array}{llll}20 & 2,5 & 1 & \text { Tri. }\end{array}$ $\begin{array}{lll}60 & 2,5 & 0,8 \\ 6 & \text { Tri. }\end{array}$ $\begin{array}{lll}60 & 2 & 0,8 \\ 40 & 1,5 & 0,4\end{array}$ $40 \quad 1,5 \quad 0,4$ Tri. $2020 \quad 0,4$ Tri. $\begin{array}{lll}25 & 2 & 0,8 \\ \text { Tri. }\end{array}$ $\begin{array}{lll}20 & 0,8 & 0,2 \\ 15 & \text { Tri. }\end{array}$ 15052 Tri. $40 \quad 1,5 \quad 0,5$ Tri. $40 \quad 1,5 \quad 0,4$ Tri. $100 \quad 1,6 \quad 0,5$ Tri. $20 \quad 1,3 \quad 0,4$ Tri. $\begin{array}{lll}20 & 1 & 0,4 \\ & \text { Tri. }\end{array}$ $30 \quad 1,5 \quad 0,4$ Tri. 2010,2 Tri. 24031,5 Tri. 2010,3 Tri. $40 \quad 1,5 \quad 0,4$ Tri. $\begin{array}{lll}60 & 1,7 & 0,7 \\ \text { Tri. }\end{array}$ $\begin{array}{lll}30 & 1,2 & 0,4 \\ 30 & 1,2 & 0,5\end{array}$ $\begin{array}{lll}30 & 1,2 & 0,5 \\ 20 & 1 & 0,3\end{array}$ 2010,3 Tri. 2010,3 Tri. 2010,3 Tri. 6010,3 Tri. $40 \quad 0,4 \quad 0,2$ Tri. $\begin{array}{lll}40 & 2 & 0,3 \\ 40 & \text { Tri. }\end{array}$ $40 \quad 1,5 \quad 0,6$ Tri. $\begin{array}{lll}40 & 0,4 & 0,2 \\ \text { Tri. }\end{array}$ $\begin{array}{lll}270 & 1,5 & 0,8 \\ \text { Tri. }\end{array}$ 2021,5 Tri. $20 \quad 1,2 \quad 0,4$ Tri. $20 \quad 1,5 \quad 0,6$ Tri. 11020,9 Tri.

$\mathrm{m} m$

(P)

20

PV1

PV1

20360 PV1

PVI

PV

PV3

PV

PV3 $\begin{array}{lllll}\text { PV3 } & \text { CAN } & 0,3 & 14,0 & 774\end{array}$

$\begin{array}{lllll}P V 3 & \text { CAN } & 0,4 & 54,0 & 828\end{array}$

$\begin{array}{lllll}P V 3 & C A N & 0,4 & 3,6 & 832\end{array}$

$\begin{array}{lllll}P V 3 & \text { CAN } & 0,4 & 2,4 & 834\end{array}$

PV3 CAN

PV1 CAN

PV1 CAN

PV1 CAN

PV3 CAN

PV3 CAN

PV3 CAN

PV3 CAN

PV3 CAN

PV3 CAN

PV3 CAN

PV3 CAN

PV3 CAN

PV2 CAN

10600 PV3 CAN

PV2 CAN

PV2 CAN

PV2 CAN

PV2 CAN

PV2 CAN

PV2 CAN

PV2 CAN

10550 PV2 CAN

PV2 CAN

PV2 CAN

PV2 CAN

PV2 CAN

PV2 CAN

PV2 CAN

PV2 CAN

PV2 CAN

PV2 CAN

PV2 CAN

20200 PV2 CAN

PV1 CAN

.

CAN

$0,4 \quad 2,4 \quad 836$

$\begin{array}{lll}0,3 & 910,0 & 1.746\end{array}$

$\begin{array}{lll}0,3 & 16,0 & 1.762\end{array}$

$\begin{array}{lll}0,3 & 9,0 & 1.771\end{array}$

$\begin{array}{lll}0,3 & 1,6 & 1.773\end{array}$

$\begin{array}{lll}0,3 & 5,6 & 1.779\end{array}$

$\begin{array}{lll}0,6 & 60,0 & 1.839\end{array}$

$\begin{array}{lll}0,5 & 9,0 & 1.848\end{array}$

$\begin{array}{lll}0,5 & 75,0 & 1.923\end{array}$

$\begin{array}{lll}0,4 & 4,5 & 1.927\end{array}$

$\begin{array}{lll}0,4 & 25,0 & 1.952\end{array}$

$\begin{array}{lll}0,3 & 60,0 & 2.012\end{array}$

$\begin{array}{lll}0,3 & 48,0 & 2.060\end{array}$

0,3

12,0

0,3

0,4

0,4

0,5

0,4

0,4

0,25

0,25

0,25

0,25

0,4

0,3

0,4

0,4

0,4

0,4

0,4

0,4

0,4

0,4

0,4

0,4

0,5

CAN

CAN

CAN

0,5

0,5

0,5

CAN

0,4

0,4

0,4
$80,0 \quad 2.152$

$20,0 \quad 2.172$

$96,0 \quad 2.268$

$750,0 \quad 3.018$

$15,0 \quad 3.033$

$12,0 \quad 3.045$

$40,0 \quad 3.085$

$5,2 \quad 3.090$

$4,0 \quad 3.094$

$9,0 \quad 3.103$

$110,0 \quad 3.213$

$540,0 \quad 3.753$

3,0

3.756

12,0

3.768

$35,7 \quad 3.804$

$7,2 \quad 3.811$

$9,0 \quad 3.820$

$3,0 \quad 3.823$

$3,0 \quad 3.826$

$3,0 \quad 3.829$

$9,0 \quad 3.838$

$16,0 \quad 3.854$

$12,0 \quad 3.866$

18,0

28,8

3.884

162,0

3.913

4.075

$30,0 \quad 4.105$

$4,8 \quad 4.110$

$9,0 \quad 4.119$

$99,0 \quad 4.218$
Perda de $S$ perda de solo $(\mathrm{Mg})$ solo $(\mathrm{Mg})$

\begin{tabular}{rr}
17 & 929 \\
65 & 994 \\
4 & 998 \\
3 & 1.001 \\
3 & 1.004 \\
1.092 & 2.096 \\
19 & 2.115 \\
11 & 2.126 \\
2 & 2.128 \\
7 & 2.134 \\
72 & 2.206 \\
11 & 2.217 \\
90 & 2.307 \\
5 & 2.313 \\
30 & 2.343 \\
72 & 2.415 \\
58 & 2.472 \\
14 & 2.487 \\
96 & 2.583 \\
24 & 2.607 \\
115 & 2.722 \\
900 & 3.622 \\
18 & 3.640 \\
14 & 3.654 \\
48 & 3.702 \\
6 & 3.708 \\
5 & 3.713 \\
11 \\
11 & 3.724 \\
132 & 3.856 \\
648 & 4.504 \\
4 & 4.508 \\
14 & 4.522 \\
43 & 4.565 \\
9 & 4.574 \\
11 & 4.584 \\
4 & 4.588 \\
4 & 4.592 \\
4 & 4.595 \\
11 & 4.606 \\
19 & 4.625 \\
14 & 4.640 \\
22 & 4.661 \\
19 & 4.696 \\
\hline 4 & 4.890 \\
19 & 4.926 \\
19 & 4.943 \\
19 &
\end{tabular}


iB AR Tipo

$1 \mathrm{X}-3$ S. gr.

$1 \times-3$ S. gr.

$1 \mathrm{X}-3 \mathrm{~S}$ S.gr.

$1 \mathrm{X}-3 \mathrm{~S}$. gr.

$1 \mathrm{X}-3$ S. gr.

$1 X-3$ S. gr.

$1 X-3$ S. peq.

1 Z-1 S. gr.

1 Z-1 S. gr.

$1 Z-1$ S. peq.

1 Z-2 S. gr.

1 Z-2 S. peq.

1 Z-3 S. peq.

1 Z-3 Dren.

1 Z-3 Dren.

1 Z-3 Dren.

1 Z-4 S. gr.

1 Z-4 S. gr.

1 Z-4 S. gr.

1 Z-4 S. gr.

1 Z-4 S. gr.

1 Z-4 S. gr.

1 Z-4 S. peq.
Com. Lar. Prof Form. Dist. Lar. Solo $m \quad m \quad m \quad m \quad m$

\begin{tabular}{|c|c|c|}
\hline 30 & 1,5 & \\
\hline 20 & 1,5 & \\
\hline 45 & 1,4 & 0,5 \\
\hline 40 & 1,5 & \\
\hline 20 & 1,5 & \\
\hline 50 & 2 & \\
\hline 40 & 1 & \\
\hline 20 & 1,5 & \\
\hline 15 & 0,9 & \\
\hline 60 & 0,8 & 0,2 \\
\hline 60 & 1,5 & 0,4 \\
\hline 40 & 1 & 0,2 \\
\hline 20 & 1 & \\
\hline 100 & 1,8 & 0,7 \\
\hline 80 & 1,7 & 0,6 \\
\hline 120 & 2 & 0,6 \\
\hline 20 & 1,5 & \\
\hline 20 & 1,5 & \\
\hline 40 & 1,5 & 0,4 \\
\hline 30 & 3 & \\
\hline 20 & 1 & \\
\hline & 1,5 & \\
\hline & & \\
\hline
\end{tabular}
$\begin{array}{lll}60 & 1,5 & 0,4 \\ \text { Tri. }\end{array}$

$\begin{array}{lll}45 & 1,4 & 0,5 \\ \text { Tri. }\end{array}$

$\begin{array}{lll}40 & 1,5 & 0,4 \\ \text { Tri. }\end{array}$

$\begin{array}{lll}20 & 1,5 & 0,3 \\ \text { Tri. }\end{array}$

$\begin{array}{lll}50 & 2 & 1,5 \\ 4 & \text { Tri. }\end{array}$

$\begin{array}{lll}40 & 1 & 0,2 \\ & \text { Tri. }\end{array}$

0,4 Tri.

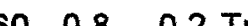

$\begin{array}{lll}60 & 1,5 & 0,4 \\ \text { Tri. }\end{array}$

$\begin{array}{lll}40 & 1 & 0,2 \\ 2 & \text { Tri. }\end{array}$

$\begin{array}{lll}20 & 1 & 0,2 \\ 2 & \text { Tri. }\end{array}$

$\begin{array}{lll}100 & 1,8 & 0,7 \\ 8 & \text { Tri. }\end{array}$

(and

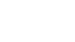

$\begin{array}{lllll}\text { PV3 } & \text { CAN } & 0,4 & 18,0 & 4.236\end{array}$

$\begin{array}{lllll}\text { PV3 } & \text { CAN } & 0,4 & 6,0 & 4.242\end{array}$

PV3 CAN

PV3 CAN

0,4

15,8

PV3 CAN

0,4

12,0

PV3 CAN

$20 \quad 480 \mathrm{PV} 3$

CAN

0,4

0,4

4,5

4.258

4.270

75,0

4.274

0,4

96,0

CAN

0,3

CAN

$15 \quad 390 \mathrm{Li} 1$

CAN

0,3

6,0

4.349

CAN

$20 \quad 360$ Li1

$20 \quad 200$ Li1

CAN

CAN

CAN

CAN

CAN

CAN

CAN

CAN

CAN

CAN

0,3

0,3

2,0

124,8

0,3

18,0

0,4

72,0

20,0

63,0

40,8

0,4

0,4

72,0

0,4

7,5

0,4

0,4

6,0

12,0

36,0

0,4

3,0

4.445

4.451

4.453

4.578

4.596

4.668

4.688

4.751

4.792

4.864

4.871

4.877

4.889

4.925

CAN

0,4

3,0

4.928

$20 \quad 280 \mathrm{Li} 1$

CAN

0,4

16,8

4.931

4.948
Perda de $S$ perda de solo(Mg) solo(Mg)

$\begin{array}{rr}22 & 5.083 \\ 7 & 5.090 \\ 19 & 5.109 \\ 14 & 5.124 \\ 5 & 5.129 \\ 90 & 5.219 \\ 115 & 5.334 \\ 7 & 5.341 \\ 2 & 5.344 \\ 150 & 5.494 \\ 22 & 5.515 \\ 86 & 5.602 \\ 24 & 5.626 \\ 76 & 5.701 \\ 49 & 5.750 \\ 86 & 5.836 \\ 9 & 5.845 \\ 7 & 5.853 \\ 14 & 5.867 \\ 43 & 5.910 \\ 4 & 5.914 \\ 4 & 5.917 \\ 20 & 5.938\end{array}$

Sub-bacia 2

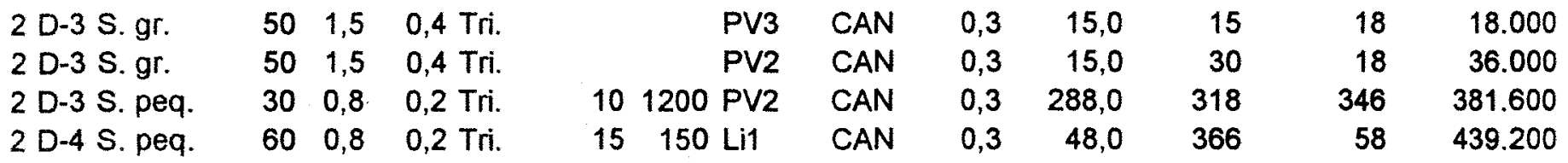

Sub-bacia 3

$\begin{array}{llrrr}3 \text { D-1 S. gr. } & 100 & 1,5 & 0,4 \text { Tri. } \\ 3 \text { D-1 S. gr. } & 80 & 1,5 & 0,8 \text { Tri. } \\ 3 \text { D-1 S. gr. } & 30 & 1,5 & 0,4 \text { Tri. } \\ 3 \text { D-1 S. gr. } & 30 & 1,5 & 0,4 \text { Tri. } \\ \text { 3 D-1 S. gr. } & 80 & 3 & 1,5 \text { Tri. } \\ \text { 3 D-1 S. gr. } & 40 & 1,5 & 0,4 \text { Tri. } \\ 3 \text { D-1 S. gr. } & 20 & 1 & 0,3 \text { Tri. } \\ 3 \text { D-1 S. gr. } & 50 & 1 & 0,3 \text { Tri. } \\ 3 \text { D-1 S. gr. } & 50 & 1 & 0,3 \text { Tri. } \\ 3 \text { D-1 S. gr. } & 20 & 2 & 0,6 \text { Tri. } \\ 3 \text { D-1 S. gr. } & 20 & 1 & 0,3 \text { Tri. } \\ 3 \text { D-1 S. gr. } & 100 & 2 & 0,6 \text { Tri. } \\ 3 \text { D-1 S. gr. } & 40 & 1,5 & 0,4 \text { Tri. } \\ \text { 3 D-1 S. gr. } & 60 & 1,5 & 0,4 \text { Tri. } \\ \text { 3 D-1 S. gr. } & 60 & 1,5 & 0,6 \text { Tri. }\end{array}$

$\begin{array}{llrrr}\text { PV2 } & \text { CAN } & 0,3 & 30,0 & 30 \\ \text { PV2 } & \text { CAN } & 0,3 & 48,0 & 78 \\ \text { PV2 } & \text { CAN } & 0,3 & 9,0 & 87 \\ \text { PV2 } & \text { CAN } & 0,3 & 9,0 & 96 \\ \text { PV2 } & \text { CAN } & 0,3 & 180,0 & 276 \\ \text { PV2 } & \text { CAN } & 0,3 & 12,0 & 288 \\ \text { PV2 } & \text { CAN } & 0,3 & 3,0 & 291 \\ \text { PV2 } & \text { CAN } & 0,3 & 7,5 & 299 \\ \text { PV2 } & \text { CAN } & 0,3 & 7,5 & 306 \\ \text { PV2 } & \text { CAN } & 0,3 & 12,0 & 318 \\ \text { PV2 } & \text { CAN } & 0,3 & 3,0 & 321 \\ \text { PV2 } & \text { CAN } & 0,3 & 60,0 & 381 \\ \text { PV2 } & \text { CAN } & 0,3 & 12,0 & 393 \\ \text { PV2 } & \text { CAN } & 0,3 & 18,0 & 411 \\ \text { PV2 } & \text { CAN } & 0,3 & 27,0 & 438\end{array}$

$\begin{array}{rr}36 & 36.000 \\ 58 & 93.600 \\ 11 & 104.400 \\ 11 & 115.200 \\ 216 & 331.200 \\ 14 & 345.600 \\ 4 & 349.200 \\ 9 & 358.200 \\ 9 & 367.200 \\ 14 & 381.600 \\ 4 & 385.200 \\ 72 & 457.200 \\ 14 & 471.600 \\ 22 & 493.200 \\ 32 & 525.600\end{array}$


SB AR Tipo Com. Lar. Prof Form. Dist. Lar. Solo $\mathrm{m} m \mathrm{~m}$

3 D-1 S. gr.

3 D-1 S. gr.

3 D-1 S. peq.

$3 \mathrm{D}-2$

$3 \mathrm{D}-2$

$3 \mathrm{D}-2$

$3 \mathrm{D}-2$

3 D-2 S. peq.

3 E-1 S. gr.

3 E-1 S. gr.

3 E-1 S. gr.

3 E-1 S. gr.

3 E-1 S. gr.

3 E-1 S. gr.

3 E-1 S. gr.

3 E-1 S. gr.

3 E-1 S. gr.

3 E-1 S. peq.

3 E-2 S. gr.

3 E-2 S. gr.

3 E-2 S. gr.

3 E-2 S. gr.

3 E-2 S. peq.

3 E-2 Dren.

3 E-3 S. gr.

3 E-3 S. gr.

3 E-3 S. gr.

3 E-3 S. gr.

3 E-3 S. gr.

3 E-3 S. gr.

3 E-3 S. gr.

3 E-3 S. gr.

3 E-3 S. peq.

$$
\mathrm{m}
$$

$\begin{array}{lll}50 & 1,5 & 0,4 \\ \text { Tri. }\end{array}$

$\begin{array}{lll}50 & 1,5 & 0,4 \\ \text { Tri. }\end{array}$

$30 \quad 0,8 \quad 0,2$ Tri.

$100 \quad 1,5 \quad 0,4$ Tri.

$80 \quad 1,5 \quad 0,8$ Tri.

$\begin{array}{lll}30 & 1,5 & 0,4 \\ 30 & \text { Tri. }\end{array}$

$30 \quad 1,5 \quad 0,4$ Tri.

$\begin{array}{lll}30 & 0,8 & 0,2 \\ \text { Tri. }\end{array}$

$\begin{array}{lll}20 & 0,8 & 0,5 \\ \text { Tri. }\end{array}$

$\begin{array}{lll}60 & 2,5 & 1,5 \\ \text { Tri. }\end{array}$

$\begin{array}{lll}40 & 1,1 & 0,5 \\ 40\end{array}$

$\begin{array}{lll}40 & 3 & 1,8 \\ \text { Tri. }\end{array}$

1010,2 Tri.

$\begin{array}{lll}20 & 1,5 & 0,3 \\ \text { Tri. }\end{array}$

$\begin{array}{lll}10 & 2 & 0,5 \\ 4 r i .\end{array}$

$40 \quad 1,3 \quad 0,3$ Tri.

$\begin{array}{lll}60 & 1,3 & 0,3 \\ \text { Tri. }\end{array}$

$\begin{array}{lll}20 & 0,5 & 0,2 \\ \text { Tri. }\end{array}$

$40 \quad 1,2 \quad 0,5$ Tri.

$\begin{array}{lll}50 & 2 & 0,4 \\ & \text { Tri. }\end{array}$

$\begin{array}{lll}50 & 2 & 0,4 \\ & \text { Tri. }\end{array}$

$\begin{array}{lll}40 & 1,1 & 0,3 \\ 40 & 0,8 & 0,2\end{array}$

$\begin{array}{lll}40 & 0,8 & 0,2\end{array}$ Tri.

$\begin{array}{lll}250 & 2,5 & 1\end{array}$ Tri.

$80 \quad 1,2 \quad 0,5$ Tri.

$\begin{array}{lll}50 & 1,2 & 0,4 \\ \text { Tri. }\end{array}$

$\begin{array}{lll}60 & 1,5 & 0,7 \\ \text { Tri. }\end{array}$

$40 \quad 1,5 \quad 0,5$ Tri.

$40 \quad 1,5 \quad 0,5$ Tri.

$\begin{array}{lll}40 & 1,5 & 0,4 \\ 70 & \text { Tri. }\end{array}$

$\begin{array}{lll}70 & 2,5 & 0,6 \\ \text { Tri. }\end{array}$

$\begin{array}{lll}20 & 1,5 & 0,4 \\ 40 & \text { Tri. }\end{array}$

$\begin{array}{lll}40 & 0,8 & 0,2\end{array}$ $m \quad m$

$10 \quad 1200$
$10 \quad 350$

PV2

PV2 CAN

CAN

PV2 CAN

PV2 CAN

PV2 CAN

PV2 CAN

PV2 CAN

CAN

PV2 CAN

PV2 CAN

PV2 CAN

PV2 CAN

PV2 CAN

PV2 CAN

PV2 CAN

PV2 CAN

PV2 CAN

40300 PV2 CAN

PV2 CAN

PV2 CAN

PV2 CAN

PV2 CAN

20200 PV2 CAN

PV2 CAN

PV2 CAN

PV2 CAN

PV2 CAN

PV2 CAN

PV2 CAN

PV2 CAN

PV2 CAN

PV2 CAN

10300 PV2 CAN
Di/Cur Volume $S$ Vol $\mathrm{cm} \quad \mathrm{m} 3 \quad \mathrm{m3}$

$\begin{array}{lll}0,3 & 15,0 & 453\end{array}$

$0,3 \quad 15,0 \quad 468$

$0,3 \quad 288,0 \quad 756$

$0,3 \quad 30,0 \quad 786$

$0,3 \quad 48,0 \quad 834$

$0,3 \quad 9,0 \quad 843$

$0,3 \quad 9,0 \quad 852$

$0,3 \quad 84,0 \quad 936$

$0,3 \quad 4,0 \quad 940$

$\begin{array}{lll}0,3 & 112,5 & 1.053\end{array}$

$\begin{array}{lll}0,3 & 11,0 & 1.064\end{array}$

$\begin{array}{lll}0,3 & 108,0 & 1.172\end{array}$

$0,3 \quad 1,0 \quad 1.173$

$\begin{array}{lll}0,3 & 4,5 & 1.177\end{array}$

$0,3 \quad 5,0 \quad 1.182$

$\begin{array}{lll}0,3 & 7,8 & 1.190\end{array}$

$\begin{array}{lll}0,3 & 11,7 & 1.202\end{array}$

$\begin{array}{lll}0,3 & 7,5 & 1.209\end{array}$

$0,4 \quad 12,0 \quad 1.221$

$0,4 \quad 20,0 \quad 1.241$

$0,4 \quad 20,0 \quad 1.261$

$\begin{array}{lll}0,4 & 6,6 & 1.268\end{array}$

$0,4 \quad 32,0 \quad 1.300$

$\begin{array}{lll}0,4 & 312,5 & 1.612\end{array}$

$\begin{array}{lll}0,3 & 24,0 & 1.636\end{array}$

$\begin{array}{lll}0,3 & 12,0 & 1.648\end{array}$

$0,3 \quad 31,5 \quad 1.680$

$0,3 \quad 15,0 \quad 1.695$

$0,3 \quad 15,0 \quad 1.710$

$\begin{array}{lll}0,3 & 12,0 & 1.722\end{array}$

$\begin{array}{lll}0,3 & 52,5 & 1.774\end{array}$

0,3

6,0

1.780

$0,3 \quad 96,0 \quad 1.876$
Perda de $S$ perda de solo(Mg) solo $(\mathrm{Mg})$

$\begin{array}{rr}18 & 543.600 \\ 18 & 561.600 \\ 346 & 907.200 \\ 36 & 943.200 \\ 58 & 1.000 .800 \\ 11 & 1.011 .600 \\ 11 & 1.022 .400 \\ 101 & 1.123 .200 \\ 5 & 1.128 .000 \\ 135 & 1.263 .000 \\ 13 & 1.276 .200 \\ 130 & 1.405 .800 \\ 1 & 1.407 .000 \\ 5 & 1.412 .400 \\ 6 & 1.418 .400 \\ 9 & 1.427 .760 \\ 14 & 1.441 .800 \\ 9 & 1.450 .800 \\ 14 & 1.465 .200 \\ 24 & 1.489 .200 \\ 24 & 1.513 .200 \\ 8 & 1.521 .120 \\ 38 & 1.559 .520 \\ 375 & 1.934 .520 \\ 29 & 1.963 .320 \\ 14 & 1.977 .720 \\ 38 & 2.015 .520 \\ 18 & 2.033 .520 \\ 18 & 2.051 .520 \\ 14 & 2.065 .920 \\ 63 & 2.128 .920 \\ 7 & 2.136 .120 \\ 115 & 2.251 .320\end{array}$

Sub-bacia 4

4 V-3 S. peq.

$4 \mathrm{~V}-4 \mathrm{~S}$. peq.

4 V-5 S. gr.

4 V-5 S. gr.

$4 \mathrm{~V}-5 \mathrm{~S}$. peq.

4 V-5 Dren.

$4 \mathrm{~V}-6$ S. peq.

4 U-1 S. gr.

4 U-1 S. gr.

4 U-1 S. gr.

4 U-1 S. gr.

4 U-1 S. peq. $\begin{array}{lll}60 & 0,4 & 0,1\end{array}$

$\begin{array}{lll}40 & 0,6 & 0,4 \\ \text { Tri. }\end{array}$

$\begin{array}{lll}50 & 1,7 & 0,6 \\ \text { Tri. }\end{array}$

$201,2 \quad 0,4$ Tri.

4010,3 Tri.

$300 \quad 2,5 \quad 1,2$ Tri.

2010,2 Tri.

20030,4 Tri.

$\begin{array}{lll}50 & 2 & 0,4 \\ \text { Tri. }\end{array}$

$40 \quad 1,5 \quad 0,3$ Tri.

$\begin{array}{lll}100 & 2 & 0,4 \\ \text { Tri. }\end{array}$

$\begin{array}{lll}40 & 0,7 & 0,2\end{array}$
10500 PV2 CAN

20300 PV2 CAN

PV2 CAN

PV2 CAN

10300 PV2 CAN

PV2 CAN

30240 PV2 CAN

Cb2 CAN

Cb2 CAN

$\mathrm{Cb} 2$ CAN

$\mathrm{Cb} 2$

$10 \quad 400 \mathrm{Cb} 2$

$\begin{array}{rrr}0,4 & 60,0 & 60 \\ 0,5 & 72,0 & 132 \\ 0,4 & 25,5 & 158 \\ 0,4 & 4,8 & 162 \\ 0,4 & 180,0 & 342 \\ 0,4 & 450,0 & 792 \\ 0,4 & 16,0 & 808 \\ 0,3 & 120,0 & 928 \\ 0,3 & 20,0 & 948 \\ 0,3 & 9,0 & 957 \\ 0,3 & 40,0 & 997 \\ 0,3 & 112,0 & 1.109\end{array}$

$\begin{array}{rr}72 & 72.000 \\ 86 & 158.400 \\ 31 & 189.000 \\ 6 & 194.760 \\ 216 & 410.760 \\ 540 & 950.760 \\ 19 & 969.960 \\ 144 & 1.113 .960 \\ 24 & 1.137 .960 \\ 11 & 1.148 .760 \\ 48 & 1.196 .760 \\ 134 & 1.331 .160\end{array}$


SB AR Tipo Com. Lar. Prof Form. Dist. Lar. Solo $m \quad m \quad m \quad m$

4 U-2 S. gr. $\quad 150 \quad 3 \quad 0,3$ Tri.

4 U-2 S. gr. $\quad 250 \quad 1,7 \quad 0,7$ Tri.

4 U-2 S. gr. $\quad 50 \quad 1,5 \quad 0,4$ Tri.

4 U-2 S. gr. $\quad 50 \quad 1,5 \quad 0,3$ Tri.

4 U-2 S. gr. $\quad 15 \quad 1,3 \quad 0,4$ Tri.

4 U-2 S. gr. $\quad 70 \quad 3 \quad 0,4$ Tri.

4 U-2 S. peq. $\quad 40 \quad 0,7 \quad 0,2$ Tri.

4 l-2 S. gr. $\quad 40 \quad 1,5 \quad 0,4$ Tri.

4 l-2 S. gr. $40 \quad 1 \quad 0,3$ Tri.

4 l-2 S. peq. 80110,2 Tri.
Uso

$\begin{array}{rrrrrr} & \text { Cb2 } & \text { CAN } & 0,3 & 67,5 & 1.177 \\ & \text { Cb2 } & \text { CAN } & 0,3 & 148,8 & 1.326 \\ & \text { Cb2 } & \text { CAN } & 0,3 & 15,0 & 1.341 \\ & \text { Cb2 } & \text { CAN } & 0,3 & 11,3 & 1.352 \\ & \text { Cb2 } & \text { CAN } & 0,3 & 3,9 & 1.356 \\ & \text { Cb2 } & \text { CAN } & 0,3 & 42,0 & 1.398 \\ 20 & 300 \mathrm{Cb} 2 & \text { CAN } & 0,3 & 42,0 & 1.440 \\ & \text { PV3 } & \text { CAN } & 0,3 & 12,0 & 1.452 \\ & \text { PV3 } & \text { CAN } & 0,3 & 6,0 & 1.458 \\ 20 & 260 \text { PV3 } & \text { CAN } & 0,3 & 104,0 & 1.562\end{array}$

Perda de $S$ perda de solo(Mg) solo(Mg)

$\begin{array}{rr}81 & 1.412 .160 \\ 179 & 1.590 .660 \\ 18 & 1.608 .660 \\ 14 & 1.622 .160 \\ 5 & 1.626 .840 \\ 50 & 1.677 .240 \\ 50 & 1.727 .640 \\ 14 & 1.742 .040 \\ 7 & 1.749 .240 \\ 125 & 1.874 .040\end{array}$

Sub-bacia 5

$\begin{array}{lrrllllllllr}5 \text { V-2 S. gr. } & 40 & 1,5 & 0,6 \text { Tri. } & & \text { PV2 } & \text { CAN } & 0,4 & 18,0 & 18 & 22 & 21.600 \\ 5 \text { V-2 S. gr. } & 60 & 2 & 0,7 \text { Tri. } & & \text { PV2 } & \text { CAN } & 0,4 & 42,0 & 60 & 50 & 72.000 \\ 5 \text { V-2 S. gr. } & 60 & 1,5 & 0,5 \text { Tri. } & & \text { PV2 } & \text { CAN } & 0,4 & 22,5 & 83 & 27 & 99.000 \\ 5 \text { V-2 S. gr. } & 100 & 1,5 & 0,4 \text { Tri. } & & \text { PV2 } & \text { CAN } & 0,4 & 30,0 & 113 & 36 & 135.000 \\ 5 \text { V-2 S. peq. } & 40 & 0,5 & 0,2 \text { Tri. } & 10 & 300 \text { PV2 } & \text { CAN } & 0,4 & 60,0 & 173 & 72 & 207.000\end{array}$

Sub-bacia 6

\begin{tabular}{|c|c|c|c|c|c|c|c|c|c|c|c|}
\hline 6 V-7 S. peq. & 20 & 1 & 0,2 Tri. & 20 & 180 PV2 & CAN & 0,5 & 18,0 & 18 & 22 & 21.600 \\
\hline $6 \mathrm{~V}-8 \mathrm{~S}$. peq. & 40 & 1 & 0,2 Tri. & 20 & 660 PV3 & CAN & 0,6 & 132,0 & 150 & 158 & 180.000 \\
\hline 6 V-9 S.p peq & 40 & 1 & 0,2 Tri. & 20 & 450 PV4 & CAN & 0,6 & 90,0 & 240 & 108 & 288.000 \\
\hline $6 \mathrm{~V}-1$ S. gr. & 40 & 1,5 & 0,3 Tri. & & PV2 & CAN & 0,6 & 9,0 & 249 & 11 & 298.800 \\
\hline $6 \mathrm{~V}-1$ S. peq. & 40 & 0,4 & 0,2 Tri. & 10 & 300 PV2 & CAN & 0,6 & 48,0 & 297 & 58 & 356.400 \\
\hline 6 N-5 S.gr. & 25 & 1 & 0,6 Tri. & & PV3 & CAN & 0,5 & 7,5 & 305 & 9 & 365.400 \\
\hline $6 \mathrm{~N}-5$ S. gr. & 20 & 1,5 & 0,5 Tri. & & PV3 & CAN & 0,5 & 7,5 & 312 & 9 & 374.400 \\
\hline $6 \mathrm{~N}-5$ S. peq. & 10 & 0,3 & 0,1 Tri. & 20 & 800 PV3 & CAN & 0,5 & 6,0 & 318 & 7 & 381.600 \\
\hline $6 \mathrm{~N}-1$ S. peq. & 10 & 0,3 & 0,1 Tri. & 10 & $300 \mathrm{Cb} 2$ & CAN & 0,3 & 4,5 & 323 & 5 & 387.000 \\
\hline
\end{tabular}

Sub-bacia 7

\begin{tabular}{|c|c|c|c|c|c|c|c|c|c|c|c|c|}
\hline 7 T-1 S.gr. & 20 & 1,6 & 0,4 Tri. & & & $\mathrm{Cb} 3$ & CAN & 0,4 & 6,4 & 6 & 8 & 7.200 \\
\hline 7 T-1 s. gr. & 40 & 1,5 & 0,3 Tri. & & & $\mathrm{Cb} 3$ & CAN & 0,4 & 9,0 & 15 & 11 & 18.000 \\
\hline 7 T-1 S. peq. & 20 & 1 & 0,2 Tri. & 10 & 600 & $\mathrm{Cb} 3$ & CAN & 0,4 & 120,0 & 135 & 144 & 162.000 \\
\hline 7 T-2 s. gr. & 60 & 3 & 0,5 Tri. & & & PV2 & CAN & 0,4 & 45,0 & 180 & 54 & 216.000 \\
\hline 7 T-2 S. gr. & 70 & 2 & 0,4 Tri. & & & PV2 & CAN & 0,4 & 28,0 & 208 & 34 & 249.600 \\
\hline 7 T-2 S. peq. & 20 & 0,5 & 0,2 Tri. & 40 & 480 & PV2 & CAN & 0,4 & 12,0 & 220 & 14 & 264.000 \\
\hline 7 T-3 s. gr. & 150 & 3 & 0,6 Tri. & & & PV2 & CAN & 0,4 & 135,0 & 355 & 162 & 426.000 \\
\hline 7 T-3 s. gr. & 200 & 2 & 0,4 Tri. & & & PV2 & CAN & 0,4 & 80,0 & 435 & 96 & 522.000 \\
\hline $7 \mathrm{~T}-3 \mathrm{~S} . \mathrm{gr}$. & 200 & 3 & 0,3 Tri. & & & PV2 & CAN & 0,4 & 90,0 & 525 & 108 & 630.000 \\
\hline 7 T-3 s. gr. & 60 & 1,5 & 0,4 Tri. & & & PV2 & CAN & 0,4 & 18,0 & 543 & 22 & 651.600 \\
\hline 7 T-3 s.gr. & 100 & 2,5 & 0,4 Tri. & & & PV2 & CAN & 0,4 & 50,0 & 593 & 60 & 711.600 \\
\hline 7 T-3 s. gr. & 50 & 1,5 & 0,4 Tri. & & & PV2 & CAN & 0,4 & 15,0 & 608 & 18 & 729.600 \\
\hline 7 T-3 S. peq. & 30 & 1,5 & 0,5 Tri. & 10 & 300 & PV2 & CAN & 0,4 & 337,5 & 946 & 405 & 1.134 .600 \\
\hline 7 T-4 S.gr. & 35 & 1,5 & 0,4 Tri. & & & PV2 & CAN & 0,5 & 10,5 & 956 & 13 & 1.147 .200 \\
\hline 7 T-4 S. peq. & 40 & 1 & 0,2 Tri. & 10 & 200 & PV2 & CAN & 0,5 & 80,0 & 1.036 & 96 & 1.243 .200 \\
\hline
\end{tabular}


iB AR Tipo

7 T-5 s.gr.

7 T-5 S. gr.

7 T-5 S. gr.

7 T-5 S. peq.

$7 \mathrm{~N}-2 \mathrm{~s} . \mathrm{gr}$.

$7 \mathrm{~N}-2$ S. gr.

$7 \mathrm{~N}-2 \mathrm{~S}$. peq.

7 N-3 S. gr.

$7 \mathrm{~N}-3$ S. gr.

$7 \mathrm{~N}-3$ S. peq.

$7 \mathrm{~N}-4$ S. peq.

7 0-1 S. peq.

7 0-3 S. peq.

$70-4$ S. peq.

7 0-5 S. peq.

$70-6$ s. peq.

$70-6$ S. gr.

7 0.6 S. gr.

7 0.7 S. peq.
Com. Lar. Prof Form. Dist. Lar. Solo

$$
m \mathrm{~m} m
$$

$\begin{array}{rrrr}60 & 2 & 0,7 & \text { Tri. } \\ 40 & 1,5 & 0,6 & \text { Tri. } \\ 60 & 1,5 & 0,5 & \text { Tri. } \\ 40 & 0,5 & 0,2 & \text { Tri. } \\ 50 & 1,5 & 0,7 & \text { Tri. } \\ 30 & 1,5 & 0,5 & \text { Tri. } \\ 10 & 0,3 & 0,1 & \text { Tri. } \\ 40 & 1,5 & 0,7 & \text { Tri. } \\ 30 & 1,5 & 0,6 & \text { Tri. } \\ 10 & 0,3 & 0,1 & \text { Tri. } \\ 10 & 0,4 & 0,1 & \text { Tri. } \\ 10 & 0,3 & 0,1 & \text { Tri. } \\ 100 & 0,3 & 0,1 & \text { Tri. } \\ 100 & 0,3 & 0,1 & \text { Tri. } \\ 150 & 0,3 & 0,1 & \text { Tri. } \\ 50 & 1 & 0,2 & \text { Tri. } \\ 100 & 3 & 0,8 & \text { Tri. } \\ 60 & 2,5 & 0,9 & \text { Tri. } \\ 40 & 0,8 & 0,2 & \text { Tri. }\end{array}$

Uso m $m$

10

Di/Cur Volume $S$ Vol $\mathrm{cm} \quad \mathrm{m} 3$ $\mathrm{m} 3$

$\begin{array}{lllll}\text { PV2 } & \text { CAN } & 0,4 & 42,0 & 1.078\end{array}$

$\begin{array}{llll}\text { PV2 CAN } & 0,4 & 18,0 & 1.096\end{array}$

$\begin{array}{lllll}\text { PV2 } & \text { CAN } & 0,4 & 22,5 & 1.119\end{array}$

$\begin{array}{lll}0,4 & 80,0 & 1.199\end{array}$

$\begin{array}{lll}0,4 & 26,3 & 1.225\end{array}$

$\begin{array}{lll}0,4 & 11,3 & 1.236\end{array}$

$\begin{array}{lll}0,4 & 7,5 & 1.244\end{array}$

$0,4 \quad 21,0 \quad 1.265$

$\begin{array}{lll}0,4 & 13,5 & 1.278\end{array}$

$\begin{array}{lll}0,4 & 2,7 & 1.281\end{array}$

$\begin{array}{lll}0,6 & 7,6 & 1.288\end{array}$

$\begin{array}{lll}0,4 & 3,6 & 1.292\end{array}$

$0,5 \quad 18,0 \quad 1.310$

$\begin{array}{lll}0,5 & 10,5 & 1.320\end{array}$

$0,5 \quad 15,8 \quad 1.336$

$0,5 \quad 45,0 \quad 1.381$

$\begin{array}{lll}0,8 & 120,0 & 1.501\end{array}$

$\begin{array}{lll}0,8 & 67,5 & 1.569\end{array}$

$0,4 \quad 115,2 \quad 1.684$
Penda de $S$ perda de solo( $\mathrm{Mg})$ solo( $\mathrm{Mg})$

$\begin{array}{rr}50 & 1.293 .600 \\ 22 & 1.315 .200 \\ 27 & 1.342 .200 \\ 96 & 1.438 .200 \\ 32 & 1.469 .700 \\ 14 & 1.483 .200 \\ 9 & 1.492 .200 \\ 25 & 1.517 .400 \\ 16 & 1.533 .600 \\ 3 & 1.536 .840 \\ 9 & 1.545 .960 \\ 4 & 1.550 .280 \\ 22 & 1.571 .880 \\ 13 & 1.584 .480 \\ 19 & 1.603 .380 \\ 54 & 1.657 .380 \\ 144 & 1.801 .380 \\ 81 & 1.882 .380 \\ 138 & 2.020 .620 \\ 2.021 & \end{array}$

Sub-bacia 8

8 O-2 S. peq. $\quad 10 \quad 0,3 \quad 0,1$ Tri

8 W- S. peq. $20 \quad 0,3 \quad 0,1$ Tri.

8 W- S. peq. $\quad 40 \quad 0,3 \quad 0,2$ Tri.

40566 Li1 CAN

$0,4 \quad 2,1$

$0,4 \quad 2,4$

20 (500 PV5 LA CAN

$0,8 \quad 30,0$

$20500 \mathrm{Li} 1 / \mathrm{Li} 2 \mathrm{CAN}$

$0,8 \quad 30,0$

$0,8 \quad 26,4$

$0,3 \quad 10,0$

$\mathrm{Li} 1 / \mathrm{Cb}$ CAN

$\mathrm{Li} / \mathrm{Cb}$ CAN

$0,3 \quad 10,0$

2
4
34
64
91
101
111

2.400

5.280

41.280

77.280

108.960

120.960

132.960

Sub-bacia 9

9 Ár. S. peq. $\begin{array}{rrrr}50 & 0,6 \quad 0,2 \text { Tri. } 40 \\ & \text { Sub-bacia } 10\end{array}$

10 Ár. S. peq. $40 \quad 0,6 \quad 0,2$ Tri.

$40200 \mathrm{Li}-1$ CAN

$0,4 \quad 12,0$

12

14

14.400

Sub-bacia 11

11 S-1 S.gr. $\quad 20 \quad 1,5 \quad 0,6$ Tri.

11 S-1 S.gr. $\quad 201,5 \quad 0,5$ Tri.

11 S-1 S.gr. $\quad 10030,8$ Tri.

11 S-1 S. gr. $\quad 10030,8$ Tri.

11 S-1 S.gr. $\quad 602,5 \quad 0,9$ Tri.

11 S-1 S. peq. 1010,2 Tri.

11 S-2 S.gr. 100330,5 Tri.

11 S-2 S.gr. 2020,5 Tri.

$\begin{array}{rrrrrrr} & \text { PV2 } & \text { CAN } & 0,8 & 9,0 & 9 & 11 \\ & \text { PV2 } & \text { CAN } & 0,8 & 7,5 & 17 & 9 \\ & \text { PV2 } & \text { CAN } & 0,8 & 120,0 & 137 & 144 \\ & \text { PV2 } & \text { CAN } & 0,8 & 120,0 & 257 & 144 \\ & \text { PV2 } & \text { CAN } & 0,8 & 67,5 & 324 & 81 \\ & 240 \text { PV2 } & \text { CAN } & 0,8 & 6,0 & 330 & 7 \\ & \text { Li1 } & \text { CAN } & 0,3 & 75,0 & 405 & 90 \\ & \text { Li1 } & \text { CAN } & 0,3 & 10,0 & 415 & 12\end{array}$

11

9

144

144

81

7

90

12
10.800

19.800

163.800

307.800

388.800

396.000

486.000

498.000 
SB AR Tipo

11 S-2 S. gr.

11 S-2 S. peq.

$11 \mathrm{~s}-2$ Dren.

11 S-3 S. gr.

11 S-3 S. gr.

11 S-3 S. gr.

11 S-3 S. peq.

11 S-4 S. gr.

11 S-4 S. gr.

11 S-4 S. gr.

11 S-4 S. peq.

11 S-5 S. gr.

11 S-5 S. gr.

11 S-5 S. peq.

11 s-6 S. gr.

11 s-6 s. gr.

11 s-6 s. peq.

11 S-7 S. gr.

11 S-7 S. gr.

$11 \mathrm{~s}-7 \mathrm{~S} . \mathrm{gr}$.

11 S-7 S. gr.

11 S-7 S. gr.

11 S-7 S. gr.

11 s-7 S. peq.

$11 \mathrm{~S}-8 \mathrm{~S} . \mathrm{gr}$.

11 S-8 S. peq.

11 S-9 S. gr.

11 s-9 S. gr.

11 S-1 S. gr.

11 S-1 S. gr.

11 s-1 S. gr.

11 S-7 S. peq.

11 Ár. S. peq.

11 Ár. S. peq.

11 Ár. S. peq.

11 Ár. S. peq.

11 Ár. S. peq.

11 Ár. S. gr.

11 Ár. S. peq.

11 Ár: S. gr.

11 Ár. S. peq.

11 Ár. S. peq.

11 Ár. S. peq.

11 Ár. S. peq.

11 Ár. S. peq.
Com. Lar. Prof Form $m \quad m \quad m$

$\begin{array}{rrr}70 & 6 & 3 \text { Tri. } \\ 10 & 1 & 0,3 \text { Tri. } \\ 170 & 1,8 & 2 \text { Tri. } \\ 200 & 3 & 1,3 \text { Tri. } \\ 200 & 2 & 0,9 \text { Tri. } \\ 300 & 2 & 2 \text { Tri. } \\ 40 & 1 & 0,2 \text { Tri. } \\ 200 & 8 & 5 \text { Tri. } \\ 50 & 9 & 3 \text { Tri. } \\ 150 & 6 & 1,6 \text { Tri. } \\ 50 & 1 & 0,3 \text { Tri. }\end{array}$

$\begin{array}{lll}300 & 3 & 2 \\ & \text { Tri. }\end{array}$

$\begin{array}{lll}70 & 1,5 & 0,7 \\ 40 & 0,9 & 0,3\end{array}$

$\begin{array}{lll}40 & 0,9 & 0,3 \\ \text { Tri. }\end{array}$

$\begin{array}{lll}60 & 1,5 & 0,3 \\ \text { Tri. }\end{array}$

8020,4 Tri.

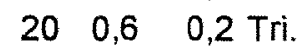

$\begin{array}{lll}50 & 2 & 0,9 \\ 5 & \text { Tri. }\end{array}$

5020,5 Tri.

4010,3 Tri.

$\begin{array}{lll}50 & 1,5 & 0,5 \\ 40 & \text { Tri. }\end{array}$

4020,5 Tri.

$\begin{array}{lll}50 & 1 & 0,3 \\ 40 & \text { Tri. }\end{array}$

$\begin{array}{lll}40 & 0,8 & 0,2 \\ \text { Tri. }\end{array}$

10030,5 Tri.

1010,3 Tri.

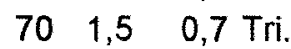

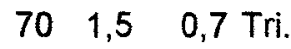

$\begin{array}{lll}50 & 2 & 0,9 \\ 50 & \text { Tri. }\end{array}$

$\begin{array}{lll}50 & 2 & 0,5 \\ 40 & \text { Tri. }\end{array}$

4010,3 Tri.

$\begin{array}{lll}40 & 0,8 & 0,2 \\ \text { Tri. }\end{array}$

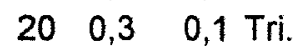

$\begin{array}{lll}20 & 0,2 & 0,1\end{array}$ Tri.

$\begin{array}{lll}40 & 0,3 & 0,1\end{array}$ Tri.

$\begin{array}{lll}40 & 0,3 & 0,1 \\ 40 & 0,3 & 0,1\end{array}$

$\begin{array}{lll}40 & 0,3 & 0,1\end{array}$ Tri.

$\begin{array}{lll}35 & 1,5 & 0,4 \\ 40 & 0,2 & 0,1\end{array}$

$\begin{array}{lll}40 & 0,2 & 0,1\end{array}$ Tri.

$\begin{array}{lll}20 & 0,6 & 0,4\end{array}$ Tri.

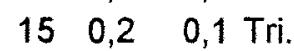

$\begin{array}{lll}20 & 0,2 & 0,1\end{array}$

$\begin{array}{lll}20 & 0,2 & 0,1\end{array}$

$\begin{array}{lll}20 & 0,2 & 0,1\end{array}$ Tri.

$\begin{array}{lll}40 & 0,2 & 0,1\end{array}$
Dist. Lar
$m \mathrm{~m}$

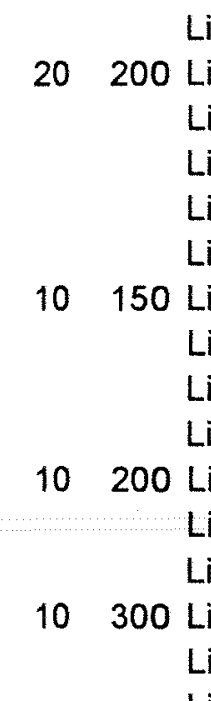

$40 \quad 240 \mathrm{Li}$

PV1pp CAN

PV1pp CAN

PV1pp CAN

PV1pp CAN

PV1pp CAN

PV1pp CAN

10550 PV1pp CAN

Li1

CAN

$20300 \mathrm{Li} 1$

Li1

CAN

Li1

CAN

PV2

CAN

PV2

$\mathrm{PV} 2$

10600 PV8

$40 \quad 300$ PV6

10400 Pv3

10200 Li1

10110 Pv 3

20300 Li1

Li1

$20 \quad 220$ Li1

Pv3

$10400 \mathrm{PV} 3$

10160 Pv5

$10 \quad 350$ Li1

$10 \quad 200$ Li1

20600 Li1
Di/Cur Volume $s \mathrm{Vol}$ $\mathrm{cm} \quad \mathrm{m} 3 \quad \mathrm{~m} 3$

$\begin{array}{lll}0,3 & 630,0 & 1.045\end{array}$

$\begin{array}{lll}0,3 & 15,0 & 1.060\end{array}$

$0,3 \quad 306,0 \quad 1.366$

$0,3 \quad 390,0 \quad 1.756$

$0,3 \quad 180,0 \quad 1.936$

$\begin{array}{lll}0,3 & 600,0 & 2.536\end{array}$

$0,3 \quad 60,0 \quad 2.596$

$\begin{array}{lll}0,3 & 4.000,0 \quad 6.596\end{array}$

$\begin{array}{lll}0,3 & 675,0 & 7.271\end{array}$

$\begin{array}{lll}0,3 & 720,0 & 7.991\end{array}$

$0,3 \quad 150,0 \quad 8.141$

$\begin{array}{llll}0,3 & 900,0 & 9.041\end{array}$

0,3

36,8

9.078

$\begin{array}{lll}0,3 & 162,0 & 9.240\end{array}$

$0,4 \quad 13,5$

9.253

0,4

32,0

9.285

0,4

0,4

7,2

9.292

$45,0 \quad 9.337$

$0,4 \quad 25,0 \quad 9.362$

0,4

6,0

9.368

0,4

0,4

18,8

9.387

20,0

9.407

$\begin{array}{ll}7.5 & 9.415\end{array}$

0,4

176,0

0,3

0,3

75,0

9.591

22,5

9.666

0,3

36,8

9.688

0,3

36,8

9.725

9.762

$\begin{array}{ll}45.0 & 9.807\end{array}$

$25,0 \quad 9.832$

$6,0 \quad 9.838$

$192,0 \quad 10.030$

$\begin{array}{ll}2,3 & 10.032\end{array}$

$8,0 \quad 10.040$

$12,0 \quad 10.052$

$\begin{array}{ll}6,6 & 10.059\end{array}$

$9,0 \quad 10.068$

$10,5 \quad 10.078$

$\begin{array}{ll}4,4 & 10.082\end{array}$

$2,4 \quad 10.085$

$\begin{array}{ll}6,0 & 10.091\end{array}$

$3,2 \quad 10.094$

$7,0 \quad 10.101$

$4,0 \quad 10.105$

$12,0 \quad 10.117$
Perda de $S$ perda de solo $(\mathrm{Mg})$ solo $(\mathrm{Mg})$

$\begin{array}{rr}756 & 1.254 .000 \\ 18 & 1.272 .000 \\ 367 & 1.639 .200 \\ 468 & 2.107 .200 \\ 216 & 2.323 .200 \\ 720 & 3.043 .200 \\ 72 & 3.115 .200 \\ 4.800 & 7.915 .200 \\ 810 & 8.725 .200 \\ 864 & 9.589 .200 \\ 180 & 9.769 .200\end{array}$

$1.080 \quad 10.849 .200$

$44 \quad 10.893 .300$

$194 \quad 11.087 .700$

$\begin{array}{ll}16 & 11.103 .900\end{array}$

$38 \quad 11.142 .300$

$9 \quad 11.150 .940$

$54 \quad 11.204 .940$

$30 \quad 11.234 .940$

$\begin{array}{ll}7 & 11.242 .140\end{array}$

$23 \quad 11.264 .640$

$24 \quad 11.288 .640$

$9 \quad 11.297 .640$

$211 \quad 11.508 .840$

$90 \quad 11.598 .840$

$27 \quad 11.625 .840$

$44 \quad 11.669 .940$

$44 \quad 11.714 .040$

$54 \quad 11.768 .040$

$30 \quad 11.798 .040$

$7 \quad 11.805 .240$

$230 \quad 12.035 .640$

3 312.038 .340

$10 \quad 12.047 .940$

$14 \quad 12.062 .340$

812.070 .260

$11 \quad 12.081 .060$

1312.093 .660

512.098 .940

312.101 .820

712.109 .020

$4 \quad 12.112 .860$

$8 \quad 12.121 .260$

5 12.126 .060

$14 \quad 12.140 .460$ 
SB AR Tipo

12 Ár. S. peq.

12 Ár. S. peq.

12 Ár. S. peq.

12 Ár. S. gr.

12 Ár. S. gr.

12 Ár. S. peq.

12 Ár. S. peq.

12 Ár. S. peq.

12 Ár. S. peq.

12 Ár. S. peq.

12 Ár. S. peq.

12 Ár. S. peq.

12 Ár. S.gr.

12 Ár. S. gr.

12 Ár. S. peq.

12 Ár. S. gr.

12 Ár. S. peq.

12 Ár. S. peq.

12 Ár. S.gr.

12 Ar. S. peq.

12 Ár. S. peq.

12 Ár. S. peq.

12 Ár. S. peq.
Com. Lar. Prof Form

$m \quad m \quad m$

$\begin{array}{rlll}40 & 0,2 & 0,1 \text { Tri. } \\ 40 & 0,3 & 0,1 \text { Tri. } \\ 20 & 0,3 & 0,1 \text { Tri. } \\ 10 & 0,8 & 0,4 & \text { Tri. } \\ 60 & 1,2 & 0,4 & \text { Tri. } \\ 40 & 0,4 & 0,2 \text { Tri. } \\ 40 & 0,3 & 0,1 & \text { Tri. } \\ 40 & 0,3 & 0,1 \text { Tri. } \\ 40 & 0,4 & 0,2 \text { Tri. } \\ 20 & 0,4 & 0,2 \text { Tri. } \\ 40 & 0,4 & 0,2 \text { Tri. } \\ 40 & 0,6 & 0,3 \text { Tri. } \\ 100 & 0,8 & 0,4 \text { Tri. } \\ 50 & 0,6 & 0,4 \text { Tri. } \\ 60 & 0,4 & 0,2 \text { Tri. } \\ 40 & 0,9 & 0,6 \text { Tri. } \\ 20 & 0,2 & 0,1 \text { Tri. } \\ 20 & 0,2 & 0,1 \text { Tri. } \\ 20 & 0,9 & 0,8 \text { Tri. } \\ 20 & 0,3 & 0,1 \text { Tri. } \\ 20 & 0,2 & 0,1 \text { Tri. } \\ 40 & 0,3 & 0,2 \text { Tri. } \\ 40 & 0,3 & 0,2 \text { Tri. }\end{array}$

Dist. Lar. Solo

$m \mathrm{~m}$

20140 Li1 CAN

20 100 Li1 CAN

401000 Li6

Li3

CAN

CAN

$\mathrm{Li} 3$

CAN

$5 \quad 200 \mathrm{Li} 3$

CAN

$10 \quad 350 \mathrm{Li} 3$

CAN

$10 \quad 400 \mathrm{Li} 3$

CAN

$20 \quad 520 \mathrm{Li} 3$

CAN

$40 \quad 560 \mathrm{Li} 3$

CAN

$20500 \mathrm{Pv} 3$

CAN

$10 \quad 250 \mathrm{PV} 3$

Li1

Li1

$5250 \mathrm{Li1}$

Pv3

$20 \quad 260$ P 3

$10 \quad 250 \mathrm{Li} 1$

PV1

$40 \quad 400$ Li6

$40 \quad 600$ Pv5

20400 Pv5

20400 Pv5
Di/Cur Volume $S$ Vol $\mathrm{cm} \quad \mathrm{m} 3 \quad \mathrm{m3}$

$\begin{array}{rrr}0,4 & 2,8 & 3 \\ 0,4 & 3,0 & 6 \\ 0,4 & 7,5 & 14 \\ 0,3 & 1,6 & 15 \\ 0,3 & 14,4 & 30 \\ 0,3 & 64,0 & 94 \\ 0,3 & 21,0 & 115 \\ 0,3 & 24,0 & 139 \\ 0,3 & 41,6 & 180 \\ 0,3 & 11,2 & 191 \\ 0,5 & 40,0 & 231 \\ 0,4 & 90,0 & 321 \\ 0,4 & 16,0 & 337 \\ 0,4 & 6,0 & 343 \\ 0,4 & 120,0 & 463 \\ 0,5 & 10,8 & 474 \\ 0,5 & 2,6 & 477 \\ 0,4 & 5,0 & 482 \\ 0,6 & 7,2 & 489 \\ 0,4 & 3,0 & 492 \\ 0,5 & 3,0 & 495 \\ 0,6 & 24,0 & 519 \\ 0,4 & 24,0 & 543\end{array}$

Perda de $S$ perda de solo $(\mathrm{Mg})$ solo $(\mathrm{Mg})$

\begin{tabular}{rrr}
3 & 3 & 3.600 \\
6 & 4 & 7.200 \\
4 & 9 & 16.200 \\
5 & 2 & 18.120 \\
0 & 17 & 35.400 \\
4 & 77 & 112.200 \\
5 & 25 & 137.400 \\
9 & 29 & 166.200 \\
0 & 50 & 216.120 \\
1 & 13 & 229.560 \\
1 & 48 & 277.560 \\
1 & 108 & 385.560 \\
7 & 19 & 404.760 \\
3 & 7 & 411.960 \\
3 & 144 & 555.960 \\
4 & 13 & 568.920 \\
7 & 3 & 572.040 \\
2 & 6 & 578.040 \\
9 & 9 & 586.680 \\
2 & 4 & 590.280 \\
\hline 5 & 4 & 593.880 \\
9 & 29 & 622.680
\end{tabular}

Sub-bacia 13

13 Ár. S. peq. $\quad 20 \quad 0,3 \quad 0,1$ Tri. $\quad 40 \quad 400$ PV6pp CAN

$0,4 \quad 3,0$

2

4

2.400

13 Ár. S. peq.

$\begin{array}{lll}40 & 0,2 & 0,1 \\ \text { Tri. }\end{array}$

20500 Li1

CAN

$0,3 \quad 10,0$

12

12

14.400

Sub-bacia 14

14 Ár. S. peq.

$\begin{array}{lll}20 & 0,5 & 0,2 \\ \text { Tri. }\end{array}$

$\begin{array}{lll}40 & 0,3 & 0,1 \\ 40 & 0,3 & 0,2\end{array}$

$\begin{array}{lll}40 & 0,3 & 0,2 \\ \text { Tri. }\end{array}$

$\begin{array}{lll}40 & 0,3 & 0,1\end{array}$ $\begin{array}{lll}40 & 240 \text { PV6pp } & \text { CAN } \\ 20 & 600 \text { Li-1 } & \text { CAN } \\ 20 & 400 \text { Pv5/Li1 CAN } \\ 20 & 600 \text { Li1 } & \text { CAN }\end{array}$
$0,4 \quad 6,0$

$0,4 \quad 18,0$

$0,6 \quad 24,0$

$0,6 \quad 18,0$

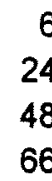

7
22
29

22
7.200

28.800

57.600

79.200

\section{Sub-bacia 15}

15 Ar. S. gr. $\quad 20 \quad 1,7 \quad 1$ Tri.

15 Ár. S. gr. $\quad 30 \quad 1 \quad 0,4$ Tri.

15 Ár. S. gr. $\quad 50 \quad 0,8 \quad 0,3$ Tri.

15 Ár. S. gr. $\quad 9 \quad 3,5 \quad 0,4$ Tri.

15 Ár. S. peq. $120 \quad 0,3 \quad 0,2$ Tri.

15 Ár. S. gr. 2010,3 Tri.

15 Ar. S. gr. $\quad 20 \quad 1,5 \quad 0,4$ Tri.

15 Ár. S. peq. $80 \quad 0,6 \quad 0,2$ Tri.

15 Ár. Dren. 603 1,5 Tri.

15 Ár. S. peq. $40 \quad 0,6 \quad 0,2$ Tri.

$\begin{array}{rrrrrr} & \text { Li1 } & \text { CAN } & 0,4 & 17,0 & 17 \\ & \text { Li1 } & \text { CAN } & 0,4 & 6,0 & 23 \\ & \text { Li1 } & \text { CAN } & 0,4 & 6,0 & 29 \\ & \text { Li1 } & \text { CAN } & 0,4 & 6,3 & 35 \\ 20 & 500 \text { Li1 } & \text { CAN } & 0,4 & 90,0 & 125 \\ & \text { Li1 } & \text { CAN } & 0,5 & 3,0 & 128 \\ & \text { Li1 } & \text { CAN } & 0,5 & 6,0 & 134 \\ 20 & \text { 700 Li1 } & \text { CAN } & 0,5 & 168,0 & 302 \\ & \text { Li1 } & \text { CAN } & 0,5 & 135,0 & 437 \\ 20 & 400 \text { Li1 } & \text { CAN } & 0,4 & 48,0 & 485\end{array}$

$\begin{array}{rr}20 & 20.400 \\ 7 & 27.600 \\ 7 & 34.800 \\ 8 & 42.360 \\ 108 & 150.360 \\ 4 & 153.960 \\ 7 & 161.160 \\ 202 & 362.760 \\ 162 & 524.760 \\ 58 & 582.360\end{array}$


SB AR Tipo Com. Lar. Prof Form. Dist. Lar. Solo Uso Di/Cur Volume S Vol Perda de S perda de $\begin{array}{llllllll}m & m & m & m & \mathrm{~cm} & \mathrm{~m} 3 & \mathrm{~m} 3 & \mathrm{solo}(\mathrm{Mg}) \mathrm{solo}(\mathrm{Mg})\end{array}$

\begin{tabular}{|c|c|c|c|c|c|c|c|c|c|c|c|c|c|}
\hline 15 Ár. & Dren. & 80 & 1,5 & 0,6 Tri. & & & Li1 & CAN & 0,4 & 36,0 & 521 & 43 & 625.560 \\
\hline 15 Ár. & S. peq. & 50 & 0,6 & 0,2 Tri. & 20 & 300 & Pvi & CAN & 0,5 & 45,0 & 566 & 54 & 679.560 \\
\hline 15 Ár. & Dren. & 80 & 1,5 & 0,6 Tri. & & & Pv1 & CAN & 0,5 & 36,0 & 602 & 43 & 722.760 \\
\hline $15 \mathrm{~K} 1$ & S. peq. & 120 & 0,3 & 0,2 Tri. & 20 & 400 & Li2 & CAN & 0,4 & 72,0 & 674 & 86 & 809.160 \\
\hline $15 \mathrm{~K} 1$ & S. gr. & 9 & 3,5 & 0,4 Tri. & & & Li1 & CAN & 0,4 & 6,3 & 681 & 8 & 816.720 \\
\hline $15 \mathrm{~K} 2$ & S. peq. & 40 & 0,8 & 0,2 Tri. & 10 & 300 & PV1 & CAN & 0,4 & 96,0 & 777 & 115 & 931.920 \\
\hline $15 \mathrm{~K} 2$ & S. gr. & 50 & 2 & 0,9 Tri. & & & PV1 & CAN & 0,4 & 45,0 & 822 & 54 & 985.920 \\
\hline $15 \mathrm{~K} 2$ & S. gr. & 50 & 2 & 0,5 Tri. & & & PV1 & CAN & 0,4 & 25,0 & 847 & 30 & 1.015 .920 \\
\hline $15 \mathrm{~K} 3$ & S. peq. & 50 & 0,2 & 0,1 Tri. & 20 & 200 & PV5 & CAN & 0,3 & 5,0 & 852 & 6 & 1.021 .920 \\
\hline & S. gr. & 40 & 1,5 & 0,7 Tri. & & & $\mathrm{Cb} 2$ & CAN & 0,4 & 21,0 & 873 & 25 & 1.047 .120 \\
\hline $15 \mathrm{~K} 5$ & s. peq. & 80 & 0,6 & 0,2 Tri. & 20 & 400 & Li1 & CAN & 0,4 & 96,0 & 969 & 115 & 1.162 .320 \\
\hline
\end{tabular}

Sub-bacia16

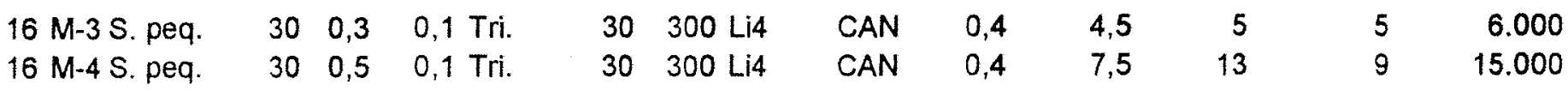

Sub-bacia 17

\begin{tabular}{|c|c|c|c|c|c|c|c|c|c|c|c|c|}
\hline 17 P-1 S.gr. & 20 & 2 & 0,6 Tri. & & & Li4 & CAN & 1 & 12,0 & 12 & 14 & 14.400 \\
\hline 17 P-1 S. gr. & 20 & 2,5 & 0,8 Tri. & & & Li4 & CAN & 1 & 20,0 & 32 & 24 & 38.400 \\
\hline 17 P-1 S. gr. & 20 & 4 & 0,8 Tri. & & & Li4 & CAN & 1 & 32,0 & 64 & 38 & 76.800 \\
\hline 17 P-1 S. gr. & 40 & 1,5 & 0,5 Tri. & & & Li4 & CAN & 1 & 15,0 & 79 & 18 & 94.800 \\
\hline 17 P-1 S. gr. & 100 & 0,8 & 0,3 Tri. & & & Li4 & CAN & 1 & 12,0 & 91 & 14 & 109.200 \\
\hline 17 P-1 S. gr. & 300 & 0,8 & 0,2 Tri. & & & Li4 & CAN & 1 & 24,0 & 115 & 29 & 138.000 \\
\hline 17 P-1 S. peq. & 10 & 0,3 & 0,1 Tri. & 40 & 400 & Li4 & CAN & 1 & 1,5 & 117 & 2 & 139.800 \\
\hline 17 P-2 S. peq. & 20 & 0,5 & 0,3 Tri. & 20 & 360 & $\mathrm{Cb} 2$ & CAN & 0,4 & 27,0 & 144 & 32 & 172.200 \\
\hline 17 P-3 S. peq. & 10 & 0,3 & 0,1 Tri. & 40 & 400 & Li1 & CAN & 0,3 & 1,5 & 145 & 2 & 174.000 \\
\hline 17 Q-1 S. peq. & 10 & 0,3 & 0,1 Tri. & 50 & 550 & PV5pp & CAN & 0,4 & 1,7 & 147 & 2 & 175.980 \\
\hline 17 Q-2 S. peq. & 10 & 0,3 & 0,1 Tri. & 50 & 450 & Lit & CAN & 0,4 & 1,4 & 148 & 2 & 177.600 \\
\hline 17 R-1 S. peq. & 150 & 0,3 & 0,1 Tri. & 40 & 400 & Li1 & CAN & 0,5 & 22,5 & 171 & 27 & 204.600 \\
\hline 17 R-3 S. peq. & 170 & 0,3 & 0,1 Tri. & 40 & 440 & PV5pp & CAN & 0,5 & 28,1 & 199 & 34 & 238.260 \\
\hline 17 M-1 S. peq. & 100 & 0,3 & 0,1 Tri. & 30 & 500 & Li4 & CAN & 0,4 & 25,0 & 224 & 30 & 268.260 \\
\hline 17 M-2 S. peq. & 40 & 0,3 & 0,1 Tri. & 30 & 600 & Li4 & CAN & 0,4 & 12,0 & 236 & 14 & 282.660 \\
\hline
\end{tabular}

Sub-bacia 18

$\begin{array}{lllllllllll}8 \text { R-2 S. peq. } & 150 & 0,3 & 0,1 \text { Tri. } & 40 & 360 \text { PV5pp CAN } & 0,6 & 20,3 & 20 & 24 & 24.000 \\ \text { 8 R-4 S. peq. } & 170 & 0,3 & 0,1 \text { Tri. } & 40 & 440 \text { PV5pp CAN } & 0,5 & 28,1 & 48 & 34 & 57.660\end{array}$

Sub-bacia 20

\begin{tabular}{|c|c|c|c|c|c|c|c|c|c|c|c|c|}
\hline $\mathrm{OH}$ & S. gr. & 30 & 1,4 & 0,5 Tri. & & PV7 & CAN & 0,8 & 10,5 & 11 & 13 & 13.200 \\
\hline $\mathrm{OH}$ & S. gr. & 40 & 1 & 0,3 Tri. & & PV7 & CAN & 0,8 & 6,0 & 17 & 7 & 20.400 \\
\hline $\mathrm{H}$ & S. gr. & 20 & 2 & 0,5 Tri. & & PV7 & CAN & 0,8 & 10,0 & 27 & 12 & 32.400 \\
\hline $\mathrm{OH}$ & S. gr. & 10 & 0,6 & 0,2 Tri. & 40 & $840 \mathrm{PV} 7$ & CAN & & 12,6 & 40 & 15 & 47.520 \\
\hline
\end{tabular}


SB AR Tipo

Com. Lar. Prof Form. Dist. Lar. Solo Uso

Diveur Volume $S$ Vol m $m$ $\mathrm{cm} \quad \mathrm{m} 3 \quad \mathrm{m3}$
Perda de $S$ perda de solo(Mg) solo(Mg)
$21 \mathrm{~F} \quad$ S.gr. $20 \quad 2 \quad 0,6$ Tri.

$21 \mathrm{~F} \quad$ S.gr. $\quad 20 \quad 2,5 \quad 0,8$ Tri.

$21 \mathrm{~F} \quad$ S.gr. $20 \quad 4 \quad 0,8$ Tri.

$21 \mathrm{~F} \quad$ S. peq. $20 \quad 0,5 \quad 0,2$ Tri.

$21 \mathrm{G}$ S.gr. $40 \quad 3 \quad 0,3$ Tri.

$21 \mathrm{G}$ S.gr. $40 \quad 3 \quad 0,8 \mathrm{Tr}$.

$21 \mathrm{G}$ S.gr. $20 \quad 0,4 \quad 0,5$ Tri.

$21 \mathrm{H}$ S.gr. $40 \quad 1,5 \quad 0,3$ Tri.

$21 \mathrm{H}$ S.gr. $40 \quad 1,5 \quad 0,5$ Tri.

$21 \mathrm{H}$ S.gr. $40 \quad 1,3 \quad 0,4$ Tri.

$21 \mathrm{H}$ S.gr $\quad 20 \quad 1,3 \quad 0,4 \mathrm{Tr}$.

$\begin{array}{rrrrrrrr} & \text { PV1 } & \text { CAN } & 0,6 & 12,0 & 12 & 14 & 14.400 \\ & \text { PV1 } & \text { CAN } & 0,6 & 20,0 & 32 & 24 & 38.400 \\ & \text { PV1 } & \text { CAN } & 0,6 & 32,0 & 64 & 38 & 76.800 \\ & \text { 840 PV1 } & \text { CAN } & 0,6 & 21,0 & 72 & 25 & 86.400 \\ \text { PV7pp CAN } & 0,4 & 18,0 & 90 & 22 & 108.000 \\ & \text { PV7pp CAN } & 0,5 & 48,0 & 138 & 58 & 165.600 \\ & \text { PV7pp CAN } & 0,5 & 2,0 & 140 & 2 & 168.000 \\ \text { PV7 } & \text { CAN } & 0,8 & 9,0 & 149 & 11 & 178.800 \\ \text { PV7 } & \text { CAN } & 0,8 & 15,0 & 164 & 18 & 196.800 \\ \text { PV7 } & \text { CAN } & 0,8 & 10,4 & 174 & 12 & 209.280 \\ \text { PV7 } & \text { CAN } & 0,8 & 5,2 & 180 & 6 & 215.520\end{array}$

Sub-bacia 22

$22 \mathrm{~F} \quad$ S.gr. $\quad 40 \quad 1,5 \quad 0,5$ Tri.

$22 \mathrm{~F}$ S.gr. $100 \quad 0,8 \quad 0,3 \mathrm{Tr}$.

$22 \mathrm{~F}$ S. gr. $300 \quad 0,8 \quad 0,2$ Tri. $\begin{array}{llll}\text { PV1 CAN } & 0,6 & 15,0 & 15\end{array}$

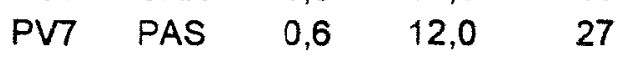

$\begin{array}{lllll}P V 7 & P A S & 0,6 & 24,0 & 51\end{array}$
18

14

18.000

32.400

29

61.200 